UNIVERSIDADE DE SÃO PAULO

ESCOLA DE ENFERMAGEM DE RIBEIRÃO PRETO

JOSELY PINTO DE MOURA

A COLONIZAÇÃO DOS PROFISSIONAIS DA ENFERMAGEM POR Staphylococcus aureus: PROBLEMÁTICA E DESAFIOS

RIBEIRÃO PRETO 


\section{A COLONIZAÇÃO DOS PROFISSIONAIS DA ENFERMAGEM POR Staphylococcus aureus: PROBLEMÁTICA E DESAFIOS}

Tese apresentada ao Programa Interunidades de Doutoramento em Enfermagem da Escola de Enfermagem da Universidade de São Paulo e Escola de Enfermagem de Ribeirão Preto da Universidade de São Paulo para obtenção do título de Doutor em Ciências.

Área de Concentração: Enfermagem

Linha de pesquisa: Prática Social e Profissional em Saúde

Orientador: Prof ${ }^{\mathrm{a}} \mathrm{Dr}^{\mathrm{a}}$ Elucir Gir

Co-orientadora: Prof ${ }^{a}$ Dra $^{a}$ Fabiana Cristina Pimenta 
AUTORIZO A REPRODUÇÃO E DIVULGAÇÃO TOTAL OU PARCIAL DESSE TRABALHO, POR QUALQUER MEIO CONVENCIONAL OU ELETRÔNICO, PARA FINS DE ESTUDO E PESQUISA, DESDE QUE CITADA A FONTE.

FICHA CATALOGRÁFICA

Moura, Josely Pinto de

A colonização dos profissionais da enfermagem por staphylococcus aureus: problemática e desafios. Ribeirão Preto, 2009.

$113 p+1 C D$ ROM: il., $30 \mathrm{~cm}$.

Tese de Doutorado, apresentada à Escola de Enfermagem de Ribeirão Preto/USP. Área de concentração: Enfermagem.

Orientadora: Gir, Elucir

1. Staphylococcus aureus. 2. Resistência à meticilina.

3. equipe de enfermagem 4. Portador sadio 4. Prevalência. 


\section{FOLHA DE APROVAÇÃO}

Josely Pinto de Moura

A colonização dos profissionais da enfermagem por staphylococcus aureus: problemática e desafios.

Tese apresentada no Programa Interunidades de Doutoramento em Enfermagem dos campi de São Paulo e Ribeirão Preto da Universidade de São Paulo, para obtenção do título de Doutor em Enfermagem

Aprovada em:

\section{Banca Examinadora}

Prof.Dr

Instituição: Assinatura:

Prof.Dr.

Instituição: Assinatura:

Prof.Dr.

Instituição: Assinatura:

Prof.Dr. Instituição: Assinatura:

Prof.Dr. Assinatura: 
Dedicatória

A Deus por me dar força e coragem ao longo desta jornada.

À minha família pelo apoio e pela paciência, principalmente aos meus pais e filhos, Henrique e Humberto, alegria da minha vida. 
Agradecimento Especial

À Profa Dra $^{a}$ Elucir Gir o meu sincero agradecimento, meu carinho, respeito, minha consideração e profunda admiração.

À Profa ${ }^{r} r^{a}$ Fabiana Cristina Pimenta agradeço a contribuição e os ensinamentos.

Aे FAPEMIG

pela bolsa de estudos durante o Curso de Doutorado. 


\section{Agradecimentos}

À equipe do Laboratório de Bacteriologia Médica do Instituto de Patologia Tropical e Saúde Pública da Universidade Federal do Goiás, pela colaboração prestada e pelo acolfimento. Especialmente à Lara Stefânia de Oliveira Neto Leão, Ana Claudia de Oliveira, Silvana Santiago, Leda Maria Valadão e Juliana O. Rosa o meu agradecimento.

Ao Hospital das Clínicas da Universidade de São Paulo, agradeço a autorização para a realização da pesquisa $e$, aos participantes deste estudo, meu muito obrigada.

À Dra Miyeko Hayashida pelo exemplo profissional e pela colaboração na análise dos dados.

À colega e profissional $\mathbb{D r}^{a}$ Elaine Drehmer Cruz e Dra Silvia Rita Marin da Silva Canini, que muito contribuíram com sua experiência e ensinamentos.

À Luiza Tayar Facchin e Janaina Pereira da Silva pela ajuda na coleta de dados.

À Carla Aparecida Arantes Tomasauskas pela presteza e eficiência no atendimento.

À admininstração Santa Casa de Misericórdia de Passos pelo apoio e colaboração para a realização do curso.

À Cecília Anita Guimarães Marques, coordenadora de enfermagem, pelo suporte, incentivo, pela compreensão nos momentos difíceis, o meu muito obrigada.

Aos meus colegas profissionais da Santa Casa de Misericórdia de Passos, especialmente aos do Serviço de Controle de Infecção Hospitalar, Vanderlei e Vanildes, pelo incentivo e colaboração.

Aos meus amigos e familiares que me incentivaram, apoiaram, o meu muito obrigada! 
O Senhor é o meu pastor; nada me faltará.

Deitar-me faz em pastos verdejantes; guia-me mansamente a águas tranqüilas.

Refrigera a minha alma; guia-me nas veredas da justiça por amor do seu nome.

Ainda que eu ande pelo vale da sombra da morte, não temerei mal algum, porque tu estás comigo; a tua vara e o teu cajado me consolam.

Preparas uma mesa perante mim na presença dos meus inimigos; unges com óleo a minha cabeça, o meu cálice transborda.

Certamente que a bondade e a misericórdia me seguirão todos os dias da minha vida, e habitarei na casa do Senhor por longos dias.

Salmo 23 


\section{RESUMO}

Moura, J. P. A colonização dos profissionais da enfermagem por Staphylococcus aureus: problemática e desafios. 2009. 113f. Tese (Doutorado) Escola de Enfermagem Ribeirão Preto, Universidade de São Paulo, São Paulo, 2009.

Introdução: A problemática referente à conduta com profissionais na área de saúde colonizados por Staphylococcus aureus sensíveis e resistentes à metilcilina está em grande evidência, por ser este um importante patógeno causador de doenças com alta morbi-mortalidade.(LOWY, 1998). Atualmente as infecções por Staphylococcus aureus não respondem mais ao tratamento com os antimicrobianos anteriormente utilizados (CDC, 2006). O Staphylococcus aureus, resistente à meticilina (MRSA), vem se disseminando nos serviços de saúde e tem sido uma das causas de infecções com maior dificuldade de tratamento (CDC,1999). A maioria das infecções ocorre em pessoas colonizadas com o micro-organismo, sendo o carreador de longo tempo um fator de risco mais fortemente associado com infecção subsequente (WERTHEIM et al, 2005a). Objetivos: Avaliar a colonização e o perfil de susceptibilidade dos Staphylococcus aureus isolados na saliva da equipe de enfermagem atuante nas unidades de terapia intensiva, clínica médica, clínica cirúrgica e gineco-obstétrica de uma instituição de saúde de grande porte do interior paulista. Determinar a prevalência de portadores de Staphylococcus aureus resistentes à meticilina e à mupirocina, levando em consideração o tempo de atuação profissional, jornada no hospital e tempo de contato com os pacientes desse hospital. Métodos: Foram coletadas três amostras da saliva de 351 indivíduos, correspondendo a $94,1 \%$ dos profissionais da equipe de enfermagem com intervalo de dois meses entre as coletas. As amostras foram semeadas em agar manitol salgado e colônias típicas de Staphylococcus aureus foram identificadas pela coloração de Gram, produção de catalase, coagulase, Dnase, fermentação do manitol e o perfil de susceptibilidade determinado pelo teste de difusão de disco. Resultados: A prevalência entre os trabalhadores foi de $144(41,0 \%)$ sendo 25 $(7,1 \%)$ caracterizados como resistentes e 104 (29,6\%) como sensíveis à meticilina (MSSA) $15(4,3 \%)$ não foram recuperados para o antibiograma. Os carreadores 
transitórios representaram $81,2 \%$ e os persistentes $18,8 \%$. A resistência à mupirocina foi de $73,1 \%$ entre os MRSA e $9,3 \%$ nos MSSA. Os resultados evidenciaram que os enfermeiros e técnicos de enfermagem constituem a categoria profissional mais susceptível à colonização por MRSA. O tempo na instituição não teve uma forte correlação com a colonização do profissional, pois trabalhadores com menor tempo na instituição também tiveram alta incidência de colonização. Discussão: Ao considerarmos outros fatores envolvidos como o setor de trabalho, fica evidenciado um panorama de risco para a segurança do paciente. Conclusão: Constatamos, na cavidade bucal, um potencial reservatório e fonte de disseminação de Staphylococcus aureus nos serviços de saúde, bem como um fator de risco de infecção para o trabalhador e, portanto, a necessidade de estudos específicos e intervenções para a prevenção e controle de MRSA, considerando principalmente a condição de setores especiais.

Descritores: Staphylococcus aureus; Resistência à meticilina; Equipe de enfermagem, Portador sadio, Prevalência. 
ABSTRACT

Moura, J. P. Colonization of nursing professionals by Staphylococcus aureus: problem and challenges. 2009. 113f. Tese (Doutorado) - Escola de Enfermagem Ribeirão Preto, Universidade de São Paulo, São Paulo, 2009.

Introduction: The problem of how to manage health professionals colonized by methicillin sensitive and resistant Staphylococcus aureus is very evident, as this important pathogen causes different diseases with high morbidity and mortality rates (LOWY, 1998). Today, infections by Staphylococcus aureus no longer respond to treatment with formerly used antibiotics (CDC, 2006). Methicillin resistant Staphylococcus aureus is spreading across health services and has been one of the infection causes most difficult to treat (CDC, 1999). Most infections affect people colonized by the microorganism. Long-term carriers are a risk factor more strongly associated with subsequent infection (WERTHEIM et al, 2005a). Aims: To assess the colonization and susceptibility profile of Staphylococcus aureus isolated in the saliva of nursing teams active at the intensive care, medical clinic, surgical clinic and gynecological-obstetrical units of a large health institution in the interior of São Paulo State, Brazil. To determine the prevalence of nursing professionals carrying methicillin and mupirocin resistant Staphylococcus aureus, in view of their length of professional activity, work hours at the hospital and time of contact with hospital patients. Methods: Three saliva samples were collected from 351 individuals, corresponding to $94.1 \%$ of nursing team professionals, with a two-month interval between the collections. The samples were seeded in mannitol salt agar and typical colonies of S. aureus were identified through Gram stain; catalase, coagulase and Dnase production; mannitol fermentation and susceptibility profile determined by the disk diffusion test. Results: Prevalence levels among workers corresponded to 144 $(41,0 \%)$ colonized by $S$ aureus, $25(7,10 \%)$ of whom were characterized as MRSA and 104 (29.6\%) as methicillin sensitive Staphylococcus aureus, while 15 (4.3\%) were not recovered for the antibiogram. Transitory carriers represented $81,2 \%$ and persistent carriers $18,8 \%$. Mupirocin resistance was $73.1 \%$ among MRSA and $9.3 \%$ among MSSA. Results evidenced that nursing technicians and nurses were the professional category most susceptible to MRSA. No strong correlation was found 
between length of professional activity at the institution and colonization, as professionals working less time at the institution also displayed high colonization ratios. Discussion: These results are relevant for the study institution. When considering other factors involved in professional categorization and the work site, a picture of risk for patient safety is evidenced. Conclusion: Workers' oral cavity is a potential reservoir and source of dissemination of $S$. aureus in health services, as well as a risk factor for infection. Hence, specific studies and MRSA prevention and control interventions are needed, mainly when considering the condition of special sectors.

Descriptors: Staphylococcus aureus; Methicillin resistance; Nursing team, Carrier state, Prevalence. 


\section{RESUMEN}

Moura, J. P. La colonización de los profesionales de enfermería por staphylococcus aureus: problemática y retos. 2009. 113f. Tese (Doutorado) Escola de Enfermagem Ribeirão Preto, Universidade de São Paulo, São Paulo, 2009.

Introducción: La problemática referente a la conducta con profesionales en el área de la salud colonizados por Staphylococcus aureus sensibles y resistentes a la meticilina está muy evidente, porque este es un importante patógeno causador de diversas enfermedades con alta morbi-mortalidad (LOWY, 1998). Hoy día, las infecciones por Staphylococcus aureus no más responden al tratamiento con los antimicrobianos anteriormente utilizados (CDC, 2006). La Staphylococcus aureus resistente a la meticilina (MRSA) se está diseminando en los servicios de salud y ha sido una de las causas de infecciones con mayor dificultad de tratamiento (CDC, 1999). La mayoría de las infecciones ocurre en personas colonizadas con el microorganismo, siendo el portador de largo tiempo un factor de riesgo más fuertemente asociado con infección subsecuente (WERTHEIM et al, 2005a). Objetivos: Evaluar la colonización y el perfil de susceptibilidad de las Staphylococcus aureus aisladas en la saliva del equipo de enfermería actuante en las unidades de terapia intensiva, clínica médica, clínica quirúrgica y ginecológicaobstétrica de una institución de salud de gran porte del interior del estado de São Paulo, Brasil. Determinar la prevalencia de profesionales de enfermería portadores de Staphylococcus aureus resistentes a la meticilina y a la mupirocina, considerando el tiempo de actuación profesional, jornada en el hospital y tiempo de contacto con los pacientes de esos hospitales. Métodos: Fueron recolectadas tres muestras de la saliva de 351 individuos, correspondiendo al $94,1 \%$ de los profesionales del equipo de enfermería con intervalo de dos meses entre las recolectas. Las muestras fueron sembradas en agar manitol salado y colonias típicas de $S$. aureus fueron identificadas mediante la coloración Gram, producción de catalasa, coagulasa, Dnasa, fermentación del manitol y el perfil de susceptibilidad determinado por el test de difusión por disco. Resultados: La prevalencia entre los trabajadores fue de 144 $(41,0 \%)$ colonizados por $S$ aureus, y entre estos $25(7,1 \%)$ fueron caracterizados 
como MRSA y $104(29,6 \%)$ como Staphylococcus aureus sensibles a la meticilina (MSSA), mientras $15(4,3 \%)$ no fueron recuperados para el antibiograma. Los portadores transitorios representaron el $81,2 \%$ y los persistentes el 18,8\%. La resistencia a la mupirocina fue del $73,1 \%$ entre las MRSA y el $9,3 \%$ en las MSSA. Los resultados evidenciaron que los técnicos de enfermería y los enfermeros son la categoría profesional más susceptible a la MRSA. No fue encontrada correlación fuerte entre el tiempo en la institución y la colonización del profesional, ya que los trabajadores con menor tiempo en la institución también mostraron alta incidencia de colonización. Discusión: Constatamos que estos resultados son relevantes para la institución estudiada. Considerando otros factores involucrados, como la categorización profesional y el local de trabajo, se evidencia un panorama de riesgo para la seguridad del paciente. Conclusión: Constatamos en la cavidad oral un potencial despósito y fuente de diseminación de $S$. aureus en los servicios de salud, y también un factor de riesgo de infección para el trabajador. Por lo tanto, son necesarios estudios específicos e intervenciones de prevención y control de la MRSA, principalmente considerando la condición de sectores especiales.

Descriptores: Staphylococcus aureus; Resistencia a la meticilina; Grupo de enfermería, Portador sano, Prevalencia. 


\section{LISTA DE TABELAS}

Tabela 1 - Caracterização demográfica e profissional dos trabalhadores de um hospital público estadual ( $n=356)$, Ribeirão Preto, 2007

Tabela 2 - Caracterização da área e unidade de atuação dos trabalhadores de um hospital público estadual ( $n=356)$, Ribeirão Preto, 2007

Tabela 3 - Distribuição dos trabalhadores de um hospital público estadual segundo a colonização por Staphylococcus aureus, Ribeirão Preto, 2007

Tabela 4 - Caracterização demográfica, turno e jornada de trabalho dos trabalhadores de um hospital público estadual segundo a colonização por Staphylococcus aureus, Ribeirão Preto, 2007.

Tabela 5 - Caracterização profissional dos trabalhadores de um hospital público estadual segundo a colonização por Staphylococcus aureus, Ribeirão Preto, 2007.

Tabela 6 - Unidade de lotação dos trabalhadores de um hospital público estadual segundo a colonização por Staphylococcus aureus, Ribeirão Preto, 2007.

Tabela 7 - Perfil de sensibilidade aos antimicrobianos de isolados da saliva classificadas como MRSA, de trabalhadores da saúde um hospital público estadual, Ribeirão Preto, 2007

Tabela 8 - Percentual de resistência aos antimicrobianos dos Staphylococcus aureus classificados como MRSA e MSSA, isolados de amostras de saliva dos trabalhadores da saúde de um hospital público estadual, Ribeirão Preto, 2007. 


\section{LISTA DE ABREVIATURAS E SIGLAS}

MRSA

CDC

$\mathrm{SCC}$ mec

PVL

UTI

PBP

MSSA

MLS

DHFR

MIC

RNA

DNA

VRSA

PFGE

CA-MRSA

VISA / GISA

CLSI

APECIH

GRSA

HA-MRSA

APIC

SHEA

$\mathrm{IHI}$

HCFMRP/USP

DE

VRE

CEP

DNAse

EERP

FAPESP

$\mathrm{NaCl}$

NBR
Staphylococcus aureus resistente à meticilina

Center for Disease Control and Prevenction

staphylococcal chromosome cassette mec

Panton-valentine leucocidina

Unidade de Terapia Intensiva

protein biding penicillins

Staphylococcus aureus meticilina-sensíveis

Macrolídeos, lincosaminas e estreptograminas

di-hidrofolato redutase

Concentração Inibitória Mínima

Ácido ribonucléico

Ácido desoxirribonucléico

Staphylococcus aureus resistente à vancomicina

Pulsed Field Gel Eletroforese

Staphylococcus aureus resistente à meticilina na comunidade

Staphylococcus aureus com resistência intermediária à vancomicina

Clinical and Laboratory Standards Institute

Associação Paulista de Estudos e Controle de Infecção Hospitalar Staphylococcus aureus resistente aos glicopeptídios

Staphylococcus aureus resistente à meticilina associadas ao ambiente hospitalar

Association for Professionals in Infection Control and Epidemiology

Society for Healthcare Epidemiology of America

Institute for Healthcare Improvement

Hospital das Clínicas da Faculdade de Medicina de Ribeirão Preto da USP

Departamento de Emergência

Enterococos resistentes à vancomicina

Comitê de Ética em Pesquisa

Desoxiribonuclease

Escola de Enfermagem de Ribeirão Preto

Fundação de Amparo à Pesquisa do Estado de São Paulo

Cloreto de sódio

Norma brasileira 
$\mathrm{pH}$

RNAse

STM

USP

PABA
Potencial hidrogeniônico

Ribonuclease

Sulfametoxazol trimetoprima

Universidade de São Paulo

para-amino benzóico 


\section{SUMÁRIO}

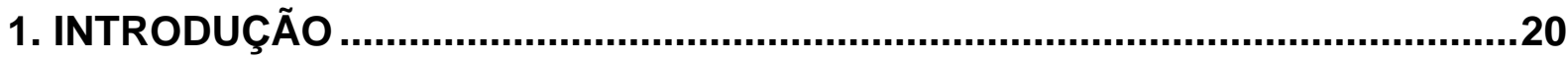

2. O PROBLEMA DE PESQUISA E HIPÓTESES ..............................................30

3. FUNDAMENTAÇÃO TEÓRICA ....................................................................33

3.1 Aspectos microbiológicos e identificação dos estafilococos ..............................33

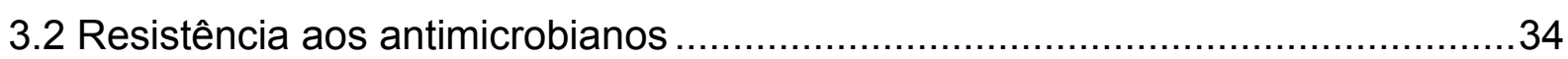

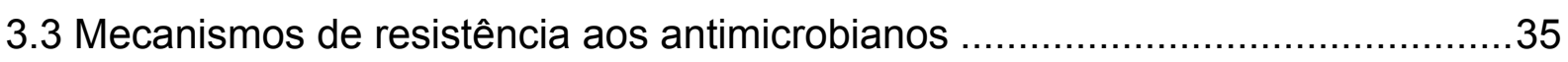

3.4 Medidas para prevenção e controle de MRSA em serviços de saúde ................46

3.4.1 Campanha “5 Milhões de Vidas” (FIVE MILLION LIVES CAMPAIGN, 2008)...47

4. OBJETIVOS ...............................................................................................54

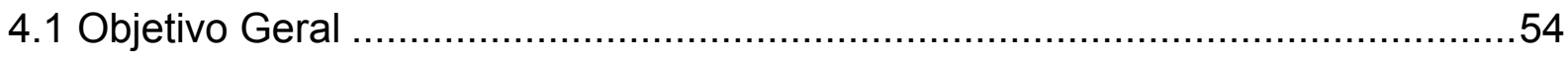

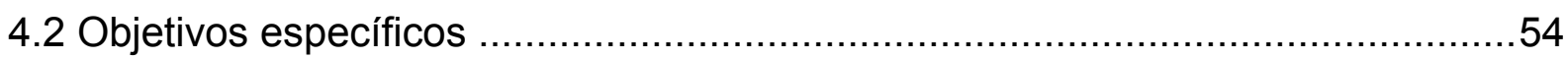

5. MATERIAIS E MÉTODOS .............................................................................56

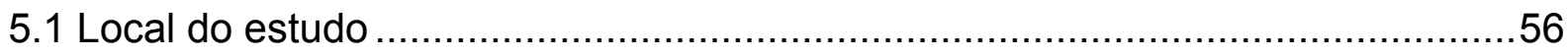

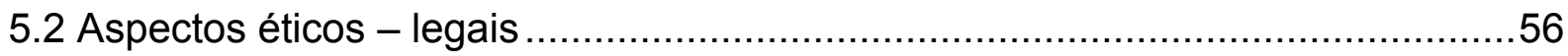

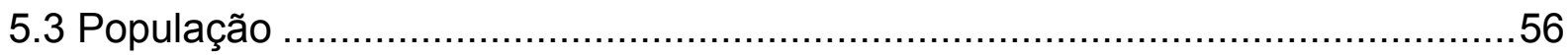

5.4 Procedimento para coleta das amostras ............................................ 57

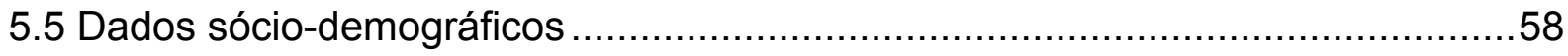

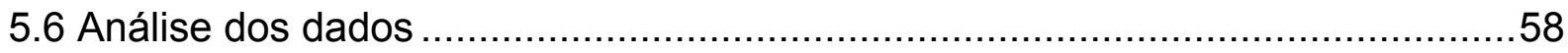

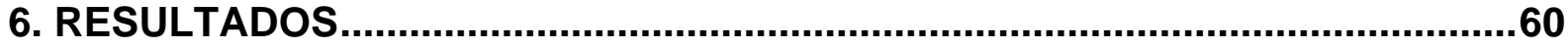

6.1 Caracterização demográfica e profissional dos sujeitos da pesquisa ................60

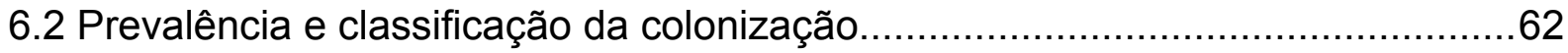

6.3 Caracterização demográfica e profissional dos participantes segundo a colonização por Staphylococcus aureus sensíveis (MSSA) e resistentes (MRSA) à meticilina.

6.4 Caracterização fenotípica do Staphylococcus aureus ....................................67

7. DISCUSSÃO DOS RESULTADOS.................................................................70

7.1 Caracterização demográfica e profissional dos trabalhadores, segundo a colonização por Staphylococcus aureus .............................................. 70

7.1.1 Prevalência do Staphylococcus aureus em trabalhadores da área de saúde ..70

7.1.2 Caracterização demográfica e profissional dos trabalhadores colonizados .....76 
7.1.3 Caracterização fenotípica de Staphylococcus aureus .

.78

7.1.4 Prevalência da resistência à mupirocina em trabalhadores da área de saúde ......78

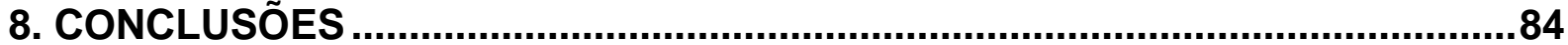

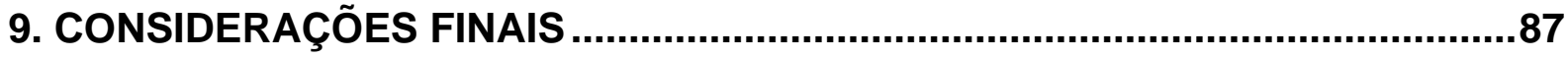

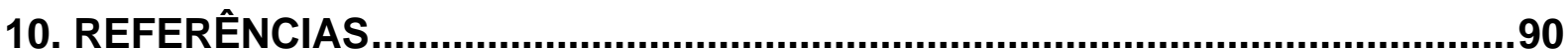

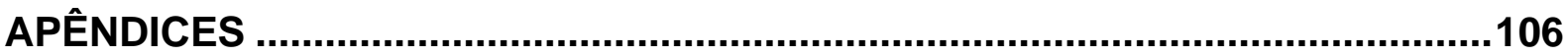

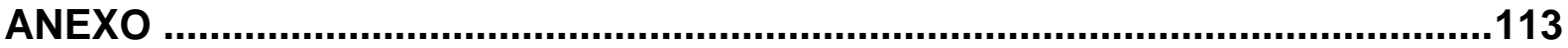




\section{INTRODUÇÃO}

A problemática referente à conduta com portadores de infecções resistentes a múltiplas drogas e aos profissionais na área de saúde colonizados por estes microorganismos está em grande evidência. Entre eles encontramos o Staphylococcus aureus, um micro-organismo relevante por ser um importante patógeno causador de diversas doenças com alta morbi-mortalidade, como as foliculites, intoxicação gastrintestinal, doença sistêmica fatal e síndrome do choque tóxico (LOWY, 1998).

Os Center for Disease Control and Prevenction (CDC) publicaram (CDC, 2006) um guia com as recomendações sobre o cuidado prestado a estes portadores devido à importância da temática para a saúde pública; contudo, por se tratar de um tema emergente, muitas questões ainda não estão resolvidas. Infecções causadas por Staphylococcus aureus meticilina resistente (MRSA) são particularmente problemáticas: sua incidência aumentou inexoravelmente ao longo da última década, sendo muito mais letais se comparadas às infecções estafilocócicas por germes suscetíveis à meticilina (CDC, 2006). O Staphylococcus aureus, resistente à meticilina (MRSA) aumenta a morbidade e mortalidade. Uma vez introduzido em uma instituição torna-se endêmico, de difícil controle e freqüentemente impossível sua erradicação (PANG, 2009).

As infecções por Staphylococcus aureus não respondem mais ao tratamento com os antimicrobianos anteriormente utilizados (CDC, 2006). O Staphylococcus aureus resistente a múltiplas drogas vem se disseminando nos serviços de saúde, particularmente o MRSA tem sido uma das causas de infecções com maior dificuldade de tratamento. Ele está se disseminando também na comunidade (CAMRSA) (HEROLD et al.,1998; CDC, 1999). É um patógeno potencialmente emergente que vem apresentando frequência crescente de isolados e pode atingir pessoas sem fatores de risco, como hospitalizações prévias ( FARIA, 2005; SCHULMAN; DASSEY; MASCOLA, 2004).

Um estudo realizado para estimar a extensão de CA-MRSA, pesquisou a prevalência da colonização nasal por S. aureus em 100 amostras de uma população sem fatores de risco e encontrou uma freqüência de $40 \%$ dessa bactéria, sendo 7,5\% CA-MRSA. A prevalência da colonização por MRSA em pessoas saudáveis na 
comunidade potencializa a necessidade de uma maior vigilância do controle de infecção hospitalar, já que esta população que carreia CA-MRSA pode tornar-se reservatório bacteriano no ambiente hospitalar ( MENEGOTTO; PICOLI, 2007).

A infecção por MRSA afeta desproporcionalmente às populações. É um problema de saúde pública, principalmente relacionado aos cuidadores de saúde (KLEVENS et al., 2007).

A maioria das infecções ocorre em pessoas colonizadas, sendo o carreador de longo tempo um fator de risco mais fortemente associado à infecção subsequente (WERTHEIM et al, 2005a). Em função disto, torna-se fundamental a identificação da prevalência deste micro-organismo em profissionais da área de saúde, mais especificamente aqueles que prestam cuidados direto ao paciente. Essa condição é necessária em grande parte dos hospitais onde o MRSA é endêmico. A severidade da doença e os altos custos com tratamentos de saúde justificam investimentos para sua prevenção e controle. É imperativo para as instituições de saúde realizar uma vigilância sistemática do MRSA e disseminar os resultados encontrados aos profissionais de saúde ( COIA et al., 2006 ).

Apesar do Staphylococcus aureus ser uma causa comum de doenças, particularmente entre pessoas colonizadas, a infecção por MRSA ainda carece de estimativas de colonização (MATTHEW et al., 2006). Na população humana, aproximadamente $20 \%$ são portadores de pelo menos algum tipo de Staphylococcus aureus, são os chamados carreadores persistentes. Contudo, aproximadamente $60 \%$ dos indivíduos são considerados carreadores intermitentes dessa bactéria e os outros $20 \%$ nunca apresentaram qualquer tipo dela. As taxas mais altas de colonização por este organismo encontram-se entre profissionais de saúde, usuários de droga endovenosa, pacientes diabéticos insulino-dependentes, indivíduos com doenças de pele ou em uso de cateter venoso por longos períodos prolongados (KLUYTMANS; BELKUM; VERBRUGH, 1997).

A prevalência nacional estimada de colonização nasal por Staphylococcus aureus, nos Estados Unidos, no período de 2001 a 2002 foi de 32,4\% para Staphylococcus aureus e de $0,8 \%$ para MRSA, sendo, portanto uma população estimada de 89,4 milhões e 2,3 milhões de pessoas respectivamente. A maior prevalência foi em participantes de seis a onze anos e a colonização por MRSA na população acima de 60 anos do sexo feminino e sem exposição recente a serviço de saúde. Na análise molecular, o SCCmec (staphylococcal chromosome cassette mec) 
tipo IV foi mais frequentemente isolado em jovens e negras não hispânicas e o gene PVL (Panton-valentine leucocidina) esteve presente em nove $(2,4 \%)$ dos isolados. Apesar de muitas pessoas nos Estados Unidos terem sido colonizadas com Staphylococcus aureus, com diferença na prevalência por demografia, a colonização por MRSA é considerada baixa (MATTHEW et al., 2006).

Em uma análise molecular dos portadores de MRSA na comunidade, foi avaliada a prevalência de portadores colonizados e identificados os fatores de risco, associados à colonização e obtiveram uma prevalência de $3,5 \%$. Os profissionais de saúde tiveram uma menor taxa de colonização, $(19,1 \%)$ que os sujeitos da comunidade, $(25,2 \%)$ por Staphylococcus aureus, mas tiveram uma taxa significativamente mais alta para colonização de MRSA. O fator de risco mais significativo para a colonização foi a idade, abaixo de vinte anos ou entre 71 e 80 anos $(p<0,001)$. Outros fatores relacionados ao MRSA foram ter tido doença gastrintestinal recente e internação hospitalar; e ao estafilococo comunitário foi o uso excessivo de antimicrobiano. Também neste estudo ficou evidente a alta colonização entre pessoas não relacionadas ao ambiente hospitalar, contribuindo, portanto, com o aumento da incidência na comunidade (LU et al., 2005).

A proteção do indivíduo vai depender da sua microbiota que atua como barreira contra a colonização de micro-organismos potencialmente patogênicos e inibe uma super multiplicação de micro-organismos oportunistas e faz o controle da multiplicação desses agentes oportunistas ao que se denomina de resistência à colonização (SULLIVAN; EDLUND; NORD, 2001).

A terapêutica antimicrobiana poderá comprometer a microbiota autóctone/normal do hospedeiro que atua como uma barreira protetora contra microorganismos exógenos e oportunistas (POLLE et al., 2004).

A microbiota normal humana da orofaringe e do trato gastrintestinal é um ecossistema complexo que existe em simbiose com o hospedeiro. A microbiota previne a invasão de patógenos e participa de vários processos metabólicos (EDLUND; NORD, 1993). Entretanto, em determinadas circunstâncias, os microorganismos da própria microbiota do hospedeiro podem causar infecções graves (EDLUND; NORD, 1993). 
A supressão da microbiota anaeróbia está associada à diminuição da resistência intrínseca do hospedeiro, a colonização por micro-organismos exógenos. A administração de agentes antimicrobianos, terapeutica ou profilática, causa distúrbios no equilíbrio ecológico entre o hospedeiro e a microbiota normal. O maior impacto dos agentes antimicrobianos ocorre na microbiota intestinal. As alterações na microbiota dependem das propriedades antimicrobianas, além da absorção, via de eliminação, e possível inativação enzimática e/ou ligação à matéria fecal. As alterações na microbiota intestinal resultam principalmente em diarréia e infecções fúngicas, normalmente, após o término do tratamento. O uso de antimicrobianos, que não alteram significativamente a microbiota, reduz o risco da seleção e disseminação de micro-organismos resistentes entre os pacientes, bem como os processos de recombinação (SULLIVAN; EDLUND; NORD, 2001).

A narina anterior é considerada o local principal de aderência do Staphylococcus aureus (KLYTMANS; BELKUM; VERBRUGH, 1997; LOWY,1998). Também houve observações de altas taxas de Staphylococcus aureus meticilina resistente (MRSA) em garganta das crianças (HAYAKAWA et al., 1999). Um estudo recente demonstrou que ao contrário do que se supunha, a colonização é mais persistente na garganta do que na narina anterior, que um mesmo indivíduo pode ter diferentes cepas de Staphylococcus aureus nestes sítios. Obteve uma taxa de 15\% de MRSA isolado na faringe e $4 \%$ na narina, sugerindo que a cultura de material da faringe pode ser usada para a detecção de MRSA em carreadores, e que a utilização de mupirocina nasal não é satisfatória para reduzir a incidência de infecções hospitalares. Recomendam-se mais estudos sobre o tema (NILSSON; RIPA, 2006).

De acordo com Santos (1987) e Voss (2004), tanto os profissionais que prestam assistência direta, como aqueles que desempenham funções burocráticas, apresentaram positividade para colonização por Staphylococcus aureus. A sua localização na orofaringe entre os membros da equipe que atuam nas instituições de saúde tem sido preocupação constante dos estudiosos nas últimas décadas, isso porque, no cotidiano dessas instituições, nenhuma medida efetiva com vistas ao controle desse micro-organismo tem sido aplicada na prática (NAKASHIMA et al., 1984; SANTOS, 1987).

A transmissão de MRSA do profissional para familiares já foi documentada (EVEILLARD et al., 2004) e, no Brasil, investigação realizada em hospital 
universitário, demonstrou incidência de colonização nasal de 38,23\% (52/136) entre profissionais de enfermagem de unidades críticas (WEISS; FAGUNDES; MEZZOMO, 2002).

Gould (2005) discutiu o significado clínico do MRSA e destaca que este microorganismo tem sido responsável pelo maior panorama de infecção hospitalar que o mundo já vivenciou.

A maioria dos profissionais de saúde colonizados são os portadores transitórios de MRSA, mas podem se tornar portadores persistentes, especialmente quando eles têm lesões de pele. A identificação e o tratamento de profissionais de saúde colonizados podem reduzir a incidência de MRSA, assim como pacientes colonizados não identificados podem agir como um reservatório endêmico (BENDAVID; MERMEL; PARENTAL, 2008).

.Em nossa observação diária e através de manifestações verbais espontâneas de funcionários, tanto em discussões em grupo como em palestras, bem como na dissertação de mestrado, constatamos falhas na adoção do "Protocolo Específico de Isolamento" para bactérias multirresistentes (MOURA, 2004) fato este que contribui com a disseminação do micro-organismos no ambiente hospitalar. No Brasil, o MRSA é responsável por 26,6 a $71 \%$ das cepas de Staphylococcus aureus isoladas em diversos hospitais do país (LEVY et al, 1991).

Neste contexto, consideramos o estudo de Infecção Hospitalar fundamental para os profissionais da área de saúde, uma vez que os micro-organismos hospitalares são virulentos e podem causar inúmeras infecções, tanto para os pacientes, como para os profissionais e visitantes (RODRIGUES et al., 1997).

O conceito de infecção hospitalar, definido pelo Ministério da Saúde (MS) Brasil (1998), é aquela adquirida após a admissão do cliente, que se manifesta durante a hospitalização ou após a alta, desde que possa ser relacionada à internação ou a procedimentos hospitalares. Contudo, a sua erradicação não é possível devido a dois fatores principais: um deles é de caráter endógeno, proveniente da própria microbiota humana, e está relacionado às condições de saúde do hospedeiro, ou seja, idade, uso de imunossupressores, antimicrobianos e quimioterápicos, estado nutricional, doença crônica, tempo prolongado de internação, doença de base, entre outras. O outro fator é de caráter exógeno e diz respeito às causas externas tais como: infecção cruzada, procedimentos invasivos, uso de materiais e equipamentos contaminados, hábito da não-higienização das 
mãos, limpeza e desinfecção inadequadas do recinto, presença de vetores como insetos e roedores e sujidade do ambiente (BRASIL, 1998; FERNANDES et al., 2000). Tais fatores apresentam como agravantes de grande significado epidemiológico, tanto no contexto da saúde pública como no da assistência hospitalar, de elevarem as taxas de morbi-mortalidade, ampliar o tempo de permanência dos pacientes no hospital e, conseqüentemente, onerarem os custos do tratamento, com danos irreparáveis, sejam do ponto de vista humano, econômico ou social (BRASIL, 1998; CDC, 2006).

Um estudo retrospectivo de um hospital universitário regional de Maringá, Paraná; demonstrou que houve um incremento de 60,2\% das infecções hospitalares causadas por MRSA, no ano de 2005. A maior ocorrência de tais infecções por MRSA estavam associadas ao uso de dispositivos médicos invasivos. Portanto, é fundamental a atenção aos problemas relacionados às infecções nosocomiais e a execução de medidas preventivas para redução de seu número (SOUZA; FIGUEIREDO, 2008).

Essa condição pode ser revertida através de intervenções bem conduzidas como demonstrado em um estudo realizado durante dois anos em uma unidade de cuidado intensiva (UTI). Os pacientes foram divididos em grupos: controle, intervenção e pós-intervenção. A intervenção tratava-se de programas educacionais para trabalhadores da área da saúde, higienização das mãos; identificação precoce de pacientes e profissionais colonizados ou infectados por MRSA, identificação de leito para isolamento de contato; descolonização dos pacientes e profissionais de saúde portadores nasais de MRSA com mupirocina durante cinco dias. Como resultado foi encontrado uma taxa de infecção hospitalar do período de controle de 10,2, no período de intervenção de 5,1 e de pós-intervenção de 2,5/1,000 pacientes/dia $(p<0.001$ ) e MRSA nas infecções da corrente sanguínea eram 3,6, 0,9 e 1,8/1,000 cateter/dia venoso central $(p=0.281)$. As taxas de mortalidade foram, respectivamente $26,6 \% ; 27,3 \%$ e $21,0 \%$ ( $p$ < 0.001). Portanto, a intervenção para a prevenção e controle de infecções por MRSA em UTI, demonstrou ser eficiente na redução da infecção da corrente sanguínea e na incidência das infecções hospitalares por MRSA, e também na redução significativa da taxa de mortalidade global (MOREIRA et al, 2007a).

Pesquisadores ressaltam a importância da implantação de uma política de monitoramento acerca da adoção de medidas de higiene rigorosa no próprio 
ambiente, no isolamento dos pacientes com MRSA e no que se refere à descolonização com antissépticos adequados à triagem de rotina de todos os pacientes e profissionais de saúde que os assistem, bem com a adesão desses profissionais ao uso de equipamentos de proteção individual, durante o contato com os pacientes colonizados, e consideram que tais procedimentos são eficazes no tocante à freqüência de infecções causadas por MRSA em unidades de internação, especialmente, nas unidades de terapia intensiva, clínicas médica, cirúrgica, ginecológica e obstétrica, consideradas a especificidade de tratamento de seus clientes (WESTPHAL et al., 1997; LESSING; JORDENS; BOWLER, 1996; BOYCE, 2001).

A adesão dos profissionais às medidas simples, porém básicas como a higienização das mãos e medidas de controle referentes ao isolamento de maneira geral demonstram resultados preocupantes e nos induzem a buscar os motivos que levam a diversas falhas na adoção das medidas preventivas para isolamento específico. Pittet; Mourouga e Perneger (1999), descrevendo uma abordagem feita sobre higiene das mãos na equipe multiprofissional do Hospital da Universidade de Genebra, Suíça, relataram que, nessa experiência, quanto maior a necessidade de higiene das mãos, menos elas eram efetivamente lavadas, isto é, quanto mais ocupado o profissional de saúde, menos provável se torna a lavagem das mãos. Essa exposição eleva consideravelmente o risco de aquisição e disseminação de bactérias multirresistentes.

Lessing, Jordens e Bowler (1996) argumentaram que embora a triagem para MRSA entre os trabalhadores seja recomendada por normas americanas e britânicas, essa prática ainda é controversa, apresentando vantagens e desvantagens. Dentre as desvantagens as autoras citaram a identificação de portadores transitórios, alteração da rotina hospitalar e possibilidade do profissional ser estigmatizado. Contudo, trazem como vantagem a prevenção do risco, uma vez que um único profissional pode desencadear um surto de infecção. Recomendaram esse recurso deve fazer parte do programa de prevenção e controle de MRSA das instituições de saúde, porém o mesmo deve ser utilizado de forma criteriosa.

É real o risco potencial da resistência microbiana nos reverter a um mundo de mortes prematuras e enfermidades crônicas. Nossos avós vivenciaram um mundo sem antibióticos e isso poderá acontecer com nossos netos (APECIH, 1999). Portanto, o papel dos hospitais deve ser o de assegurar políticas de uso racional de 
antimicrobianos, assim como prevenir a transmissão e a expansão dos microorganismos multirresistentes.

Um capítulo à parte se faz necessário para analisar também a resistência à mupirocina, por ser um antibiótico que tem sido usado para descolonização da mucosa nasal e de lesões cutâneas de pacientes ou profissionais da saúde quando o Staphylococcus aureus apresenta-se resistente à meticilina. Neste contexto, a mupirocina, antimicrobiano de uso tópico, é recomendada para a descolonização (COIA et al., 2006; WERTHEIM; VOS, 2005b). Tem a descolonização por objetivo principal limitar a disseminação deste agente nos serviços de saúde, e assim reduzir o grande impacto clínico produzido por ele nas infecções hospitalares, notadamente aquelas relacionadas a procedimentos cirúrgicos e cateteres vasculares (WERTHEIM; VOS, 2005b).

Estudos recentes têm avaliado a vigilância ativa por meio da cultura em swab nasal e/ou de orofaringe para identificar portadores do MRSA no ambiente hospitalar, e demonstrando que essa medida vem contribuindo para redução das taxas de infecção (NETTO DOS SANTOS, FONSECA, GONTIJO, 1996; ROBICSEK et al., 2008)

A adoção da triagem por teste molecular de identificação rápida de MRSA em pacientes em pré-operatório cirúrgico de urgência, para sua posterior descolonização se necessária, demonstrou a significativa redução de bacteremia por Staphylococcus aureus. Contudo, a correlação não pôde ser comprovada em face dos múltiplos fatores envolvidos (TRAUTMANN et al., 2008).

O uso da mupirocina, no pré-operatório de 96 pacientes, submetidos à esofagectomia radical eletiva com toracotomia e laparotomia, demonstrou também uma significativa redução no índice de infecção hospitalar entre pacientes que eram portadores de Staphylococcus aureus (UNEMURA et al., 2006).

A eficácia de um programa de prevenção e controle de infecção em UTI no Brasil pós intervenção de descolonização, e vigilância de controle foi demonstrada com índices de redução de infecção hospitalar e mortalidade significativos (SIMOR et al., 2007; MOREIRA et al., 2007b).

Entretanto, resistência à mupirocina tem sido descrita em hospitais que fazem uso regular dessa prática (UDO; JACOB; MATHEW, 2001a; SIMOR et al., 2007; NETTO DOS SANTOS, FONSECA, GONTIJO, 1996). Já se demonstrou que a 
resistência é facilmente transferível entre Staphylococcus aureus e exibe relação com o seu uso prolongado em locais onde o MRSA é endêmico (UDO; JACOB; MATHEW, 2001a).

Para que a estratégia de vigilância ativa do MRSA e descolonização dos portadores continuem a ser efetiva, é fundamental que se avalie o nível de resistência à mupirocina encontrado nos serviços de saúde de maneira que se possa contar sempre com este aliado ao controle das infecções hospitalares.

$E$, finalmente, para que se possa analisar a magnitude da problemática apresentada, é necessário que diversas regiões de nosso país conheçam sua prevalência de portadores colonizados de Staphylococcus aureus e MRSA para que se planejem medidas adequadas à situação apresentada, sendo esta a principal justificativa deste trabalho. 


\section{O PROBLEMA DE PESQUISA E HIPÓTESES}

Em nossa atuação, na área de infecção hospitalar, bem como durante a realização da dissertação de mestrado em enfermagem fundamental, a temática sobre a prevalência de Staphylococcus aureus meticilina resistentes em profissionais de saúde, e suas interfaces com as infecções nosocomiais nos despertou um grande interesse, na prática diária, nós nos deparávamos frequentemente com pacientes portadores destas cepas. Também observamos que não existia uma padronização de condutas para prevenção da disseminação dessas cepas nas diferentes instituições de saúde; uma vez que alguns autores defendem a descolonização do portador e outros são contrários à conduta.

Inquestionavelmente, os Staphylococcus aureus representam um grande desafio no que tange ao controle da infecção nas instituições de saúde. Portanto, essa realidade mostra a necessidade de investigações acerca da prevalência de Staphylococcus aureus meticilina resistentes em profissionais de saúde e suas interfaces com as infecções nosocomiais, com vistas a preencher essa lacuna existente nos serviços; processo de suma importância para manter a qualidade de vida da população que circula nas instituições de saúde.

A prevalência de MRSA nas instituições nem sempre é mensurada, contudo são descritos os riscos potenciais dos pacientes em adquirirem infecção hospitalar. como descreve recente publicação dos Centers for Disease Control (CDC). Esses dados representam a primeira estimativa nacional sobre a carga de MRSA invasiva, utilizando bases populacionais e busca ativa de casos. (KLEVENS et al., 2007) contribuindo para a nossa compreensão sobre a verdadeira incidência de infecções invasivas por MRSA.

As estimativas, baseadas em dados norte-americanos para 2005 (GRUNDMANN et al., 2006; KLEVENS et al., 2006; KUEHNERT et a., 2005; NOSKIN et al., 2005), são as seguintes: existência de número superior a 94.000 casos de MRSA invasivo na população dos EUA. Por volta de 19.000 desses casos $(18 \%)$ evoluíram a óbito durante a internação inicial. Aproximadamente $75 \%$ dos casos eram bacteremias não-complicadas; outros incluíam empiema, endocardite e osteomielite. A maioria das infecções invasivas por MRSA (aproximadamente 86\%) 
ocorre em indivíduos com exposição a ambientes hospitalares ou de assistência à saúde, enquanto aproximadamente $14 \%$ ocorrem em indivíduos sem hospitalizações recentes ou qualquer outro fator de risco para MRSA. Porém, na maioria global dos casos a infecção manifestou-se ou foi descoberta quando os indivíduos estavam fora do ambiente hospitalar.

Portanto, a prevenção efetiva de colonização por MRSA, durante a internação pode evitar infecções. Então, prevenir a transmissão no ambiente hospitalar é extremamente importante.

\begin{abstract}
A falta de adesão às medidas de precauções-padrão somada à permanência no hospital, ao contato com os pacientes, faz com que esses profissionais fiquem sujeitos à colonização por micro-organismos virulentos, colocando-os na condição de portadores e disseminadores de infecção, colaborando, assim, para a ocorrência de surtos graves e muitas vezes irreversíveis à saúde do cliente e da própria comunidade hospitalar. $\mathrm{O}$ controle do MRSA, ao contrário da maioria das intervenções em assistência à saúde, pode não apenas ser benéfico em termos de custos, mas também representar economia com o investimento inicial mais do que compensado pela economia em antibióticos e outros tratamentos e testes diagnósticos necessários aos pacientes com suspeita ou infecção estabelecida, insumos para precaução e tempo de permanência, sem mencionar o impacto financeiro da negativa e litígios potenciais (FIVE MILLION LIVES CAMPAIGN, 2008).
\end{abstract}

Sob essa ótica, constata-se a necessidade de mudança de atitude, de um planejamento estratégico contendo medidas preventivas padronizadas e a definição da metodologia de execução descrita; bem como enaltecemos a necessidade da pesquisa para a área da saúde, particularmente para a enfermagem, pois assegurará um impacto positivo na assistência, a partir do acompanhamento dos resultados e conseqüentemente da melhoria de sua qualidade tanto para os clientes como para a comunidade de saúde em geral.

O enfermeiro assistencial, bem como o docente, hoje, na condição de educador, deve ter o compromisso de formar um profissional competente, crítico, facilitador das ações apreendidas ao longo de sua formação. Deve, ainda, no exercício de sua função, orientar o aluno a exercer sua profissão com a visão de líder, tanto fora como dentro das instituições de saúde, intervindo com ações efetivas nas etapas do controle das infecções hospitalares. É com essa compreensão acerca da temática, que nos propusemos a realizar esta investigação 


\section{FUNDAMENTAÇÃO TEÓRICA}

\subsection{Aspectos microbiológicos e identificação dos estafilococos}

O termo Staphylococcus origina-se do grego, staphyle, e significa cacho de uvas, por causa do arranjo microscópico característico em agrupamentos. Microscopicamente, Staphylococcus aureus é um micro-organismo Gram positivo e produz catalase, caracterizado individualmente por cocos com um diâmetro de 0,71,2 micra (MANDELL, 1990). São imóveis, não-esporulados e geralmente nãoencapsulados. Essa bactéria pode apresentar-se em diversas formas, que vão desde isolados, aos pares, em cadeias curtas, ou agrupados irregularmente, devido à sua divisão celular, que ocorre em três planos perpendiculares (CASSETTARI; STRABELLI; MEDEIROS, 2005; KONEMAN et al., 2001; TRABULSI; ALTHERTHUM, 2005). O Staphylococcus foi descrito, pela primeira vez em 1880, em pus de abscessos cirúrgicos, pelo cirurgião escocês Alexandre Ogston e, atualmente, é um dos microorganismos mais comuns nas infecções piogênicas em todo o mundo.

O gênero Staphylococcus pertence à família Micrococcae, juntamente como os gêneros Planococcus, Micrococcus e Stomatococcus. Atualmente, o gênero Staphylococcus possui 37 espécies, sendo que 17 delas podem ser isoladas de amostras biológicas humanas. Geralmente, esse gênero faz parte da microbiota da pele humana normal e de outros sítios anatômicos. A espécie de maior interesse médico, principalmente em ambiente nosocomial, é o Staphylococcus aureus, que está frequentemente relacionado com diversas infecções em seres humanos (CASSETTARI; STRABELLI; MEDEIROS, 2005; KONEMAN et al., 2001).

Staphylococcus aureus se desenvolvem em meios comuns, caldo ou ágar simples, $\mathrm{pH}=7$, à temperatura ótima de $37^{\circ} \mathrm{C}$. As colônias formadas após 18-24 horas de incubação, apresentam-se arredondadas, lisas e brilhantes. A coloração dessas colônias varia desde o acinzentado até o amarelo-ouro, e a pigmentação aumenta com o tempo de incubação prolongado, não chegando a ser formada nos casos de crescimento em condições anaeróbicas, ou na cultura em caldo. Em placas 
de ágar sangue, um halo de hemólise desenvolve-se em torno das colônias formadas (CASSETTARI; STRABELLI; MEDEIROS, 2005; KONEMAN et al., 2001; TRABULSI; ALTHERTHUM, 2005). Outro meio importante para a identificação do Staphylococcus aureus é o ágar manitol-sal, seletivo para essa espécie, uma vez que o Staphylococcus aureus consegue fermentar o manitol, produzindo ácido lático. Essa espécie se desenvolve também na presença de $7,5 \%$ de $\mathrm{NaCl}$, que estimula a produção de coagulase, enzima que caracteriza a espécie (CASSETTARI; STRABELLI; MEDEIROS, 2005; KONEMAN et al., 2001).

\subsection{Resistência aos antimicrobianos}

Os micro-organismos apresentam mecanismos de seleção natural que resultam na emergência de isolados resistentes aos diferentes antimicrobianos, assim, quando uma população microbiana é exposta a um antibiótico, os microorganismos mais suscetíveis são eliminados, sobrevivendo somente os resistentes ao antimicrobiano. Esses micro-organismos podem transferir os genes de resistência à sua descendência ou ainda, para outras bactérias relacionadas, através da conjugação, por meio de plasmídios. Esse processo natural é exacerbado pelo abuso de antimicrobianos no tratamento das enfermidades humanas, sendo utilizado também na pecuária, piscicultura e agricultura. A doença e a resistência a ela associada também prosperam em condições de instabilidade civil, de pobreza, migração de massa e degradação ambiental, principalmente quando há exposição de grande número de pessoas às doenças infecciosas, aliada à ineficiência dos serviços de saúde (ORGANIZAÇÃO MUNDIAL DA SAÚDE (OMS), 2000).

A evolução crescente da resistência antimicrobiana provém de um cenário multifatorial que inclui a utilização excessiva e/ou inadequada dos antibióticos no ambiente hospitalar, na comunidade, nas indústrias alimentícias e veterinárias, bem como a relativa facilidade com que os micro-organismos resistentes ultrapassam barreiras geográficas. A importância dos agentes antimicrobianos no aumento do fenômeno da resistência reside no seu papel selecionador das estirpes resistentes, através da pressão seletiva, resultante de seu amplo emprego (TAVARES, 2000; HOSEIN et al., 2002; SEFTON, 2002). 
Os Staphylococcus aureus, apresentam resistência amplamente difundida em todo o mundo enquanto outras espécies mantêm em todos os países notável sensibilidade às drogas ativas (LIVERMORE, 2003).

Talvez seja o Staphylococcus aureus o patógeno de maior preocupação devido à virulência intrínseca, diversidade de infecções potencialmente fatais e capacidade de adaptação às diferentes condições ambientais (RAMMELKAMP; MAXON, 1942).

Um dos principais objetivos dos programas de controle de infecções hospitalares é o de prevenir a disseminação de patógenos multirresistentes.

O reconhecimento de padrões de resistência emergentes é feito inicialmente pelo laboratório de microbiologia clínica, por meio dos testes de sensibilidade que identificam estes agentes (ainda que presuntivamente) de modo mais correto e o mais rápido possível, informando imediatamente ao Serviço de Controle de Infecção Hospitalar (STARLING; SILVA, 1998).

Grande parte dos laboratórios informa os padrões de resistência. Contudo, não existe uma definição-padrão para resistência múltipla de bactérias, usualmente considera-se como sendo multirresistentes os micro-organismos com resistência a duas ou mais classes de antimicrobianos aos quais as bactérias são normalmente susceptíveis (STARLING; SILVA, 1998).

\subsection{Mecanismos de resistência aos antimicrobianos}

A resistência às penicilinas do grupo beta-lactâmico atua ligando-se às enzimas chamadas PBP ("protein biding penicillins"), inibindo-as, resultando em rompimento da camada de peptidoglicano da parede celular estafilocócica e eventual mor bacteriana. Cepas suscetíveis de Staphylococcus aureus produzem quatro PBP: PBP1,2,3 e 4, sendo as PBP 1,2 e 3 consideradas como principais alvos do beta-lactâmicos (MOREIRA; DAUM, 1995).

As Beta-lactamases são enzimas bacterianas que provocam hidrólise do anel beta-lactâmico de alguns antibióticos, alterando e causando a perda de sua atividade antibacteriana. Ocorre assim a resistência quando a concentração de antimicrobianos é diminuída a níveis abaixo dos necessários para inibir as PBP. 
Algumas beta-lactamases são excretadas para o ambiente ao redor da bactéria, e outras permanecem ligadas à membrana celular (MOREIRA; DAUM, 1995).

Foram identificadas quatro variedades de beta-lactamases estafilocócicas, chamadas de A,B,C e D. Na maioria das cepas estafilocócicas, a produção de betalactamase é induzida pelos antibióticos beta-lactâmicos. As cepas constitutivas, isto é, que produzem beta-lactamases independente da exposição aos beta-lactâmicos, são raras (MOREIRA; DAUM, 1995).

Quanto ao Fenótipo de Resistência $\mathrm{MLS}_{\mathrm{B}}$ em Staphylococcus aureus, temos os macrolídeos, lincosaminas e estreptograminas (MLS) que são antimicrobianos amplamente empregados no tratamento de infecções estafilocócicas. São antibióticos quimicamente distintos que compartilham o mesmo mecanismo de ação: a inibição da síntese protéica bacteriana. Estruturalmente, os macrolídeos são substâncias compostas por um anel lactonado que possui 14 (eritromicina, claritromicina), 15 (azitromicina) ou 16 (josamicina, esperomicina e lisomicina) átomos de carbono associados a uma glicoproteína, via ligação glicosídica. A eritromicina foi introduzida na prática médica, em 1952, como o primeiro antibiótico macrolídeo. Logo após o primeiro ano de sua introdução na terapêutica clínica, isolados de estafilococos resistentes a eritromicina foram relatados nos EUA, Europa e Japão (ROBERTS et al., 1999).

Um dos mecanismos de resistência estafilocócica à eritromicina, à lincomicina e à clindamicina é a alteração enzimática do local de ligação desses antibióticos na célula bacteriana. Os genes que conferem este fenótipo podem ser plasmidiais ou cromossomais (MOREIRA; DAUM, 1995).

Outro mecanismo de resistência, apenas aos macrolídeos, tem o gene codificador plasmidial e resulta numa bomba dependente de ATP que retira o antibiótico da célula, mantendo sua concentração intracelular abaixo da necessária para se ligar ao ribossomo. Ainda outro mecanismo de resistência, apenas às lincosaminas, com gene codificador plasmidial, consiste em inativação enzimática desses antibióticos (MOREIRA; DAUM, 1995).

A resistência do Staphylococcus aureus ao cloranfenicol deve-se à acetilação do cloranfenicol por uma enzima induzível, codificada por gene plasmidial (MOREIRA; DAUM, 1995).

Estafilococos apresentam dois mecanismos de resistência às tetraciclinas. Um mecanismo codificado por genes plasmidiais, induzível, consiste na retirada do 
antibiótico de dentro da célula, diminuindo seu acúmulo intracelular. O outro mecanismo, codificado por gene plasmidial ou cromossômico, consiste em proteção do ribossomo, por uma proteína citoplasmática que interage ou se associa ao ribossomo, tornando-o insensível à ligação com tetraciclina (MOREIRA; DAUM, 1995).

A resistência de Staphylococcus aureus às sulfonamidas é adquirida por mutação cromossomal que resulta em hiperprodução de ácido para-amino benzóico (PABA) com o qual as sulfas competem para realizar sua atividade antimicrobiana.

A resistência ao trimetoprima é mediada por um gene plasmidial ou cromossômico que aparentemente codifica uma enzima di-hidrofolato redutase (DHFR) alterada que impede sua ligação ao trimetoprim (MOREIRA; DAUM, 1995).

Já foi descrita resistência de Staphylococcus aureus à teicoplanina (KAATZ et al.,1990) e ainda não à vancomicina. O mecanismo de resistência ainda não está claro (MOREIRA; DAUM, 1995).

O mecanismo de resistência à rifampicina consiste em alterar o alvo do antibiótico: subunidade beta da RNA polimerase-DNA dependente, diminuindo sua afinidade ao antibiótico (MOREIRA; DAUM, 1995).

Porém, uma compreensão mais elaborada sobre a resistência do staphylococcus aures à oxacilina se faz necessária em função da relevância do assunto.

Na era pré-antibiótica, Staphylococcus aureus era considerado como um dos mais importantes agentes causadores de infecções hospitalares graves de elevada letalidade, especialmente as cirúrgicas. Bacteremias por Staphylococcus aureus levavam ao óbito 80 a 90\% dos casos (SHEAGREN,1984; WISE; OSSMAN; LITTLEFIELD, 1989). A implantação da antibioticoterapia, no início da década de 1930, com o emprego da sulfanilamida (descoberta por Gerard Domagk, em 1932), tiveram impacto muito pequeno sobre as infecções estafilocócicas devido à sua ação diminuída em presença de pus e pelo rápido desenvolvimento de resistência de Staphylococcus aureus a estes antimicrobianos. A penicilina, em 1942, apresentou impacto maior, melhorando o prognóstico das estafilococcias, já que todas as cepas de Staphylococcus aureus, isoladas de materiais clínicos eram sensíveis à penicilina em baixa dose. Porém, já em 1942, foi descrita resistência a esse antimicrobiano em cepas obtidas de pacientes em tratamento com penicilina (WISE; OSSMAN; LITTLEFIELD, 1989). O Staphylococcus aureus passou a desenvolver resistência a 
esse betalactâmico pela produção da betalactamase (penicilinase), capaz de hidrolisar o anel betalactâmico da penicilina, tornando-a inativa. Em 1944, apenas $5 \%$ dos Staphylococcus aureus eram resistentes à penicilina, enquanto que em 1959 essa resistência já alcançava a taxa de $80 \%$, sendo estendida tanto à amoxicilina como à ampicilina (FREITAS; FONSECA ,1987; MAMISUKA, 2005; TAVARES, 2002)

Em 1960 foi descoberta uma droga do grupo das penicilinas, denominada meticilina (a primeira penicilina semisintética posta em uso clínico), que não era suscetível à ação da betalactamase e, logo depois, de outras penicilinas antiestafilocócicas, das quais a oxacilina foi a mais empregada no Brasil, e cefalosporinas de primeira geração.

Poucas semanas após o lançamento de meticilina, no início da década de 1970, foi isolada uma cepa de Staphylococcus aureus naturalmente resistente (MRSA) na Inglaterra e em locais onde o antibiótico nunca havia sido usado (WISE; OSSMAN; LITTLEFIELD, 1989).

Essa resistência à meticilina caracterizava resistência aos antibióticos betalactâmicos em geral (WISE; OSSMAN; LITTLEFIELD, 1989). No final da década de 70 , cepas isoladas na Austrália exibiam resistência a muitos outros antibióticos, além dos beta-lactâmicos, foram denominadas de MARSA por alguns autores, para designar resistência a múltiplos antibióticos ou resistência a meticilina e aminoglicosídeos. Da mesma forma que as cepas penicilino-resistentes, os MARSA também mantiveram a virulência e disseminaram-se pelo mundo (BRUMFITT; HAMILTON-MILLER, 1989). Na maioria dos relatos, uma vez que MRSA tenha sido detectado em determinado local, tende a persistir, aumentar progressivamente sua prevalência, bem como a proporção de infecções hospitalares causadas por Staphylococcus aureus (WISE; OSSMAN; LITTLEFIELD, 1989).

$\mathrm{Na}$ década de 80, infecções hospitalares, causadas por Staphylococcus aureus, aumentaram em quase todo o mundo devido ao MRSA, trazendo para o início da década de 90 uma condição semelhante à década de 50 em que o Staphylococcus aureus era o principal causador das infecções hospitalares e era virtualmente resistente a todos os antibióticos disponíveis (KAATZ et al., 1990).

As cepas MRSA rapidamente se disseminaram em ambientes hospitalares, limitando, assim, a antibioticoterapia de combate às estafilococcias por Staphylococcus aureus aos glicopeptídios vancomicina e teicoplanina (SANTOS et 
al., 2007). Em 1990, foi descrita resistência de MRSA à teicoplamina, durante tratamento de endocardite (KAATZ et al., 1990). A vancomicina é um glicopeptídio conhecido desde 1956, quando esteve à disposição da medicina. Entretanto foi preterida em função do sucesso da meticilina, da oxacilina e de outras isoxazolilpenicilinas. A vancomicina mostra-se eficiente no tratamento das infecções causadas pelas cepas MRSA, apesar de apresentar efeitos nefrotóxicos e ototóxicos (MACHADO et al., 2005; SRINIVASAN; DICK; PERL, 2002).

No entanto, o Staphylococcus aureus desenvolveu resistência àquele glicopeptídio (Staphylococcus aureus resistente à vancomicina [VRSA]) em 1997, como descreveu Hiramatsu et al. (1997), no Japão. A resistência do Staphylococcus aureus aos antibióticos tem sido desenvolvida por mutações em seus genes ou pela aquisição de genes de resistência de bactérias da mesma ou de outra espécie. Geralmente, a resistência que ocorre por mutação gera uma alteração no sítio de ação do antibiótico, enquanto a resistência por aquisição de genes de resistência frequentemente envolve a inativação ou a destruição da droga, sendo transmitida por plasmídeos e transposons (BERNARD et al., 2004; LIMA et al., 2005; TAVARES, 2002).

A resistência à meticilina é determinada pela aquisição de um cassete cromossomal estafilocócico mec (staphylococcal chromosome cassette mec - SCC $m e c$ ), um elemento genético móvel de 20-60 Kb, compreendendo o gene mecA e os elementos regulatórios de sua transcrição, gene mecl e mecRI (MATTHEWS; REED; STEWART, 1987).

Estudos genéticos demonstraram que a atual prevalência de MRSA resultou principalmente da disseminação de alguns clones, com a descrição de apenas cinco clones no mundo. Um estudo mostrou que de 359 MRSA isolados de 20 países, no período de 1961 a 1999 foram identificados 11 principais clones de MRSA dentro de cinco grupos de genótipo relacionados (ENRIGHT, et al., 2002). Similarmente, Oliveira; Tomasz e Lencastre (2002) usaram técnica de tipagem molecular para identificar os cinco maiores clones de MRSA que acometiam aproximadamente $70 \%$ dos 3.000 MRSA isolados, obtidos primariamente de hospitais dos Estados Unidos, da América e da Europa que tiveram como principal carreador médicos, enfermeiros e pessoas que tiveram contato com pacientes hospitalizados (LOWY, 1998).

Clones de estafilococos multirresistentes apresentam-se amplamente disseminados (SOUSA et al., 2001). Frente a este cenário, técnicas de biologia 
molecular (genotipagem) têm atuado como ferramentas importantes associadas à epidemiologia molecular permitindo a diferenciação de isolados com fenótipos idênticos, fornecendo informações úteis para a compreensão da distribuição mundial dos clones, além de elucidações sobre os mecanismos de resistência (Mc ELLISTREM et al., 2000).

No Brasil, um dos primeiros relatos sobre a utilização do Eletroforese de Pulsed Field Gel (PFGE) para tipagem de estafilococos ocorreu em 1995. Teixeira et al. (1995) caracterizaram 85 MRSA isolados em cinco hospitais de quatro regiões geográficas distintas (São Paulo, Rio de Janeiro, Rio Grande do Sul e Amazonas). Mostraram a existência de um clone multirresistente amplamente distribuído no norte, sudeste e sul brasileiro. Recentemente, um total de cinco linhagens principais de Staphylococcus aureus resistentes a meticilina foram descritas (OLIVEIRA; TOMASZ; LENCASTRE, 2002). Pela habilidade em causar infecções, persistir e disseminar por regiões geográficas distintas, inclusive entre continentes; estas linhagens foram denominadas de clones epidêmicos. Através de técnicas moleculares, estes clones foram classificados como Brasileiro, Ibérico, Húngaro, Nova lorque/Japão e pediátrico epidêmico (COIMBRA et al., 2003).

Até o momento, foram descritos cinco tipo de SCC mec (I, II, III, IV, V), os quais podem estar associados a estruturas genéticas móveis como transposons (Tn 554) e plasmídeos, responsáveis pela resistência a antibióticos não $\beta$-lactâmicos (ITO; HIRAMATSU, 1998; ITO et al., 2004).

Uma vez estabelecidos em um novo ambiente, os MRSA disseminam-se rapidamente e com freqüência tornam-se o clone predominante, responsável por taxas crescentes de infecções hospitalares. Os pacientes colonizados ou infectados por MRSA funcionam como reservatório do patógeno contribuindo para a manutenção de elevadas taxas de incidência. A disseminação do micro-organismo normalmente ocorre de pessoa-pessoa, via paciente ou profissionais da saúde colonizados, particularmente os assintomáticos. As mãos dos trabalhadores da saúde exercem papel fundamental nessa transmissão, embora a colonização nasal também contribua (ALGHAITHY et al., 2000; CESPEDES et al., 2002). Em instituições onde o MRSA é altamente endêmico, aproximadamente $1 \%$ de todos os pacientes hospitalizados tornam-se colonizados e, 40 a $60 \%$ desenvolvem infecções por MRSA (BOYCE, 1992). 
As cepas adquiridas em hospitais costumam apresentar multirresistência, facilidade de disseminação clonal, maior virulência e, portanto, elevadas taxas de mortalidade. Entretanto, evidências significativas da diferença na virulência clínica desses dois patógenos não foram evidenciadas (OLIVEIRA; TOMASZ; LENCASTRE, 2002).

A colonização nasal por esses patógenos também representa fator de risco para infecção em uma variedade de populações. Entre os contatos familiares de pacientes infectados por MRSA adquiridos em instituições de saúde, 14,5\% apresentavam-se colonizados por MRSA, representando fonte de colonização/infecção para a comunidade (CALFEE et al., 2003).

Existem dois tipos de MRSA isolados na comunidade (CA-MRSA); o multirresistente e o não multirresistente. O primeiro parece ter sido transmitido das instituições de saúde por pacientes ou profissionais da área para os contactantes mais próximos, enquanto que o último foi isolado de indivíduos sem fatores de risco predisponentes, sendo considerado o "verdadeiro" CA-MRSA (SALGADO et al., 2004).

Atualmente, para a investigação de surtos, pode-se utilizar as caracterizações fenotípica e genotípica para avaliação da disseminação dessas cepas. A literatura descreve que a resistência à meticilina é determinada por um gene cromossômico $(\operatorname{mec} A)$ da bactéria, o qual codifica para modificações no receptor do betalactâmico, estimulando a produção de uma proteína ligadora de penicilina (PPB2a) com baixa afinidade pelo antibiótico, resultando na resistência. Um estudo realizado em 1996, utilizando cepas analisadas em diferentes continentes, apontou as primeiras evidências da existência de cinco tipos de cassetes cromossomais estafilocócicos relacionados com a resistência à meticilina (SCCmec I, II, III, IV e V) ( VELÁZQUEZMEZA, 2005).

A vancomicina foi a única forma efetiva de tratamento de graves infecções causada por MRSA, contudo o surgimento de cepas de Staphylococcus coagulase negativa, resistentes à vancomicina, foi o primeiro indicativo de que essa bactéria estaria realizando mais um passo na escala da resistência aos antibióticos. Também ocorreu neste período o aparecimento, em hospitais dos EUA, de cepas de Enterococcus resistentes à vancomicina (VRE) isoladas de materiais clínicos (MAMISUKA, 2005; TENOVER; MCDONALD, 2005; VELÁQUEZ et al., 2002). 
O Staphylococcus aureus com resistência intermediária à vancomicina (VISA) (GISA) foi reportado em 1997, isolado de um paciente hospitalizado no Japão (HIRAMATSU et al., 1997). Nos Estados Unidos, os 4 primeiros casos foram reportados entre 1997 e 1999 (SMITH et al.,1999; SIERADZKI et al.,1999); desde então um grande número de casos foi relatado no mundo inteiro, inclusive no Brasil, em um hospital de referência para queimados, no município do Rio de Janeiro (APECIH, 2004). Em todos esses casos os pacientes fizeram uso prolongado de vancomicina para tratar infecções causadas por MRSA.

Foi demonstrado por técnicas de PFGE que nesses casos as cepas VISA apresentavam similaridades às cepas de MRSA anteriormente isoladas nesses mesmos pacientes. Foi comprovado também que havia subpopulações de VISA nessas cepas de MRSA, mas como o MIC era menor que $4 \mu \mathrm{g} / \mathrm{ml}$ foram considerados susceptíveis a vancomicina, sugerindo existir um estágio anterior ao VISA, denominado hVISA ou VISA Heterogêneo. Esse fenômeno ocorre in vitro já que esse glicopeptídeo exerce uma pressão seletiva que favorece o aparecimento de clones resistentes, que são raros, mas que se tornam uma população uniforme de VISA à medida que a exposição vancomicina continua e as cepas totalmente sensíveis vão sendo dizimadas (APECIH, 2004).

A única forma de se detectar uma cepa heteroVISA (Staphylococcus aureus com resistência intermediária à vancomicina) é por meio da análise de suas subpopulações, em que são inoculadas diferentes diluições de uma suspensão bacteriana em meio de cultura sólido (adicionado de concentrações crescentes de vancomicina) (TIWARI; SEN, 2006).

Até o momento foram descritos três casos de infecção por Staphylococcus aureus resistentes à vancomicina (VRSA) nos Estados Unidos. Foram também descritos casos de VRSA no Japão na Coréia, África do Sul, Escócia, mas com base nos padrões da British Society of Antimicrobial Chemoterapy que define $8 \mu \mathrm{g} / \mathrm{ml}$ como resistência a vancomicina, e que seriam considerados como VISA, segundo os padrões do CLSI (APECIH, 2004).

A resistência intermediária do Staphylococcus aureus (VISA) ainda não foi totalmente elucidada. Estudos têm demonstrado que essas cepas tem uma taxa de crescimento menor e que apresentam parede mais espessa que as susceptíveis à vancomicina. Cabe informar que esse tipo de VISA é raro,entretanto acredita-se que o fenômeno hVISA é muito mais comum, respondendo por cerca de 5 a $20 \%$ de 
cepas de MRSA (APECIH, 2004). Estudos bioquímicos e de microscopia eletrônica de transmissão da parede celular de uma cepa VRSA sugerem que essa célula produz maiores quantidades de peptideoglicano e de monômeros de mureína. Nessas circunstâncias, uma maior quantidade de moléculas de vancomicina fica retida nas camadas de peptideoglicano, enquanto uma quantidade muito menor do antibiótico chega à membrana citoplasmática, onde ocorre a síntese do peptideoglicano (CASSETTARI; STRABELLI; MEDEIROS, 2005; TAVARES, 1999; TIWARI; SEM, 2006).

A resistência à vancomicina (VRSA) foi obtida a partir da aquisição, por plasmídeos, do gen Van $A$ do enterococo resistente à vancomicina (VRE), conferindo assim um $\mathrm{MIC}=32 \mu \mathrm{g} / \mathrm{ml}$. Vale lembrar que, em todos os casos de pacientes com VRSA, foram isolados anteriormente cepas de MRSA e de VRE (APECIH, 2004) Na literatura encontra-se uma variedade de termos usados para descrever a resistência à vancomicina. O Clinical and Laboratory Standards Institute (CLSI, 2005) e a Sociedade Francesa de Microbiologia (SFM) utilizam as três seguintes classificações para a sensibilidade das cepas de Staphylococcus aureus à vancomicina: sensível $(\mathrm{CMl}<4 \mu \mathrm{g} / \mathrm{ml})$, intermediário $(8 \leq \mathrm{CMl} \leq 16 \mu \mathrm{g} / \mathrm{ml})$ e resistente $(\mathrm{CMI}>32 \mu \mathrm{g} / \mathrm{ml})$; entretanto, a Sociedade Britânica para a Quimioterapia Antimicrobiana (BSAC) e o Grupo Suíço de Referência para Antibióticos (SRGA) referem-se apenas a duas categorias: sensível $(\mathrm{CMI}>4 \mu \mathrm{g} / \mathrm{ml})$ e resistente $(\mathrm{CMI}>8$ $\mu \mathrm{g} / \mathrm{ml}$ ). Essas variações têm originado uma variedade de siglas, entre as quais as utilizadas para as cepas resistentes à vancomicina: VISA e VRSA. Devido ao fato de as cepas VISA e VRSA geralmente se mostrarem resistentes também à teicoplanina, foi proposto o uso de outras siglas: GISA (Staphylococcus aureus de sensibilidade intermediária aos glicopeptídios) e GRSA (Staphylococcus aureus resistente aos glicopeptídios). Várias cepas GISA foram isoladas a partir de 2000 , em São Paulo, onde diversos fatores de risco podem contribuir para o seu surgimento, sendo um deles o uso prolongado de vancomicina. Existem dificuldades descritas na identificação das cepas GISA, posto que os testes apresentando CMI elevada para glicopeptídios devem ser confirmados, já que a resistência à vancomicina é instável e o microorganismo pode deixar de expressar resistência. Outra denominação se refere às cepas que apresentam $\mathrm{CMI}<4 \mu \mathrm{g} / \mathrm{ml}$ (sensíveis) e subpopulações com CMI entre 8 e $16 \mu \mathrm{g} / \mathrm{ml}$, denominadas heteroVISA (h-VISA). Além disso, podemos encontrar denominações como CA-MRSA para identificar as 
cepas MRSA de origem comunitária e HA-MRSA, para cepas MRSA encontradas em ambiente hospitalar (LOPES, 2005; RIBEIRO et al., 2005; RODRIGUES; VESGA, 2005).

Inicialmente, MRSA era observada somente nos hospitais, mas agora está evidente que pode ser adquirida na comunidade. Nos Estados Unidos,vários casos de staphylococcus aureus adquiridos na comunidade (CA-MRSA) foram reportados no Midwest, 1980, mas muitos dos casos envolviam usuários de drogas ilícitas ou indivíduos com doença subjacente séria ou hospitalização prévia (SARAVOLATZ et al., 1982; LEVINE et al., 1982). Entretanto, já foram descritas infecções por CAMRSA em indivíduos sem fatores de risco identificáveis e sua incidência está aumentando, particularmente em crianças, tornando-se um problema crescente no mundo (HEROLD et al., 1998).

Das principais diferenças entre as cepas CA-MRSA e as associadas ao ambiente hospitalar (HA-MRSA), podem-se destacar manifestações clínicas, em sua maioria associadas a infecções de pele e partes moles, além de muitos casos de infecções respiratórias e da corrente sanguínea. Outra característica extremamente importante é o perfil de resistência a antibióticos, pois, enquanto o HA-MRSA se caracteriza por uma ampla resistência a diversos antibióticos, as cepas CA-MRSA mostram uma sensibilidade (entre $85 \%$ e 100\%) a drogas, como clindamicina, gentamicina, ciprofloxacina, sulfametoxazol/trimetoprima e vancomicina, mostrandose resistentes apenas à oxacilina e a outros betalactâmicos (LOPES, 2005; RIBEIRO et al., 2005).

O perfil de resistência diferenciado entre as cepas HAMRSA e CA-MRSA parece ser explicado pela distribuição e pelo tamanho dos cassetes cromossomiais que contêm o determinante de resistência à meticilina (SCCmec) (LOPES, 2005; RIBEIRO et al., 2005). Entre os cinco tipos de SCCmec (I, II, III, IV e V), somente os tipos I, II e III são encontrados em cepas HA-MRSA, enquanto os tipos IV e V podem ser observados em cepas CA-MRSA, nas quais o tipo IV é menor e, provavelmente, facilita a perda dos genes de resistência a diversos antibióticos, conservando-a para betalactâmicos. Outra característica importante do CA-MRSA é a presença dos genes lukF-PV e lukS-PV, que codificam a leucocidina de Panton-Valentine (PVL), uma toxina capaz de induzir a destruição de leucócitos humanos e causar grande dano tecidual, sendo considerada um fator de virulência associado a infecções de 
pele primárias severas e pneumonias necrotizantes (LOPES, 2005; LARCOMBE et al., 2007; RIBEIRO et al., 2005).

O combate às infecções provocadas pelas cepas de Staphylococcus aureus resistentes aos glicopeptídios teicoplanina e vancomicina tem como alternativas terapêuticas as estreptograminas (quinupristina/dalfopristina), as oxazolidinonas, a glicilciclina (Tigeciclina $\left.{ }^{\circledR}\right)$, além da associação de vancomicina com um antibiótico betalactâmico antiestafilocócico (TAVARES, 2002). Entretanto, medidas adicionais de controle devem ser estabelecidas no combate às cepas de bactérias resistentes.

O aporte das técnicas de tipagem molecular, nesse contexto, tem sido de relevada importância por contribuir nas diferentes etapas do controle e vigilância dessas infecções, auxiliando na adoção de medidas eficientes para a eliminação da condição de portador e o uso racional de antimicrobianos (CARDOSO, 2005).

Em relação à resistência à mupirocina sabe-se que ela pode ser de baixo ou alto nível, e ainda pode ser mediada por gene plasmidial ou cromossômico (conduta sugestiva de um transposon), e é facilmente transferível entre estafilococos (COOKSON, 1990).

A resistência de baixo nível parece dever-se à alteração do acesso do antibiótico ao seu alvo de ligação (enzima isoleucil-tRNA sintetase). É a mais comum e tem pouca importância clínica, porque a concentração de mupirocina aplicada topicamente é muito elevada. A resistência de alto nível deve-se à elaboração de uma enzima isoleucil-tRNA sintetase mutante. É mais rara e associada à falha da mupirocina em erradicar a colonização por MRSA (RODRIGUES et al, 1997).

Entretanto, resistência a este antibiótico tem sido descrita em hospitais que fazem uso regular dessa prática (NETTO DOS SANTOS, FONSECA, GONTIJO, 1996; UDO; JACOB; MATHEW, 2001a). Já se demonstrou que a resistência é facilmente transferível entre Staphylococcus aureus e exibe relação com o uso prolongado da mupirocina em locais onde o MRSA é endêmico (UDO; JACOB; MATHEW, 2001a).

Foi descrito um aumento da concentração inibitória mínima de 0,25 mcg/ml (antes do tratamento) para $8 \mathrm{mcg} / \mathrm{ml}$ (após o tratamento) (WATANABE et al., 2001). Análise genética do mecanismo de resistência de mupirocina em isolados de Staphylococcus aureus mostrou a presença do gene mup A, detectado de um plasmídeo 38kb (TRAUTMANN et al., 2008; UDO; JACOB; MATHEW, 2001b) . 
No Kuwait, pesquisadores descreveram um clone com alta resistência à mupirocina, identificado pela técnica de eletroforese em campo pulsado, em isolados de uma unidade de queimados e disseminados entre cinco outros hospitais (UDO; JACOB; MATHEW, 2001b).

\subsection{Medidas para prevenção e controle de MRSA em serviços de saúde}

Os MRSA apresentam importante implicação no controle de infecção e eram anteriormente pouco abordados, sequer existiam guias de isolamento. Contudo, a prevenção e controle dos mesmos atualmente é uma prioridade.

Um guia contendo as recomendações dos Centers for Disease Control and Prevention (CDC, 2006), denominado "Management of Multidrug-Resistant Organisms in Healthcare Settings, 2006" foi elaborado em parceria com a Association for Professionals in Infection Control and Epidemiology (APIC); Society for Healthcare Epidemiology of America (SHEA); bem como campanhas foram realizadas pelo Institute for Healthcare Improvement (IHI) "5 Million Lives Campaigne". Os pilares para o sucesso das medidas de prevenção e controle são: apoio administrativo; política de restrição da utilização de antibióticos; vigilância epidemiológica; indicação de precauções padrão e de contato; medidas de controle ambiental; educação. A exposição ao MRSA aumenta, conforme aumenta o tempo de permanência hospitalar e uso de dispositivos invasivos.

A infecção por MRSA tem uma grande importância clínica, principalmente em função das opções terapêuticas limitadas; da ocorrência de infecções graves (bacteremia, infecções de sítio cirúrgico); aumento no tempo de permanência; aumento de custos e alta mortalidade e os mecanismos de transmissão são os seguintes: mãos do profissional da saúde; equipamentos utilizados na assistência (estetoscópio, esfigmomanômetro) e roupas; contaminação ambiental; transmissão aérea; profissionais colonizados (mais comum em surtos); pacientes colonizados. papel do profissional da saúde colonizado por MRSA que podem ser colonizadores persistentes e importantes disseminadores, a saber: sinusite crônica (BOYCE, 1992), infecção do trato respiratório superior (SHERETZ et al., 1996), dermatite (WANG et al., 2001). 
Entre as recomendações de prevenção, alguns passos foram considerados essenciais, sendo eles: higiene das mãos, medidas para controle ambiental e de equipamentos, vigilância ativa de culturas, precauções de contato para pacientes colonizados ou infectados e manipulação cuidadosa de cateter venoso central e equipamentos de terapia ventilatória. Para cada uma dessas recomendações, os CDC (2006) listaram medidas que seguem abaixo descritas.

\subsubsection{Campanha "5 Milhões de Vidas” (FIVE MILLION LIVES CAMPAIGN, 2008)}

Uma iniciativa nacional liderada pelo Institute for Healthcare Improvement (IHI), a Campanha "5 Milhões de Vidas" visa melhorar a qualidade da assistência à saúde nos EUA através da prevenção da ocorrência de 5 milhões de incidentes num período determinado. O IHI é uma organização sem fins lucrativos que visa melhorar a assistência à saúde em todo o mundo. $\mathrm{O} \mathrm{IHI}$ ajuda a acelerar mudanças cultivando e colocando em práticas idéias promissoras de melhoria na assistência aos pacientes. Milhares de prestadores de serviços de saúde participam deste trabalho inovador. Esta iniciativa é voluntária e focada na proteção dos pacientes de incidentes e danos causados na assistência.

O objetivo principal desta campanha é trabalhar com foco na segurança do paciente. São diversos os "Bundles de cuidados" elaborados, são eles grupos de boas práticas referentes à determinada patologia, que individualmente resultam em melhoria da assistência, mas quando implantadas em conjunto, resultam em melhorias ainda mais substanciais. As evidências científicas que corroboram cada elemento do bundle, estão suficientemente estabelecidas a ponto de serem consideradas o cuidado padrão. Por acreditar ser este um modelo exemplar, reproduziremos abaixo seu conteúdo (FIVE LIVES CAMPAIGN, 2008).

A campanha tem como meta reduzir significantemente a transmissão e infecção por Staphylococcus aureus Meticilina Resistente (MRSA) através da implantação dos cinco componentes de cuidados (ABRAMSON; SEXTON, 1999; BOOTSMA; DIEKMANN; BONTEN, 2006; GRUNDMANN et al., 2006; MUTO et al., 2003; HUANG et al., 2006), sendo eles: 
1. Higienização das Mãos

2. Descontaminação do ambiente e dos equipamentos

3. Vigilância ativa

4. Precauções de contato para pacientes colonizados e infectados

5. Bundle (Bundle de Cateter Central e Bundle de Ventilação)

O envolvimento de uma equipe multidisciplinar é decisivo em qualquer processo de aprimoramento focando redução de infecção. Equipes bem sucedidas definem objetivos claros para seu trabalho, estabelecem linhas de base para os indicadores de desempenho, medem e analisam regularmente os resultados, e testam séries de alterações em processos e sistemas sob condições variadas, de modo a identificar aquelas que levaram a melhorias em seu ambiente particular (FIVE LIVES CAMPAIGN, 2008).

Embora o MRSA esteja atualmente disseminado em muitos hospitais nos EUA, o risco de infecções graves tende a ser maior nas UTI. Além do mais, surtos de infecção por MRSA ocorrem mais frequentemente nesses ambientes. Embora algumas autoridades recomendem o lançamento de esforços de controle amplamente nos hospitais desde o início, a Campanha recomenda que a maioria dos hospitais inicie seu trabalho em uma ou mais UTIs, ou em outra enfermaria ou população de pacientes com comprovada alta concentração de colonização e infecção por MRSA.

Os esforços iniciais em muito podem ser facilitados pela escolha de uma UTI ou enfermaria onde haja um líder clínico engajado, atuante e formador de opinião. Esta estratégia permite que a equipe multidisciplinar concentre os esforços em uma área geográfica e população de pacientes bem definidas, realizando testes rápidos de mudanças e agindo com dados em tempo real. Certamente, o desempenho confiável em todos os aspectos do pacote de controle da infecção por MRSA é mais facilmente obtido atuando-se, de início, em ambientes relativamente restritos, providos de líderes clínicos receptivos. O sucesso precoce irá demonstrar às lideranças institucionais que sucessos ainda maiores são possíveis, e que o investimento nos recursos necessários pode valer a pena. Alguns especialistas afirmam que se o resto do hospital for deixado sem fiscalização, pacientes colonizados em outras enfermarias serão admitidos na UTI, servindo como fonte de maiores disseminações. Contudo, esta ameaça salienta a necessidade do 
estabelecimento de procedimentos confiáveis, a começar pela transferência do paciente. É encorajadora a demonstração de Huang et al. (2006) sobre o amplo aperfeiçoamento do controle da infecção por MRSA focando-se inicialmente na UTI.

A prevenção da transmissão requer, quase com certeza, uma estratégia mais multifacetada. Há fortes defensores de estratégias específicas de controle, principalmente a vigilância ativa para pronta detecção de pacientes colonizados por MRSA. Contudo, a maioria dos hospitais que reduziu infecção e colonização por MRSA procedeu de uma forma mais ampla, geralmente associando à vigilância ativa, outras medidas de prevenção.

As mãos dos profissionais de saúde podem estar colonizadas por MRSA em ambientes endêmicos ou epidêmicos para esse patógeno. A contaminação transitória das mãos desses profissionais ocorre durante a assistência a pacientes infectados ou colonizados, e geralmente, acredita-se ser esta a via mais freqüente de transmissão de MRSA de um paciente a outro. Os pacientes também tendem a contaminar o ambiente a seu redor, e o MRSA pode sobreviver por horas ou até dias em objetos inanimados como mesas, estrados de camas e teclados de computador.

Por conseguinte, a higienização das mãos antes e depois dos contatos com pacientes com MRSA, ou com o ambiente a seu redor, é de vital importância para a redução de sua transmissão em instituições de saúde. Infelizmente, a adesão à higienização das mãos permanece ínfima em muitos hospitais, geralmente bem inferior a 50\%. Portanto, a higienização das mãos é um componente obrigatório para redução da infecção por MRSA (PITTET; MOUROUGA; PERNEGER, 1999; LANKFORD et al, 2003; PITTET et al, 2000; BISCHOFF et al, 2000).

Medidas preventivas - Higiene das mãos: Implementar um programa de higiene das mãos que inclua todos os níveis de profissionais. Realizar o ato antes e depois do contato com o paciente, superfícies e objetos contaminados. Monitorar a adesão através de observação ou consumo de produtos (álcool-gel).Promover rápida redução da carga bacteriana (exceto esporos de Clostridium difficile) e não ressecar as mãos. Não deve ser usado quando as mãos estiverem visivelmente sujas ou molhadas. O uso de luvas não substitui a higiene das mãos (CDC, 2006).

A contaminação do ambiente hospitalar por MRSA, que sobrevive bem neste local pode ocorrer. Os profissionais que entram em contato com objetos ou superfícies contaminadas podem contaminar suas mãos. Os pacientes internados em quartos previamente ocupados por pacientes colonizados por MRSA, 
ocasionalmente adquirem esse microorganismo, seja pelas mãos dos colaboradores, ou pelo seu contato direto com microorganismos que persistem no ambiente a seu redor. Assim, a programação regular de limpeza e desinfecção rigorosa do ambiente é essencial como prioridade em todos os hospitais (BOYCE et al., 1997; HUANG et al., 2006; CARLING; PARRY; VON BEHEREN, 2008).

Medidas para controle ambiental e de equipamentos - ambiente: Não recomendar culturas do ambiente de rotina.Realizar treinamentos para a equipe de limpeza.Desenvolver um programa de limpeza dos quartos dos pacientes em precauções de contato. Usar um "checklist" para avaliar a qualidade da limpeza e reforçar técnicas adequadas. Usar preferencialmente equipamentos individuais para assistência (CDC, 2006).

Quanto à vigilância ativa, foi analisado o fato de que pacientes colonizados representam o principal reservatório de MRSA a partir do qual ocorre a transmissão. Assim, a identificação de pacientes colonizados facilita a pronta implantação de medidas de controle destinadas a reduzir a transmissão (Huang et al., 2006).

Estudos demonstraram que a abordagem mais sensível para identificação de pacientes colonizados é realização de testes de screening para vigilância ativa em todos os pacientes admitidos, sem utilizar avaliações baseadas em critérios de risco, independente se for necessário para o hospital inteiro ou somente para a população da UTI. (LUCET et al., 2003; FURUNO et al., 2006)

Medidas preventivas - Culturas de vigilância: Detectar pacientes colonizados através de culturas de vigilância (active surveillance culture - ASC) para identificar patógenos emergentes em situações específicas. O uso de ASC para detecção de MRSA é controverso. Combinar a realização de culturas de vigilância com outras intervenções uma vez que sua freqüência é variável. Considerar: Treinamento de profissionais para coletar e processar as amostras.Comunicação imediata dos resultados para os cuidadores. Uso adicional de medidas de controle. Assegurar adesão às medidas adicionais (CDC, 2006).

A necessidade de adotar precauções de Contato para Pacientes Infectados e Colonizados advém do fato de que os pacientes podem abrigar MRSA em inúmeros locais do corpo. Apesar de as narinas serem o reservatório mais comum, os pacientes também podem abrigar o microorganismo na pele intacta das axilas (15-25\% pacientes), no períneo (30-40\%) nas mãos e nos braços (40\%). Alguns pacientes colonizados, principalmente aqueles que receberam terapia 
antimicrobiana, desenvolvem intensa colonização do trato gastrointestinal. Ostomias, feridas, úlceras de pressão e escarro são outros locais usuais de colonização. O MRSA presente na pele, trato gastrointestinal ou outros locais, geralmente se espalha pelo ambiente ao redor do paciente, resultando em contaminação de superfícies ou objetos inanimados próximos a ele.

Numerosos estudos demonstraram que as mãos dos profissionais de saúde podem ser contaminadas não apenas por contato direto mas também pelo contato com objetos ao seu redor, sendo a contaminação das mãos através do contato com pacientes infectados ou colonizados a principal via de transmissão a outros pacientes (RODRIGUES et al., 1997)

As precauções de contato têm por finalidade interromper esses importantes mecanismos de transmissão de MRSA. A utilização da paramentação recomendada (luvas, aventais) durante o contato com pacientes infectados ou colonizados, ou com o ambiente a seu redor, pode reduzir as chances de contaminação das mãos dos profissionais de saúde. O quarto privativo pode tornar menos provável que os profissionais de saúde se desloquem de paciente colonizado ou infectado para outro adjacente, não colonizado, sem a devida remoção dos paramentos (BHALLA et al., 2004; BOYCE et al., 1997; JERNIGAN et al., 1996; MCMANUS et al., 1994).

Medidas preventivas - Precauções de contato: Indicar para pacientes infectados ou colonizados. Indicar a higiene das mãos e o uso de luvas, avental de manga longa e quartos individuais ou coorte.Manter o isolamento por tempo definido pela equipe, por ser ainda uma questão não resolvida: os pacientes podem permanecer colonizados por longos períodos e devemos evitar a disseminação. Um fator limitador é a falha na detecção (CDC, 2006).

Descolonização: Não recomendar esse procedimento de rotina. Ela é mais utilizada em surtos e pode ser em pacientes e profissionais. Identificar candidatos através de culturas de vigilância: utilização limitada. Acompanhar com culturas para assegurar a descolonização que pode induzir à resistência à mupirocina (CDC, 2006).

A adoção dos Bundles de prevenção de infecção da corrente sanguínea associada ao CVC e infecção respiratória associada à ventilação mecânica partem do princípio de que pacientes com dispositivos invasivos, assim como cateter central e ventilação, estão sob grande risco de desenvolverem infecção hospitalar. Esses dispositivos ultrapassam a barreira natural da pele e das vias aéreas; além do 
mais, pacientes cateterizados ou ventilados tendem a ser mais vulneráveis a infecções em virtude de suas patologias de base. Pacientes com dispositivos invasivos que estão colonizados por MRSA apresentam grande risco de evoluírem com infecção em corrente sanguínea por MRSA e pneumonia. O cuidado intenso com esses dispositivos pode em muito reduzir a ocorrência de infecções em pacientes colonizados por MRSA. Muitos hospitais reduziram ou eliminaram as infecções relacionadas a dispositivos, através da implantação de "bundles"- grupos de melhores práticas que isoladamente melhoram a assistência, mas quando aplicadas em conjunto, resultam em melhoria muito mais substancial. Hospitais, que estão trabalhando intensamente para reduzir infecções por MRSA, devem implantar de maneira confiável os Bundles da Ventilação e do Cateter Central

Os quatro processos-chave para a redução de MRSA (higienização das mãos, descontaminação e limpeza, vigilância ativa e precauções de contato) devem ser implantados de maneira confiável, de modo a prevenir a transmissão não apenas de MRSA, mas também de outros microorganismos. Medir a adesão aos processos pode ser útil no monitoramento das melhorias. A implantação dos bundles, especificamente da Ventilação e Cateter Central, é uma quinta área de foco.

A redução da infecção por MRSA, adquirida no hospital, é o objetivo final (FIVE MILLION LIVES CAMPAIGN, 2008). Enfim, esta Campanha delineou um modelo de aplicação das recomendações dos CDC (2006) em sua prática diária. 


\section{OBJETIVOS}

\subsection{Objetivo Geral}

Avaliar a colonização de Staphylococcus aureus na saliva da equipe de enfermagem atuante nas unidades de terapia intensiva, clínica médica, clínica cirúrgica e gineco-obstétrica de uma instituição de saúde de grande porte do interior paulista.

\subsection{Objetivos específicos}

- Isolar e identificar os Staphylococcus aureus na saliva de enfermeiros, técnicos e auxiliares de enfermagem que atuam nas unidades de terapia intensiva, clínica médica, clínica cirúrgica e gineco-obstétrica de um hospital escola de grande porte do interior paulista.

- Determinar o perfil de suscetibilidade dos Staphylococcus aureus.

- Avaliar a resistência à mupirocina de Staphylococcus aureus sensíveis ou resistentes à meticilina

- Determinar a prevalência de profissionais de enfermagem portadores de Staphylococcus aureus resistentes à meticilina e à mupirocina.

- Traçar perfil de colonização desses profissionais, comparando esses perfis e a prevalência dos profissionais lotados nas diferentes unidades investigadas, levando em consideração o tempo de atuação profissional, jornada no hospital e de contato com os pacientes desses hospitais. 


\section{MATERIAIS E MÉTODOS}

\subsection{Local do estudo}

Estudo epidemiológico de corte transversal realizado no período de janeiro a dezembro de 2007, nas unidades de Terapia Intensiva (UTI), clínica médica, clínica cirúrgica e gineco-obstétrica de um hospital universitário de grande porte do interior paulista. Optamos por desenvolver a pesquisa nesses locais por serem as unidades de internação do hospital e por atenderem a clientes graves, com internação prolongada, utilização de procedimentos invasivos e solução de continuidade, entre outros agravos a sua saúde.

\subsection{Aspectos éticos - legais}

O projeto foi encaminhado à Comissão de Ética em Pesquisa do Hospital em estudo e recebeu parecer favorável - Processo n 9918/2005 (Anexo A). Os dados de pesquisa e o material (saliva) foram coletados na instituição pesquisada, somente depois da exposição dos objetivos aos participantes. Após o consentimento, eles assinaram o termo de consentimento livre esclarecido (Apêndice A).

\subsection{População}

Participaram da pesquisa todos os profissionais da equipe de enfermagem atuantes nas unidades de terapia intensiva, clínica médica, clínica cirúrgica e ginecoobstétrica. A coleta ocorreu nos três turnos de trabalho, envolvendo 351(94,1\%) dos 373 profissionais lotados nestas unidades que aquiesceram em participar da pesquisa. Dentre estes $22(5,9 \%)$ se recusaram a participar do estudo. Os 
profissionais participantes do estudo foram: enfermeiro, técnico e auxiliar de enfermagem em exercício profissional ativo, no momento da coleta dos dados, que concordaram em participar do estudo, assinaram o Termo de Consentimento Livre e Esclarecido, e que doaram três amostras de saliva no período.

Esses profissionais foram selecionados por serem considerados os responsáveis diretos pelo cuidado aos clientes dessas unidades, o que os torna potenciais veiculadores de micro-organismos e disseminadores de infecção cruzada, o que justifica a seleção dessas categorias profissionais como sujeitos desta pesquisa.

Para a realização da coleta de dados, os sujeitos participantes da pesquisa foram listados, a partir das informações obtidas junto à instituição hospitalar, e codificados em sequência numérica, subdivididos por setor.

\subsection{Procedimento para coleta das amostras}

Escolhemos a cavidade bucal para proceder à coleta de material, pois ainda que os estudos tenham o vestíbulo nasal como o sítio de escolha para a investigação de portadores de MRSA, existem fortes evidências que a cavidade bucal também seja um reservatório, e se considerarmos a dispersão de gotículas produzidas pela fala, tosse e espirro, a investigação de MRSA na boca é relevante (CRUZ, 2008). O intervalo entre as coletas se fez necessário para a investigação de MRSA em diferentes momentos.

A coleta da saliva foi realizada em três momentos distintos, com intervalos de dois meses entre as coletas. A coleta atingiu a totalidade dos profissionais lotados nas unidades selecionadas e foram coletadas nos momentos: 1 (primeira amostra, mês zero); 2 (segunda amostra, mês dois), e 3 (terceira amostra, mês quatro). Essa etapa foi realizada no período de janeiro a junho de 2007 e um segundo grupo, que se encontrava em férias na primeira coleta, foi coletado o material no período de agosto a dezembro de 2007.

A saliva foi coletada pela pesquisadora, no respectivo turno de trabalho do funcionário, em tubo de ensaio graduado, seco, com tampa, estéril e próprio para transporte. A identificação do profissional e do material foi realizada por meio de 
codificação, mantendo em sigilo a sua identidade. Os sujeitos que não tiveram as três amostras da saliva foram excluídos.

No laboratório, o procedimento realizado com a saliva consistiu em sua homogeneização por um minuto, diluição decimal, seriada em solução salina $(0,8 \%)$ e semeadura, de acordo com Westergren; Krasse (1978), em placas de Petri contendo meio de cultura seletivo, ágar manitol salgado. As colônias típicas de Staphylococcus aureus foram submetidas a testes de fenotipagem: coloração de Gram, coagulase, catalase, fermentação do manitol, DNase e lecitinase para a diferenciação e identificação de gênero e espécie. Os testes de suscetibilidade aos antimicrobianos foram, realizados pelo método de difusão em disco e obedeceram às recomendações do CLSI (2005).

\subsection{Dados sócio-demográficos}

Os dados sócio-demográficos foram obtidos de uma lista cadastral dos trabalhadores desta pesquisa. A lista foi fornecida pelo setor de Recursos Humanos da instituição e também um cadastro foi elaborado pelo pesquisador no momento do aceite para a participação da pesquisa.

\subsection{Análise dos dados}

Os dados foram analisados por meio de estatística descritiva e foram processados no Programa EPI-Info versão 3.5.1. Inicialmente realizou-se a categorização dos profissionais e prosseguimos considerando a análise da prevalência da colonização. Nesta classificação consideramos o estado de carreador. 


\section{RESULTADOS}

\subsection{Caracterização demográfica e profissional dos sujeitos da pesquisa}

Participaram da pesquisa 351 profissionais de saúde, que atenderam os critérios de inclusão. As suas características demográficas e profissionais estão dispostas na Tabela 1. Destes profissionais, constatamos que a grande maioria $305(86,9 \%)$ era do gênero feminino, como frequentemente se apresenta os quadros desta categoria profissional em serviços de saúde. A idade variou entre 21 e 64 anos, com moda de 42 e mediana de 40,5. A maioria se concentrou no intervalo entre 30 e 49 anos (65,3\%). Observamos uma baixa prevalência de profissionais com idade inferior a 30 anos (14,8\%). A categoria profissional predominante foi de auxiliares de enfermagem 233(66,4\%), seguidos pelo enfermeiro e técnico de enfermagem. Quanto ao turno de trabalho, prevaleceram os profissionais que fazem rodízio de horário $(37,3 \%)$, denotando a tendência atual da instituição, conforme relatos da equipe. Os demais $62,7 \%$ se dividiram entre os turnos da manhã, tarde e noite. A jornada semanal variou entre 30 e 60 horas, com média de 31,4 (desvio padrão 3,8 ) horas. A jornada de trabalho semanal cumprida pela maioria destes profissionais $287(81,8 \%)$, foi 30 horas, sendo a carga horária diária de seis horas nos turnos manhã e tarde e de 12 horas no turno noturno.

Quanto ao tempo de trabalho na instituição, esse variou de três a 397 meses, com média de 135 meses, sendo que a moda foi de 131 e a mediana de 119 meses. Apenas $114(32,5 \%)$ trabalhavam na instituição há menos de cinco anos; os demais atuavam por mais de seis anos, sendo que a maior proporção encontra-se no período entre 6 e 10 anos. Quanto à referência a um segundo emprego, somente $5,7 \%$ deles relataram possuí-lo, contudo 16,2\% não informaram essa condição. 
Tabela 1 - Caracterização demográfica e profissional dos trabalhadores de um hospital público estadual ( $n=351)$, Ribeirão Preto, 2008

\begin{tabular}{|c|c|c|}
\hline Variáveis & $f$ & $\%$ \\
\hline \multicolumn{3}{|l|}{ Sexo } \\
\hline Feminino & 305 & 86,9 \\
\hline Masculino & 46 & 13,1 \\
\hline \multicolumn{3}{|l|}{ Idade (anos) } \\
\hline 21 a 29 & 52 & 14,8 \\
\hline 30 a 39 & 116 & 33,1 \\
\hline 40 a 49 & 113 & 32,2 \\
\hline$\geq 50$ & 70 & 19,9 \\
\hline \multicolumn{3}{|l|}{ Categoria profissional } \\
\hline Auxiliar de enfermagem & 233 & 66,4 \\
\hline Técnico de enfermagem & 38 & 10,8 \\
\hline Enfermeiro & 80 & 22,8 \\
\hline \multicolumn{3}{|l|}{ Turno de trabalho } \\
\hline Rodízio & 131 & 37,3 \\
\hline Manhã & 73 & 20,8 \\
\hline Tarde & 60 & 17,1 \\
\hline Noturno & 87 & 24,8 \\
\hline \multicolumn{3}{|l|}{ Jornada de trabalho (horas) } \\
\hline 30 & 292 & 83,2 \\
\hline$>30$ & 59 & 16,8 \\
\hline \multicolumn{3}{|l|}{ Tempo na instituição (anos) } \\
\hline$\leq 5$ & 114 & 32,5 \\
\hline 6 a 10 & 105 & 29,9 \\
\hline 11 a 15 & 66 & 18,8 \\
\hline$\geq 16$ & 65 & 18,5 \\
\hline Não informou & 01 & 0,3 \\
\hline \multicolumn{3}{|l|}{ Trabalha em outra instituição } \\
\hline Sim & 20 & 5,7 \\
\hline Não & 274 & 78,1 \\
\hline Não informou & 57 & 16,2 \\
\hline \multicolumn{3}{|l|}{ Setor de trabalho } \\
\hline Clínicas Médicas & 131 & 37,3 \\
\hline Clínicas Cirúrgicas & 106 & 30,2 \\
\hline Unidades de Terapia Intensiva & 56 & 16,0 \\
\hline Clínicas de Ginecologia e Obstetrícia & 39 & 11,1 \\
\hline Centro Obstétrico & 19 & 5,4 \\
\hline
\end{tabular}

Sobre o setor de trabalho, constatamos que a maioria se concentrou nas clínicas médica $(37,3 \%)$ e cirúrgica $(30,2 \%)$; os demais se distribuíram nas UTI, clínica ginecológica e obstétrica e centro obstétrico. Cabe ressaltar que estas clínicas são subdivididas em setores específicos que merecem avaliação 
individualizada. Dos setores dispostos na Tabela 2, identificamos a clínica cirúrgica, médica e UTI com o maior percentual de profissionais participantes da pesquisa, e também o maior número de profissionais lotados nestes locais.

Tabela 2 - Caracterização da área e unidade de atuação dos trabalhadores de um hospital público estadual ( $n=351)$, Ribeirão Preto, 2008

\begin{tabular}{|c|c|c|}
\hline Clínicas/Especialidades & $f$ & $\%$ \\
\hline$\overline{U T I}$ & 56 & 16,0 \\
\hline UTI Unidade de Terapia Intensiva & 42 & 12,0 \\
\hline UTI Unidade de Terapia Intensiva Neurológica & 14 & 4,0 \\
\hline Clínica Obstétrica (CO) & 19 & 5,4 \\
\hline Clínica Obstétrica & 19 & 5,4 \\
\hline Clínica Médica (CM) & 131 & 37,3 \\
\hline Clínica Médica ( $\mathrm{CM}-5^{\circ}$ andar) & 40 & 11,4 \\
\hline Unidade Metabólica & 8 & 2,3 \\
\hline Transplante de Medula Óssea & 18 & 5,1 \\
\hline Clínica Médica (CM - $6^{\circ}$ andar) & 21 & 6,0 \\
\hline Moléstias Infecto-contagiosas & 24 & 6,8 \\
\hline Hematologia & 20 & 5,7 \\
\hline Clínica Cirúrgica & 106 & 30,2 \\
\hline Clínica Cirúrgica (CC $9^{\circ}$ andar) & 47 & 13,4 \\
\hline Clínica Cirúrgica (CC $10^{\circ}$ andar) & 43 & 12,2 \\
\hline Transplante de Fígado & 16 & 4,6 \\
\hline Clínica Obstétrica (GO) & 39 & 11,1 \\
\hline Clínica Obstétrica & 39 & 11,1 \\
\hline Total & 351 & 100,0 \\
\hline
\end{tabular}

\subsection{Prevalência e classificação da colonização}

Dos 351 participantes da pesquisa, coletou-se três amostras de saliva, totalizando 1053 culturas. Um total de 207 (59\%) indivíduos mostraram-se não colonizados por Staphylococcus aureus, os demais sujeitos tiveram pelo menos uma cultura positiva e foram considerados colonizados $41 \%$ por Staphylococcus aureus na saliva (Tabela 3). Destes indivíduos, 104 (29,6\%) estavam colonizados por Staphylococcus aureus 
sensíveis (MSSA) e $25(7,1 \%)$ por Staphylococcus aureus resistentes à meticilina (MRSA); 15 (4,3\%) não puderam ser recuperados para a realização do antibiograma, portanto, indefinidos quanto à sensibilidade aos antimicrobianos.

Tabela 3 - Distribuição dos trabalhadores de um hospital público estadual, segundo a colonização por Staphylococcus aureus, Ribeirão Preto, 2007

\begin{tabular}{lcc}
\hline Classificação & f & \% \\
\hline Não colonizado & $\mathbf{2 0 7}$ & $\mathbf{5 9 , 0}$ \\
Colonizado por Staphylococcus aureus & & \\
$\quad$ Sensível & 104 & 29,6 \\
$\quad$ Resistente & 25 & 7,1 \\
$\quad$ Ignorado (Não recuperado) & 15 & 4,3 \\
Subtotal & $\mathbf{1 4 4}$ & $\mathbf{4 1 , 0}$ \\
\hline Total & $\mathbf{3 5 1}$ & $\mathbf{1 0 0 , 0}$ \\
\hline
\end{tabular}

Partindo do princípio de que o carreador ocasional ou transitório tem um índice de freqüência menor ou igual a 0,5 e de que o carreador persistente maior que 0,5 ; o resultado da divisão do número de swabs coletados de cada indivíduo, proposto por Nilsson e Ripa (2006), pode-se considerar que apenas 18,8\% mostraram-se carreadores persistentes e $81,2 \%$ transitórios.

Entre os colonizados por MSSA, 26 (25,0\%) mostraram-se carreadores persistentes e $78(75,0 \%)$ mostraram-se carreadores transitórios ou ocasionais. Entre os colonizados por MRSA, encontramos 39 (97,5\%) que foram classificados como portador transitório e apenas $1(2,5 \%)$ como portador persistente.

\subsection{Caracterização demográfica e profissional dos participantes segundo a colonização por Staphylococcus aureus sensíveis (MSSA) e resistentes (MRSA) à meticilina}

A colonização, segundo as características demográficas apresentadas na Tabela 4, demonstra que prevaleceu o sexo feminino entre os sujeitos não colonizados, os portadores de MRSA e ignorados, mas foi maior para o sexo masculino entre os portadores de MSSA. 
Tabela 4 - Caracterização demográfica, turno e jornada de trabalho dos trabalhadores de um hospital público estadual, segundo a colonização por Staphylococcus aureus, Ribeirão Preto, 2007

\begin{tabular}{|c|c|c|c|c|c|c|c|c|c|c|}
\hline \multirow{3}{*}{ Variáveis } & \multirow{2}{*}{\multicolumn{2}{|c|}{$\begin{array}{c}\text { Não Colonizado } \\
(\mathrm{n}=207)\end{array}$}} & \multicolumn{6}{|c|}{ Colonizado $(n=144)$} & \multirow{2}{*}{\multicolumn{2}{|c|}{$\begin{array}{c}\text { Total } \\
(n=351)\end{array}$}} \\
\hline & & & \multicolumn{2}{|c|}{$\begin{array}{l}\text { MSSA } \\
(n=104)\end{array}$} & \multicolumn{2}{|c|}{$\begin{array}{l}\text { MRSA } \\
(n=25)\end{array}$} & \multicolumn{2}{|c|}{$\begin{array}{l}\text { Ignorado* } \\
(n=15)\end{array}$} & & \\
\hline & $f$ & $\%$ & f & $\%$ & f & $\%$ & f & $\%$ & $f$ & $\%$ \\
\hline \multicolumn{11}{|l|}{$\overline{\text { Sexo }}$} \\
\hline Feminino & 183 & 60,0 & 85 & 27,9 & 23 & 7,5 & 14 & 4,6 & 305 & 100,0 \\
\hline Masculino & 24 & 52,2 & 19 & 41,3 & 02 & 4,3 & 01 & 2,2 & 46 & 100,0 \\
\hline \multicolumn{11}{|l|}{ Idade (anos) } \\
\hline 21 a 29 & 22 & 42,3 & 25 & 48,1 & 5 & 9,6 & 0 & 0,0 & 52 & 100,0 \\
\hline 30 a 39 & 64 & 55,2 & 30 & 25,8 & 11 & 9,5 & 11 & 9,5 & 116 & 100,0 \\
\hline 40 a 49 & 79 & 69,9 & 30 & 26,5 & 2 & 1,8 & 2 & 1,8 & 113 & 100,0 \\
\hline$\geq 50$ & 42 & 60,0 & 19 & 27,1 & 7 & 10,0 & 2 & 2,9 & 70 & 100,0 \\
\hline \multicolumn{11}{|c|}{ Turno de trabalho } \\
\hline Rodízio & 75 & 57,2 & 38 & 29,0 & 12 & 9,2 & 06 & 4,6 & 131 & 100,0 \\
\hline Manhã & 44 & 60,3 & 25 & 34,3 & 02 & 2,7 & 02 & 2,7 & 73 & 100,0 \\
\hline Tarde & 35 & 58,3 & 19 & 31,7 & 06 & 10,0 & - & - & 60 & 100,0 \\
\hline Noturno & 53 & 60,9 & 22 & 25,3 & 05 & 5,7 & 07 & 8,1 & 87 & 100,0 \\
\hline \multicolumn{11}{|c|}{$\begin{array}{l}\text { Jornada de trabalho } \\
\text { (horas) }\end{array}$} \\
\hline 30 & 173 & 59,3 & 83 & 28,4 & 22 & 7,5 & 14 & 4,8 & 292 & 100,0 \\
\hline$>30$ & 34 & 57,6 & 21 & 35,6 & 03 & 5,1 & 01 & 1,7 & 59 & 100,0 \\
\hline
\end{tabular}

${ }^{\star}$ Não recuperado

Quanto à idade observou-se que entre os não colonizados prevaleceram os trabalhadores que se encontravam na faixa etária de 40 a 49 anos (69,9\%); entre os portadores de MSSA (48,1\%), encontravam-se entre 21 e 29 anos e, entre os portadores de MRSA, equiparam-se as proporções, com exceção da idade entre 40 e 49 anos. Os ignorados concentram-se principalmente na faixa etária entre 30 e 39 anos.

O rodízio mostrou-se o principal turno de trabalho dos profissionais. Entre os não colonizados, o turno mais frequente foi o noturno e entre os profissionais colonizados por MSSA, o turno da manhã e para MRSA foi o período da tarde.

A jornada de trabalho apresentou proporções semelhantes entre os não colonizados, assim como para os colonizados nas duas categorias de horas semanais $(40,7$ e $42,4 \%$ para os de 30 e $>30$, respectivamente). 
Tabela 5 - Caracterização profissional dos trabalhadores de um hospital público estadual, segundo a colonização por Staphylococcus aureus, Ribeirão Preto, 2007

\begin{tabular}{|c|c|c|c|c|c|c|c|c|c|c|}
\hline \multirow{3}{*}{ Variáveis } & \multirow{2}{*}{\multicolumn{2}{|c|}{$\begin{array}{c}\text { Não } \\
\text { Colonizado } \\
(n=207)\end{array}$}} & \multicolumn{6}{|c|}{ Colonizado $(n=144)$} & \multirow{2}{*}{\multicolumn{2}{|c|}{$\begin{array}{c}\text { Total } \\
(\mathrm{n}=351)\end{array}$}} \\
\hline & & & \multicolumn{2}{|c|}{$\begin{array}{c}\text { MSSA } \\
(n=104)\end{array}$} & \multicolumn{2}{|c|}{$\begin{array}{l}\text { MRSA } \\
(n=25)\end{array}$} & \multicolumn{2}{|c|}{$\begin{array}{c}\text { Ignorado* } \\
(n=15)\end{array}$} & & \\
\hline & $\mathrm{f}$ & $\%$ & f & $\%$ & f & $\%$ & $f$ & $\%$ & $f$ & $\%$ \\
\hline \multicolumn{11}{|l|}{ Categoria profissional } \\
\hline Auxiliar de enfermagem & 140 & 60,1 & 71 & 30,5 & 12 & 5,1 & 10 & 4,3 & 233 & 100,0 \\
\hline Técnico de enfermagem & 20 & 52,6 & 12 & 31,6 & 04 & 10,5 & 02 & 5,3 & 38 & 100,0 \\
\hline Enfermeiro & 47 & 58,8 & 21 & 26,2 & 09 & 11,3 & 03 & 3,7 & 80 & 100,0 \\
\hline \multicolumn{11}{|l|}{ Setor de trabalho } \\
\hline Clínicas Médicas & 71 & 54,2 & 50 & 38,2 & 09 & 6,9 & 01 & 0,7 & 131 & 100,0 \\
\hline Clínicas Cirúrgicas & 57 & 53,8 & 32 & 30,2 & 09 & 8,5 & 08 & 7,5 & 106 & 100,0 \\
\hline Unidades de Terapia & 37 & 66,1 & 13 & 23,2 & 04 & 7,1 & 02 & 3,6 & 56 & 100,0 \\
\hline \multicolumn{11}{|l|}{ Intensiva } \\
\hline $\begin{array}{l}\text { Clínicas de Ginecologia e } \\
\text { Obstetrícia }\end{array}$ & 28 & 71,8 & 07 & 17,9 & 03 & 7,7 & 01 & 2,6 & 39 & 100,0 \\
\hline Centro Obstétrico & 14 & 73,7 & 02 & 10,5 & - & - & 03 & 15,8 & 19 & 100,0 \\
\hline \multicolumn{11}{|l|}{ Tempo na instituição (anos) } \\
\hline$\leq 5$ & 64 & 56,1 & 37 & 32,5 & 08 & 7,0 & 05 & 4,4 & 114 & 100,0 \\
\hline 6 a 10 & 65 & 61,9 & 25 & 23,8 & 10 & 9,5 & 05 & 4,8 & 105 & 100,0 \\
\hline 11 a 15 & 40 & 60,6 & 21 & 31,8 & 03 & 4,6 & 02 & 3,0 & 66 & 100,0 \\
\hline$\geq 16$ & 37 & 56,9 & 21 & 32,3 & 04 & 6,2 & 03 & 4,6 & 65 & 100,0 \\
\hline Não informou & 01 & 100,0 & - & - & - & - & - & - & 01 & 100,0 \\
\hline \multicolumn{11}{|l|}{$\begin{array}{l}\text { Trabalha em outra } \\
\text { instituição }\end{array}$} \\
\hline Sim & 12 & 60,0 & 05 & 25,0 & 01 & 5,0 & 02 & 10,0 & 20 & 100,0 \\
\hline Não & 162 & 59,1 & 83 & 30,3 & 18 & 6,6 & 11 & 4,0 & 274 & 100,0 \\
\hline Não informou & 33 & 57,9 & 16 & 28,1 & 06 & 10,5 & 02 & 3,5 & 57 & 100,0 \\
\hline
\end{tabular}

Considerando a Tabela 5, o auxiliar de enfermagem e o enfermeiro foram encontrados com maior freqüência entre os não colonizados; o auxiliar e o técnico entre os colonizados por MSSA e o enfermeiro e o técnico de enfermagem em maior percentual, no grupo dos portadores de MRSA.

Os locais de trabalho onde se identificou o maior número de profissionais foram nas clínicas médica e cirúrgica, contudo o maior percentual de profissionais não colonizados foi no centro obstétrico e clínica ginecológica e obstétrica, sendo também do centro obstétrico o menor percentual de MRSA, ou seja, nenhum caso identificado(Tabela 6). Entre os portadores de MSSA, os locais de maior incidência de trabalhadores foram a clínica médica e clínica cirúrgica. Os locais de maior prevalência de portadores de MRSA foram a clínica cirúrgica, clínica de ginecologia e obstetrícia, UTI e clínica médica, respectivamente. Quando se avaliou a unidade de lotação do profissional de forma estratificada, por unidade de trabalho, com a condição de colonização apresentada, foi possível fazer algumas considerações muito especiais. 
Tabela 6 - Unidade de lotação dos trabalhadores de um hospital público estadual, segundo a colonização por Staphylococcus aureus, Ribeirão Preto, 2007

\begin{tabular}{|c|c|c|c|c|c|c|c|c|c|c|}
\hline \multirow{3}{*}{ Unidade de lotação } & \multirow{2}{*}{\multicolumn{2}{|c|}{$\begin{array}{c}\text { Não } \\
\text { Colonizado } \\
(\mathrm{n}=207)\end{array}$}} & \multicolumn{6}{|c|}{ Colonizado $(n=144)$} & \multirow{2}{*}{\multicolumn{2}{|c|}{$\begin{array}{c}\text { Total } \\
(n=351)\end{array}$}} \\
\hline & & & \multicolumn{2}{|c|}{$\begin{array}{c}\text { MSSA } \\
(n=104)\end{array}$} & \multicolumn{2}{|c|}{$\begin{array}{l}\text { MRSA } \\
(n=25)\end{array}$} & \multicolumn{2}{|c|}{$\begin{array}{c}\text { Ignorado* } \\
(n=15)\end{array}$} & & \\
\hline & f & $\%$ & $\mathrm{~F}$ & $\%$ & f & $\%$ & f & $\%$ & $f$ & $\%$ \\
\hline Clínica Cirúrgica - 9º & 24 & 51,1 & 16 & 34,0 & 02 & 4,3 & 05 & 10,6 & 47 & 100,0 \\
\hline Clínica Médica - $5^{\circ}$ & 21 & 52,5 & 17 & 42,5 & 02 & 5,0 & - & - & 40 & 100,0 \\
\hline Clínica Cirúrgica $-10^{\circ}$ & 22 & 51,2 & 13 & 30,2 & 06 & 14,0 & 02 & 4,6 & 43 & 100,0 \\
\hline Unidade Terapia Intensiva & 27 & 64,2 & 11 & 26,2 & 02 & 4,8 & 02 & 4,8 & 42 & 100,0 \\
\hline $\begin{array}{l}\text { Clínica Ginecologia } \\
\text { Obstetrícia }\end{array}$ & 28 & 71,8 & 07 & 17,9 & 03 & 7,7 & 01 & 2,6 & 39 & 100,0 \\
\hline Clínica Moléstias Infecciosas & 16 & 66,7 & 07 & 29,2 & 01 & 4,1 & ـ & - & 24 & 100,0 \\
\hline Clínica Médica - $6^{\circ}$ & 09 & 42,9 & 09 & 42,9 & 03 & 14,2 & - & 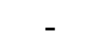 & 21 & 100,0 \\
\hline Hematologia & 12 & 60,0 & 05 & 25,0 & 02 & 10,0 & 01 & 5,0 & 20 & 100,0 \\
\hline Transplante Medula Óss & 10 & 55,6 & 08 & 44,4 & - & - & - & - & 18 & 100,0 \\
\hline Transplante Fígado & 11 & 68,7 & 03 & 18,7 & 01 & 6,3 & 01 & 6,3 & 16 & 100,0 \\
\hline UTI Neurocirurgia & 10 & 71,4 & 02 & 14,3 & 02 & 14,3 & 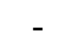 & - & 14 & 100,0 \\
\hline Centro Obstétrico & 14 & 73,7 & 02 & 10,5 & - & - & 03 & 15,8 & 19 & 100,0 \\
\hline Unidade Metabólica & 03 & 37,5 & 04 & 50,0 & 01 & 12,5 & - & - & 08 & 100,0 \\
\hline
\end{tabular}

Observa-se na Tabela 6 que os setores com maior percentual de trabalhadores não colonizados foram o centro obstétrico $14(73,7 \%)$, a clínica de ginecologia e obstetrícia 28 (71,8\%).

Os setores com maior índice de colonização por MSSA foram a unidade metabólica 04 (50\%), centro de transplante de medula óssea $08(44,4 \%)$, e clínicas médicas 09 (42,9\%), 17 (42,5\%) do quinto e sexto andares.

Entretanto, os setores onde houve a maior prevalência do portador de MRSA foram a unidade de tratamento intensivo neurológica $(14,3 \%)$, clínica médica do sexto andar (14,2\%) e clínica cirúrgica (14,0\%), sendo este o mesmo andar onde se encontra a UTI neurológica. Destaca-se também a existência de portador de MRSA na unidade metabólica $(12,5 \%)$ e na hematologia (10\%). Em menor proporção, identificou-se portadores na clínica de ginecologia e obstetrícia, clínica cirúrgica, unidade de transplante de fígado, clínica médica do quinto andar, UTI e clínica cirúrgica e unidade de moléstias infecto-contagiosas. Não foram identificados portadores de MRSA no centro obstétrico e na unidade de transplante de medula óssea. 


\subsection{Caracterização fenotípica do Staphylococcus aureus}

Após a identificação do Staphylococcus aureus em 17,7\% (186/1053) das culturas foi realizado o antibiograma para identificar a sensibilidade aos antimicrobianos. Foi identificada resistência à oxacilina em 26 culturas caracterizadas como MRSA; os demais foram classificados como MSSA por apresentarem sensibilidade à oxacilina (Tabela 7). Quinze culturas foram identificadas fenotipicamente como Staphylococcus aureus, mas como não foi possível a realização do antibiograma foram consideradas como não recuperadas (NR).

Tabela 7 - Perfil de sensibilidade aos antimicrobianos de isolados da saliva classificadas como MRSA, de trabalhadores da saúde um hospital público estadual, Ribeirão Preto, 2007 ( $n=26)$

\begin{tabular}{|c|c|c|c|c|c|c|c|c|c|c|c|c|c|}
\hline $\mathrm{n}^{0}$ suj & Oxa & Peni & Cefo & Erit & Clin & Tetra & Rifa & Cipr & Gent & Sulf & Vanc & Line & Mup \\
\hline $001 \mathrm{~b}$ & $\mathrm{R}$ & $S$ & $\mathrm{R}$ & $S$ & $S$ & $S$ & $\mathrm{R}$ & $S$ & $S$ & $S$ & $S$ & $S$ & $\mathrm{R}$ \\
\hline $009 b$ & $\mathrm{R}$ & $\mathrm{R}$ & $S$ & $S$ & $S$ & $S$ & $S$ & $S$ & $S$ & $S$ & $S$ & $S$ & $S$ \\
\hline 014a & $\mathrm{R}$ & $\mathrm{R}$ & $R$ & $S$ & $R$ & $\mathrm{R}$ & $R$ & $S$ & $R$ & $S$ & $S$ & $S$ & $R$ \\
\hline $015 a$ & $\mathrm{R}$ & $\mathrm{R}$ & $\mathrm{R}$ & $S$ & $\mathrm{R}$ & $S$ & $\mathrm{R}$ & $S$ & $\mathrm{R}$ & $S$ & $S$ & $S$ & $\mathrm{R}$ \\
\hline $025 a$ & $\mathrm{R}$ & $\mathrm{R}$ & $\mathrm{R}$ & $S$ & $\mathrm{R}$ & $\mathrm{R}$ & $\mathrm{R}$ & $S$ & $\mathrm{R}$ & $S$ & $S$ & $S$ & $\mathrm{R}$ \\
\hline $034 a$ & $\mathrm{R}$ & $\mathrm{R}$ & $S$ & $S$ & $S$ & $S$ & $S$ & $S$ & $S$ & $S$ & $S$ & $S$ & $S$ \\
\hline 039a & $\mathrm{R}$ & $\mathrm{R}$ & $\mathrm{R}$ & $\mathrm{R}$ & $\mathrm{R}$ & $S$ & $S$ & $S$ & $\mathrm{R}$ & $S$ & $S$ & $S$ & $\mathrm{R}$ \\
\hline $051 \mathrm{~b}$ & $R$ & $\mathrm{R}$ & $\mathrm{R}$ & $\mathrm{R}$ & $S$ & $S$ & $S$ & $S$ & $\mathrm{R}$ & $S$ & $S$ & $S$ & $\mathrm{R}$ \\
\hline $062 a$ & $\mathrm{R}$ & $\mathrm{R}$ & $S$ & $\mathrm{R}$ & $\mathrm{R}$ & $S$ & $S$ & $S$ & $\mathrm{R}$ & $S$ & $S$ & $S$ & $S$ \\
\hline 076c & $\mathrm{R}$ & $\mathrm{R}$ & $\mathrm{R}$ & $S$ & $\mathrm{R}$ & $\mathrm{R}$ & S & $S$ & $\mathrm{R}$ & $S$ & $S$ & $S$ & $\mathrm{R}$ \\
\hline 079a & $\mathrm{R}$ & $\mathrm{R}$ & $S$ & $\mathrm{R}$ & $\mathrm{R}$ & $\mathrm{R}$ & $\mathrm{R}$ & $\mathrm{R}$ & $R$ & $\mathrm{R}$ & $S$ & $S$ & $\mathrm{R}$ \\
\hline $082 b$ & $\mathrm{R}$ & $\mathrm{R}$ & $\mathrm{R}$ & $\mathrm{R}$ & $\mathrm{R}$ & $\mathrm{R}$ & $S$ & $S$ & $\mathrm{R}$ & $S$ & $S$ & $S$ & $\mathrm{R}$ \\
\hline $101 a$ & $\mathrm{R}$ & $\mathrm{R}$ & $\mathrm{R}$ & $S$ & $\mathrm{R}$ & $\mathrm{R}$ & $\mathrm{R}$ & $S$ & $\mathrm{R}$ & $S$ & $S$ & $S$ & $\mathrm{R}$ \\
\hline $120 a$ & $\mathrm{R}$ & $\mathrm{R}$ & $\mathrm{R}$ & $S$ & $S$ & $S$ & $\mathrm{R}$ & $S$ & $S$ & $\mathrm{R}$ & $S$ & $S$ & $S$ \\
\hline $140 a$ & $\mathrm{R}$ & $\mathrm{R}$ & $\mathrm{R}$ & $S$ & $S$ & $S$ & $S$ & $S$ & $S$ & $S$ & $S$ & $S$ & $S$ \\
\hline $140 c$ & $\mathrm{R}$ & $\mathrm{R}$ & $\mathrm{R}$ & $S$ & $\mathrm{R}$ & $\mathrm{R}$ & $\mathrm{R}$ & $S$ & $\mathrm{R}$ & $\mathrm{R}$ & $S$ & $S$ & $\mathrm{R}$ \\
\hline $154 c$ & $\mathrm{R}$ & $\mathrm{R}$ & $\mathrm{R}$ & $S$ & $S$ & $S$ & $S$ & $S$ & $S$ & $S$ & $S$ & $S$ & $S$ \\
\hline $185 a$ & $\mathrm{R}$ & $\mathrm{R}$ & $\mathrm{R}$ & $\mathrm{R}$ & $\mathrm{R}$ & $\mathrm{R}$ & $S$ & $S$ & $\mathrm{R}$ & $S$ & $S$ & $S$ & $\mathrm{R}$ \\
\hline $192 a$ & $\mathrm{R}$ & $\mathrm{R}$ & $\mathrm{R}$ & $\mathrm{R}$ & $\mathrm{R}$ & $\mathrm{R}$ & $\mathrm{R}$ & $S$ & $\mathrm{R}$ & $S$ & $S$ & $S$ & $\mathrm{R}$ \\
\hline $195 a$ & $\mathrm{R}$ & $\mathrm{R}$ & $\mathrm{R}$ & $\mathrm{R}$ & $\mathrm{R}$ & $S$ & $\mathrm{R}$ & $S$ & $\mathrm{R}$ & $S$ & $S$ & $S$ & $\mathrm{R}$ \\
\hline $198 a$ & $\mathrm{R}$ & $\mathrm{R}$ & $\mathrm{R}$ & $\mathrm{R}$ & $\mathrm{R}$ & $S$ & $\mathrm{R}$ & $S$ & $\mathrm{R}$ & $S$ & $S$ & $S$ & $\mathrm{R}$ \\
\hline $238 a$ & $\mathrm{R}$ & $\mathrm{R}$ & $\mathrm{R}$ & $\mathrm{R}$ & $R$ & $S$ & $S$ & $S$ & $\mathrm{R}$ & $S$ & $S$ & $S$ & $\mathrm{R}$ \\
\hline $254 a$ & $\mathrm{R}$ & $\mathrm{R}$ & $\mathrm{R}$ & $\mathrm{R}$ & $R$ & $\mathrm{R}$ & $\mathrm{R}$ & $S$ & $S$ & $\mathrm{R}$ & $S$ & $S$ & $\mathrm{R}$ \\
\hline $258 a$ & $\mathrm{R}$ & $\mathrm{R}$ & $S$ & $\mathrm{R}$ & $\mathrm{R}$ & $S$ & $S$ & $S$ & $\mathrm{R}$ & $S$ & $S$ & $S$ & $\mathrm{R}$ \\
\hline $268 a$ & $\mathrm{R}$ & $\mathrm{R}$ & $\mathrm{R}$ & $S$ & $\mathrm{R}$ & $\mathrm{R}$ & $S$ & $S$ & $S$ & $S$ & $S$ & $S$ & $S$ \\
\hline $287 a$ & $\mathrm{R}$ & $\mathrm{R}$ & $S$ & $S$ & $\mathrm{R}$ & $S$ & $\mathrm{R}$ & $S$ & $S$ & $S$ & $S$ & $\mathrm{R}$ & $\mathrm{R}$ \\
\hline $\mathrm{n} / \mathrm{R}$ & $26 / 26$ & $25 / 26$ & $20 / 26$ & $12 / 26$ & $19 / 26$ & $11 / 26$ & $13 / 26$ & $01 / 26$ & $17 / 26$ & $04 / 26$ & $00 / 26$ & $01 / 26$ & $19 / 26$ \\
\hline$\% \mathrm{R}$ & 100,0 & 96,1 & 76,9 & 46,1 & 73,1 & 42,3 & 50,0 & 3,8 & 65,4 & 15,4 & 0,0 & 3,8 & $\begin{array}{r}73,1 \\
\end{array}$ \\
\hline
\end{tabular}


Quanto ao perfil de sensibilidade aos antimicrobianos, os MRSA apresentaram houve resistência à penicilina $(96,1 \%)$, à cefotaxima $(76,9 \%)$ e clindamicina e mupirocina $(73,1 \%$ ) (Tabela 8$)$. Houve resistência menos expressiva à gentamicina, rifampicina, eritromicina, tetraciclina, sulfametoxazol-trimetoprima respectivamente, e resistência pouco significativa à ciprofloxacina e linezolida. Portanto, além da resistência às penicilinas e cefalosporinas, os resultados ainda demonstraram resistência a outros grupos, sendo eles a lincosamina (clindamicina) e à mupirocina.

Tabela 8 - Percentual de resistência aos antimicrobianos dos Staphylococcus aureus, classificados como MRSA e MSSA, isolados de amostras de saliva dos trabalhadores da saúde de um hospital público estadual, Ribeirão Preto, 2007

\begin{tabular}{lllllllllllll}
\hline S.aureus Oxa Peni Cefo Erit Clin Tetra Rifa Cipr Gent Sulf Vanc Line Mup \\
\hline
\end{tabular}

MRSA

$\begin{array}{llllllllllllll}(\mathbf{n}=26) & 100,0 & 96,1 & 76,9 & 46,1 & 73,1 & 42,3 & 50,0 & 3,8 & 65,4 & 15,4 & 0,0 & 3,8 & 73,1\end{array}$

MSSA

\begin{tabular}{llllllllllllll}
$\mathbf{( n = 1 4 0 )}$ & 0,0 & 72,1 & 9,3 & 25,7 & 12,1 & 7,1 & 10,0 & 2,1 & 7,1 & 2,8 & 0,0 & 7,9 & 9,3 \\
\hline
\end{tabular} Legenda: Oxa - oxacilina, Peni - penicilina, Cefo - cefotaxima, Erit - eritromicina, Clin - clindamicina, Tetra - tetraciclina, Rifa - rifampicina, Cipr - ciprofloxacina, Gent gentamicina, Sulf - sulfametozazol + trimetoprima, vanc - vancomicina, Line - linezolida, mup - mupirocina.

Uma atual revisão sistemática envolvendo 3.396 participantes com algum tipo de infecção hospitalar causada por Staphylococcus aureus, demonstrou uma redução significativa na taxa de infecção do grupo que utilizava mupirocina para descolonização do portador quando comparado ao grupo que utilizava outro produto, placebo ou sem tratamento (RR 0.55, 95\% CI 0.43 a 0.70) (VAN RIJEN, 2009).

O perfil de sensibilidade aos antimicrobianos, relativo ao MSSA, mostrou-se completamente diferente do MRSA: elevada resistência à penicilina $(72,1 \%)$ e baixa resistência aos demais antimicrobianos testados. 


\section{DISCUSSÃO DOS RESULTADOS}

Discutiremos primeiramente a caracterização demográfica e profissional dos trabalhadores, segundo a colonização por Staphylococcus aureus; caracterização fenotípica dos Staphylococcus aureus e posteriormente a resistência à mupirocina.

\subsection{Caracterização demográfica e profissional dos trabalhadores, segundo a colonização por Staphylococcus aureus}

\subsubsection{Prevalência do Staphylococcus aureus em trabalhadores da área de saúde}

Um dos objetivos do estudo foi identificar a prevalência de Staphylococcus aureus na saliva dos trabalhadores de saúde de um hospital público estadual. Coletamos três amostras de cada sujeito, somando 1053 amostras com uma positividade de $17,7 \%$ (186/1053) para o Staphylococcus aureus e de 2,5\% (26/1053) para MRSA. Entretanto, ao seanalisar estes dados considerando a prevalência por sujeito constatou-se uma prevalência de 59\% (207/351) de sujeitos não colonizados, de 41,0\% (144/351) de colonizados; sendo que destes $7,1 \%$ (25/351) de MRSA, 29,6\% (104/351) de MSSA e, 4,3\% (15/351) dos quais não foi possível a realização do antibiograma. Resultados, encontrados por Smith et at. (2003), mostraram uma positividade de 20,3\% das amostras (1017/5005) para Staphylococcus aureus, e 4,9\%(50/1017) para MARSA.

No hospital universitário da cidade de Goiânia, dentre os 268 profissionais avaliados, $227(84,7 \%)$ foram considerados colonizados por Staphylococcus aureus, enquanto que 41 (15,3\%) foram classificados como não carreadores desta bactéria. A colonização por MRSA foi de 9,7\% dos profissionais de saúde (PALOS,2007). Já no hospital de Curitiba, a taxa de colonização foi menor quando comparada a de Goiânia. Dentre os 486 profissionais investigados, 296 (60,9\%) foram considerados 
colonizados e 190 (39,1\%) foram classificados como não carreadores de Staphylococcus aureus. A prevalência de MRSA foi alta, de 12,7\%. (CRUZ, 2008). Carvalho et al. (2009) obtiveram uma prevalência de $47,6 \%$ de colonizados por Staphylococcus aureus e a prevalência de MRSA foi $4,1 \%$, em um hospital escola público de Santo André (CARVALHO et al., 2009). Portanto, entre estes quatro importantes hospitais públicos brasileiros analisamos uma maior prevalência de portadores de Staphylococcus aureus no hospital de Goiânia (84,7\%) e a maior prevalência por MRSA no hospital de Curitiba (12,7\%), sendo que do hospital em estudo, quando comparada às demais, mostrou-se intermediária.

Encontrou-se uma diversidade de resultados publicados, contudo uma revisão sistemática (ALBRICH; HARBARTH, 2008) mostrou uma média de $4,6 \%$ de colonização por MRSA nos trabalhadores da saúde. Portanto, considerou-se elevado o índice obtido em nosso estudo (7,1\%); ainda que possa nos parecer baixo se comparado a outros estudos semelhantes (12,7\%) (CRUZ, 2008) e 12\% (IBARRA et al., 2008).

Se forem considerados somente os artigos publicados nos últimos cinco anos, além dos anteriormente mencionados, (MATHANRAJ et al., 2009) na Índia identificaram 1,8\% de MRSA entre 200 de seus trabalhadores da saúde. Também ocorreu uma baixa colonização com MRSA entre os trabalhadores de saúde de um grande hospital de Roma, sendo que dos 200 trabalhadores investigados, 78 médicos e 122 enfermeiros, houve uma prevalência de 38(19\%) portadores de Staphylococcus aureus, e entre estes 3(1,5\%) portadores de MRSA.

A prevalência estimada de colonização nasal de Staphylococcus aureus na população dos Estados Unidos, 2001-2002 foi obtida através de cultura de 9.622 participantes. Os resultados obtidos foram os seguintes: a estimativa de prevalência de colonização por Staphylococcus aureus e de MRSA eram 32,4\% (IC 95\%, $30,7 \%-34,1 \%$ ) e $0,8 \%$ (IC 95\%, 0,4\%-1,4\%), respectivamente, e estimativas de Staphylococcus aureus na população eram 89,4 milhões de pessoas (IC 95\%, 84,894,1 milhões de pessoas) e MRSA de 2,3 milhões de pessoas (95\% $\mathrm{Cl}, 1,2-3,8$ milhões de pessoas), respectivamente. A prevalência de colonização de Staphylococcus aureus era mais alta em participantes de 6-11 anos. A colonização de MRSA estava associada com a idade 60 anos e sexo feminino, mas não com recente exposição aos serviços de saúde. O tipo de gene mais frequentemente isolado foi o SCCmec tipo IV em participantes de idade mais jovem; o gene de PVL 
estava presente em $9(2,4 \%)$ de 372 isolados. Portanto, são colonizadas muitas pessoas nos Estados Unidos com Staphylococcus aureus; as taxas de prevalência diferem demograficamente. A prevalência de colonização por MRSA, embora baixa nacionalmente em 2001-2002, pode variar com as características demográficas e as características individuais do sujeito (MATTHEW et al., 2006).

Foi demonstrada a prevalência da colonização nasal de MRSA entre 260 voluntários médicos reunidos para uma conferência, e que aceitaram participar desse estudo, sendo que 173(67\%) se encontravam para a Conferência Anual da Associação Médica britânica (BMA), e 87 participantes (33\%) estavam assistindo à conferencia da Associação de Cirurgiões (ASIT). Seis (2\%) dos participantes mostraram-se positivos como carreador nasal de MRSA (BMA $=1 \%$, ASIT $=5 \% ; p=$ 0,099). Os participantes da especialidade cirúrgica mostraram-se como mais provável carreador de MRSA positivo (BRADY et al., 2009).

Um estudo de coorte em uma amostra de conveniência de trabalhadores de saúde do departamento de emergência (DE), incluindo enfermeiras, médicos, e técnicos em um total de 105 trabalhadores obteve um total de 16 (15\%),(95\% intervalo de confiança - 9,6\% a 23\%) positivo para MRSA. Nenhuma diferença significativa foi observada em taxas de colonização entre enfermeiros, médicos, e técnicos. O resultado foi considerado uma alta prevalência de colonização de MRSA nasal quando comparado a indivíduos em recente vigilância na comunidade e outros estudos envolvendo o departamento de emergência (BISAGA et al, 2008). Portanto, nos Estados Unidos, a prevalência de MRSA foi de 15\% entre trabalhadores do departamento de emergência (BISAGA et al, 2008).

Outro estudo realizado em departamento de emergência buscou determinar a prevalência de colonização nasal de Staphylococcus aureus e MRSA entre prestadores de cuidado à saúde. Foi desenvolvido com uma amostra de conveniência em cinco hospitais escola em Pittsburgh. Entre os 255 sujeitos, 23\% eram médicos; $62 \%$ eram enfermeiras ou técnicos; e 15\% trabalhadores de serviço social. De 81 (31.8\%) de Staphylococcus aureus isolados, 11 (13.6\%) eram MRSA. Todas as amostras de MRSA positivas eram de enfermeiras e técnicos. Neste departamento de emergência a prevalência de Staphylococcus aureus é semelhante a este estudo, mas a colonização nasal por MRSA é mais alta que as estimativas na população geral dos Estados Unidos. Os médicos não tiveram colonização de MRSA (SUFFOLETTO et al, 2008). 
Um estudo, realizado em Shiraz, Irã (ASKARIAN et al., 2009), obteve resultados semelhantes ao do presente estudo. Foram investigados 600 trabalhadores de saúde, utilizando o método da coleta de swab nasal, para identificar a prevalência de portadores de Staphylococcus aureus. A prevalência de carreador nasal de MSSA foi de 25,7\%, em nosso estudo foi de 29,6\%, e de MRSA foi de $5,3 \%$, em nosso estudo $7,1 \%$ com mais alta colonização de MRSA nas clínicas cirúrgicas e no departamento de emergência. Não havia nenhuma diferença significativa entre os sexos $(p=0,247)$, idade $(p=0,817)$, e anos de serviço do trabalhador $(p=0,15)$ com respeito à colonização nasal por MRSA e MSSA. Na análise univariada, uma diferença significativa foi encontrada na categoria ocupação ( $p=0,032)$ entre o portador de MSSA e MRSA. Na análise multivariada, a ocupação ' enfermeiro' era independentemente associada ao portador de MRSA ( $p=0,012$, odds ratio 3,6 - 95\% intervalo de confiança 1,3-9,7). A taxa de resistência mais alta foi para gentamicina e clindamicina (69\%) entre os MRSA. Nenhuma das cepas de MRSA eram resistentes à mupirocina, linezolida e vancomicina. A existência do gene de mecA em todos os 32 MRSA isolados foi observado por PCR. Este estudo revelou que a prevalência de portador de Staphylococcus aureus ser mais baixa do que outros estudos do Irã.

Em um centro de trauma com 750 leitos, foram colecionadas amostras da orofaringe de 324 médicos e enfermeiras registradas, e a prevalência de MRSA identificada foi de 5,3\% e 36,4\% do Staphylococcus aureus (KAMINSKI et al, 2007).

A prevalência de Staphylococcus aureus em um estudo desenvolvido com trabalhadores de saúde de um hospital terciário foi de $28 \%$ entre os 200 participantes e de $2 \%$ de carreadores de MRSA. Esta incidência de colonização por MRSA foi considerada extremamente baixa (JOHNSTON et al., 2007).

Pesquisa envolvendo 715 residentes em 39 casas de cuidado em Leeds, Reino Unido, para identificar a colonização em residentes e trabalhadores e os fatores de risco para portador. Um total de 159 de 715 residentes mostrou-se positivos para MRSA, uma prevalência de 22\% (95\% intervalo de confiança, 18\%27\%) O modelo de análise multivariada mostrou como fatores de risco: uma baixa relação de enfermeiras por leitos, residência em uma casa de cuidado em uma área privada, sexo masculino, presença de um dispositivo invasivo, e uma duração de hospitalização de mais de 10 dias durante os 2 anos prévios seja 
independentemente associada à colonização de MRSA. Este estudo achou um reservatório grande de MRSA dentro da população de casa de cuidado.

Investigação realizada, há mais de vinte anos, na mesma instituição do presente estudo, entre os profissionais de enfermagem de diferentes setores avaliou a colonização em diferentes sítios anatômicos (cavidade nasal, orofaringe e mãos) e encontrou prevalência de $40,6 \%$ de portadores de Staphylococcus aureus em uma ou mais das áreas anatômicas estudadas (SANTOS, 1987).

Estudo desenvolvido em um hospital universitário de grande porte investigou a prevalência de contaminação dos jalecos com patógenos hospitalares importantes, como Staphylococcus aureus e MRSA, e enterococos resistentes à vancomicina (VRE). Foi coletada uma cultura com cotonete umedecido em lapela, bolsos, e punhos de manga. Entre os 149 jalecos dos participantes, 34 (23\%) mostraram-se contaminados com Staphylococcus aureus e dentre eles, 6 (18\%) eram MRSA. Este estudo sugere que uma proporção grande dos jalecos de trabalhadores de cuidado de saúde possa ser contaminada com Staphylococcus aureus, inclusive MRSA e podem ser um vetor importante de transmissão (TREAKLE et al., 2009).

Huang et al. (2006) identificaram que aproximadamente um terço dos pacientes colonizados por MRSA na UTI de um hospital terciário de ensino, desenvolveram doença invasiva dentro de 18 meses. Aproximadamente $50 \%$ das infecções se manifestaram após a alta hospitalar, geralmente requerendo reinternação.

Porém, um fator importante que merece ser avaliado é a persistência ou a transitoriedade da colonização, principalmente por MRSA. O estado de portador por si já é importante e torna-se ainda mais preocupante quando identificado uma colonização persistente, em diferentes momentos, do trabalhador. Obtivemos a prevalência de $78 / 104(75,0 \%)$ de carreadores transitórios e 26/104(25,0\%) carreadores persistentes de MSSA, sendo que entre os MRSA 39/40(97,5\%) eram carreadores transitórios e $1 / 40(2,5 \%)$ carreadores persistentes, ou seja, $117 / 144(81,2 \%)$ de carreadores transitórios e $27 / 144(18,8 \%)$ carreadores persistentes. O estudo de Cruz (2008) mostrou que há 67,9\% carreador transitório e $33,1 \%$ carreador persistente. Não podemos, contudo afirmar ser esta uma colonização persistente, mas sim afirmar o estado de portador em duas coletas subsequentes, o que por si só já constitui um fator de risco importante. 
Para Cruz (2008), a importância da persistência ou transitoriedade da colonização está associada a maior probabilidade de disseminação dessas bactérias, seja no ambiente hospitalar ou comunitário. A disseminação para o paciente está também relacionada ao cuidado prestado e dependente das medidas básicas de higiene adotadas. Considera-se que o trabalhador colonizado por MRSA está sujeito aos mesmos riscos da população em geral quando expostos a esses agentes, portanto, não podemos ignorar o risco da colonização por MRSA para a saúde do trabalhador.

Sendo assim, o conhecimento do estado de portador, bem como sua descolonização reduzem os riscos de infecções subsequentes. Concordamos com Albrich; Harbarth (2008) e Cruz (2008), quando consideram a possibilidade de inserir a condição de colonização ou infecção por MRSA como um evento ocupacional amparado na lei trabalhista.

Enfim, as bactérias resistentes a múltiplas drogas, como MRSA, são endêmicas em instituições de saúde nos Estados Unidos e muitos outros países do mundo. A transmissão hospitalar de cepas de MRSA como uma fonte de infecções do hospital, e recentes relatórios de Staphylococcus aureus resistentes à vancomicina obrigam os Estados Unidos a enfatizarem a necessidade de melhor controle de MRSA e outras bactérias resistentes dentro das instituições de saúde. A colonização com Staphylococcus aureus ou MRSA é relativamente comum, tanto no indivíduo saudável como no hospitalizado, frequentemente envolve as narinas anteriores e é predominantemente assintomático.

A colonização aumenta o risco de infecção. A transmissão de paciente para paciente de MRSA dentro das instituições de saúde acontece principalmente através das mãos dos trabalhadores de saúde carreadores. A Sociedade para Epidemiologia de Saúde da América (SHEA) desenvolveu diretrizes para a prevenção de transmissão de MRSA e enterococos resistentes à vancomicina (ERV) dentro das instituições de saúde, e a mais importante das recomendações é a ênfase em aderência nas diretrizes de higiene. Outras medidas que podem prevenir a transmissão hospitalar de MRSA incluem: monitoramento do uso de antibióticos, coorte de pessoal, manutenção de equipes de pessoal apropriadas, redução na média de permanência no hospital, isolamento de contato, vigilância microbiológica ativa e melhoria na educação do pessoal. Atualmente, não é conhecida a eficácia dessas intervenções de controle de infecção avaliadas separadamente, pois, a 
maioria dos estudos indicam os benefícios dos resultados com a instituição simultânea de algumas dessas medidas. Todavia, a melhor recomendação atual envolve higienização das mãos e aplicação de procedimentos mais agressivos como medidas de isolamento aplicadas ao cuidado do paciente, coorte de pessoal, e cultura de vigilância ativa, como indicado (HENDERSON et al., 2006).

\subsubsection{Caracterização demográfica e profissional dos trabalhadores colonizados}

Analisando a prevalência de portadores de Staphylococcus aureus e principalmente, a de MRSA encontrada no presente estudo à luz de outros estudos apresentados, constatou-se serem relevantes estes resultados para a instituição em estudo. Ao considerarmos outros fatores envolvidos como a categorização profissional e o local de trabalho, fica ainda mais claro o panorama apresentado do ponto de vista da segurança do paciente.

Quanto à categoria profissional chama a atenção o aspecto do auxiliar e do técnico de enfermagem mostrarem-se com maior incidência entre os portadores de Staphylococcus aureus, mas, entre os portadores de MRSA, prevaleceram os enfermeiros $(11,3 \%)$ e técnicos de enfermagem $(10,5 \%)$ e, em número bem mais reduzido, nos auxiliares de enfermagem (5,1\%), metade dos demais. Uma associação que pode ser feita a este dado é o fato dos enfermeiros e técnicos realizarem mais frequentemente as atividades de alta complexidade, muitas vezes relacionadas a procedimentos invasivos associados.

Nos estudos de Palos (2006) e Cruz (2008) também houve maior prevalência entre os técnicos de enfermagem, contudo o mesmo não ocorreu em relação aos enfermeiros.

Um estudo que investigou um surto de MRSA constatou que $80.6 \%$ dos casos eram associados aos cuidados prestados por profissionais de saúde colonizados (COOMBS et al, 2007).

Não foi possível dimensionar precisamente se o fato de trabalhar em outra instituição aumenta a prevalência de portador de Staphylococcus aureus devido à falta de informação referente a este dado. Contudo, entre aqueles que informaram esta condição, não foi demonstrado aumento do risco de incidência. 
Quanto ao tempo de trabalho na instituição, não houve uma diferença significativa dentre os portadores de Staphylococcus aureus com menos de cinco anos e aqueles com mais de 11 anos, entretanto entre os portadores de MRSA a incidência mostrou-se mais alta entre os trabalhadores que têm entre 6 a 10 anos na instituição.

Em relação à prevalência de trabalhadores colonizados por MSSA, segundo às áreas de atuação, destaca-se as maiores taxas entre os trabalhadores da unidade metabólica, de transplante de medula óssea e a clínicas médica; entretanto os locais com maior prevalência de MRSA foram a UTI neurológica, clínica médica do sexto andar e clínica cirúrgica. Um fato que merece ser ressaltado é que os pacientes da UTI neurológica normalmente são procedentes da clínica cirúrgica e os setores são contíguos; os pacientes ao receberem alta da UTI neurológica, na maioria das vezes, são encaminhados para a clínica cirúrgica.

Em outros setores também foram identificados portadores de MRSA em menor proporção, porém chama-nos a atenção alguns setores, de maior susceptibilidade dos clientes, onde a presença de um único portador de MRSA pode ser um grande fator de risco para seus clientes. Estes setores são a unidade metabólica, hematologia e transplante de fígado. Nesses locais, consideramos relevante a descolonização do profissional colonizado e culturas de vigilância da equipe.

PATEL et al (2008) constatou que entre os pacientes de UTI, a colonização de MRSA é associada com infecção subseqüente e risco de mortalidade. A vigilância ativa para colonização de MRSA pode identificar os indivíduos de risco para estes desfechos adversos, e melhorar os programas de prevenção.

Alguns resultados nos surpreenderam: a UTI e a clínica de moléstias infecciosas onde era esperado uma maior incidência revelou-nos exatamente o contrário. Uma hipótese pode ser que devido ao fato do trabalhador conhecer a situação de portador de seus pacientes, faz com ele tome mais cuidado ao manuseá-los, ou seja, a percepção de risco de contaminação leva o trabalhador a se proteger melhor.

O comprometimento e foco da liderança é um pré-requisito para obter controle de problemas intratáveis como MRSA. Os principais elementos do comprometimento da liderança são: Reconhecimento da seriedade do problema relacionado ao MRSA; o qual se associa à elevada morbimortalidade e alto impacto nos custos. Noção de que grandes reduções nas 
taxas de infecção por MRSA chegando até mesmo a zero, são possíveis. Capacitação das equipes multidisciplinares da linha de frente para fazer o trabalho, incluindo provisão de suprimentos necessários, pessoal, controle de infecção, microbiológico e recursos estruturais/ ambientais. Engajamento do corpo clínico. Revisão regular dos dados, com pronta remoção das barreiras ao sucesso (FIVE MILLION LIVES CAMPAIGN, 2008. p.11)

\subsubsection{Caracterização fenotípica de Staphylococcus aureus}

As culturas dos MRSA revelaram além de $100 \%$ de resistência à oxacilina, resistência acima de $65 \%$ para penicilina, cefotaxima, mupirocina e clindamicina e gentamicina respectivamente e baixíssima resistência à ciprofloxacina e linezolida e nenhuma resistência à vancomicina. Configura-se uma situação de limitadas opções de tratamento para o portador de infecção com este agente etiológico. Um outro agravante encontrado trata-se da resistência à mupirocina, que é considerado o antimicrobiano de escolha para descolonização do portador de MRSA. Este resultado será discutido posteriormente de forma mais detalhada.

Quanto aos portadores de MSSA, a situação mostra-se bem menos preocupante, pois o perfil apresentado é característico de Staphylococcus aureus comunitário. Nenhuma resistência à oxacilina, naturalmente, resistência de $72,1 \%$ à penicilina e baixíssima resistência aos demais antimicrobianos. Esse resultado é bastante favorável ao trabalhador.

Observou-se também uma grande quantidade de unidades formadoras de colônias por $\mathrm{ml}$ ( $\mathrm{ufc} / \mathrm{ml}$ ) na boca dos trabalhadores, pressupõem-se que sejam pessoas saudáveis. Neste sentido, os hábitos de higiene devem ser avaliados bem como a identificação e o tratamento de infecções na boca ou doença periodontal (CRUZ, 2008).

\subsubsection{Prevalência da resistência à mupirocina em trabalhadores da área de saúde}

O Staphylococcus aureus se caracteriza como colonizante de pele e mucosa. Quando resistente à meticilina, a descolonização de mucosas e pele deve ser 
considerada. A mupirocina, antimicrobiano de uso tópico, é o antimicrobiano atualmente recomendado para a descolonização da mucosa nasal e de lesões cutâneas de pacientes ou profissionais da saúde (COIA et al., 2006; WERTHEIM; VOS, 2005b). Essa descolonização visa limitar a disseminação desse agente nos serviços de saúde, e assim reduzir o grande impacto clínico produzido por ele nas infecções hospitalares, notadamente aquelas relacionadas a procedimentos cirúrgicos e cateteres vasculares (WERTHEIM; VOS, 2005b).

Estudos avaliaram a vigilância ativa por meio da cultura em swab nasal e/ou de orofaringe e demonstraram que essa medida contribui para redução das taxas de infecção (NETTO DOS SANTOS, FONSECA, GONTIJO, 1996; ROBICSEK et al, 2008)

O uso de mupirocina no pré-operatório de 96 pacientes, submetidos a esofagectomia radical eletiva com toracotomia e laparotomia demonstrou uma significativa redução no índice de infecção hospitalar entre pacientes que eram portadores de Staphylococcus aureus (UNEMURA et al, 2006).

Em um estudo epidemiológico realizado no Brasil (NETTO DOS SANTOS, FONSECA, GONTIJO, 1996), foi observada significativa resistência à mupirocina em Staphylococcus aureus, o estudo foi realizado em dois hospitais, um no Rio de Janeiro (RJ) e outro em Uberlândia (MG), sendo que utilizavam políticas diferentes para uso do referido antibiótico. A resistência observada em isolados do hospital no Rio de Janeiro foi de $63 \%$ dos padrões apresentados, onde há um uso tópico extensivo e de $6,1 \%$ em Uberlândia, MG, onde o seu uso é restrito.

Em outra região, distante geograficamente, também é emergente a resistência à mupirocina entre MRSA isolados de um hospital geral, após vinte anos de uso contínuo (ORRETT, 2008). Na Europa, foram observadas altas taxas de resistência à mupirocina em 19 hospitais e os autores concluíram que para manter a prevalência relativamente baixa é prudente o uso restrito do mesmo através de medidas estratégicas de controle (SCHMITZ et al, 1998). Em hospitais canadenses, observaram um aumento na resistência de $1,6 \%$ para $7,0 \%$ em cinco anos de vigilância (SIMOR et al, 2007).

Em diferentes áreas da Malásia que têm uma política de uso restrito de mupirocina, observou-se baixíssima porcentagem de resistência ao mesmo, de $1,25 \%$ entre 400 MRSA pesquisados nesses locais (NORAZAH et al, 2001). Já na Arábia Saudita, em Riyadh, foi demonstrado em seis de seus maiores hospitais, que 
faziam uso do antimicrobiano para descolonização do portador de MRSA, que estavam desenvolvendo resistência associada ao uso do mesmo (BADDOUR; ABUELKHEIR; FATANI, 2006).

Portanto, a resistência apresentada no hospital em estudo, que atingiu 9,3\% entre os portadores de MSSA, está variando entre os padrões que vêm se apresentando em diversos países. Entretanto, estudos confirmam o fato de a descolonização ser efetiva no controle da prevenção da disseminação de MRSA.

No Brasil, um estudo realizado em uma unidade de hemodiálise, demonstrou uma redução significativa da bacteremia associada à utilização de cateter venoso central quando impregnado com mupirocina em comparação ao grupo controle. Foi identificado bacteremia por Staphylococcus aureus em 17 pacientes (dois no grupo de mupirocina [0.71 episódios por 1000 pacientes-dia] e 15 no grupo de controle [8.92 por 1000 paciente-dias], $P<0.001)$. A relação de risco de bacteremia por Staphylococcus aureus 7.2 (95\% intervalo de confiança, 1.6 a 31.6) vezes maior em pacientes que não utilizaram mupirocina na saída do cateter (SESSO et al., 1998).

A eficácia de um programa de prevenção e controle de infecção em UTI ainda no Brasil pós-intervenção de descolonização e vigilância de controle, bem como a redução da mortalidade, foi demonstrada com índices de redução significativos (MOREIRA et al., 2007b).

Entretanto, resistência a esse antibiótico tem sido descrita em hospitais que fazem uso regular dessa prática (NETTO DOS SANTOS, FONSECA, GONTIJO, 1996; UDO; JACOB; MATHEW, 2001a). Já se demonstrou que a resistência é facilmente transferível entre Staphylococcus aureus e exibe relação com o uso prolongado da mupirocina em locais onde o MRSA é endêmico (UDO; JACOB; MATHEW, 2001a).

Resultados indicam que a resistência à mupirocina é maior quando o Staphylococcus aureus é resistente à oxacilina e que é necessário conhecer o perfil de sensibilidade aos antimicrobianos, através de vigilância epidemiológica, para planejar ações de controle da resistência aos mesmos. Este perfil também foi fortemente confirmado neste estudo onde $73,1 \%$ dos MRSA mostraram-se resistência à mupirocina em concordância com os estudos analisados. Contudo, os MSSA mostraram-se sensíveis à mupirocina $(9,3 \%)$.

Entretanto, alguns estudos vêm sendo realizados na busca de alternativas no uso de mupirocina. Um estudo inédito demonstrando que a associação da 
mupirocina ao própolis resultou em uma grande redução de colônias da bactéria (ONLEN et al., 2007).

Também a naseptina e sulfadiazina de prata já foram utilizadas como alternativa à mupirocina (HARDY et al., 2007). Foi também descrito como um fator de risco para aumento da resistência à mupirocina o uso de piperacilina tazobactan (BELLISSIMO RODRIGUES, 2008).

É relevante apontar que o uso da mupirocina faz parte de uma estratégia global de controle do MRSA em hospitais, que inclui também o banho com clorexidina degermante e as precauções de contato para com o portador de MRSA, a higienização rigorosa das mãos dos profissionais de saúde, o uso adequado de antibióticos sistêmicos, entre outras medidas. A norma mais aplicada ou adaptada em hospitais é aquela elaborada pelos Centers for Diseases Control (CDC, 2007), que aborda o sistema de precauções e isolamento e, também de suma importância na atualidade, são as orientações dos CDC específicas para os portadores de bactérias multirresistentes (CDC, 2006).

Para que a estratégia de descolonização dos portadores continue a ser efetiva, é fundamental que se avalie o nível de resistência à mupirocina encontrado nos serviços de saúde. Este diagnóstico poderá ser realizado a nível local devido à diversidade do perfil de resistência à mupirocina encontrado na literatura, bem como da heterogeneidade das medidas de controle de MRSA adotadas nas instituições.

Entretanto, o grande problema em questão é a resistência a esse antimicrobiano identificada em algumas instituições. Necessitamos do diagnóstico institucional antes de definirmos o protocolo de controle de MRSA para garantirmos a adequação e eficácia da medida.

Comparando a instituição pesquisada com as diferentes localidades apresentadas, podemos constatar que a resistência à mupirocina na instituição pesquisada é alta entre os portadores de MRSA, em relação àquelas que fazem uso restrito de mupirocina.

O seu uso deve ser bem avaliado, considerando a necessidade de reflexão sobre o uso rotineiro da mupirocina para descolonização, e a probabilidade de desenvolvimento de resistência relacionada com a política de uso (NETTO DOS SANTOS; FONSECA; GONTIJO FILHO, 1996). 
O resultado deste estudo vem mais uma vez reforçar a problemática da multirressistência e da necessidade de uma avaliação criteriosa paro o uso de antimicrobianos, mesmo que tópico, na prática diária.

É importante que o uso racional e controlado de antimicrobiano, aliado à monitorização rotineira da susceptibilidade aos Staphylococcus aureus isolados de pacientes ou profissionais da saúde, sejam estratégias adotadas pelas instituições. Medidas de controle para preservar a eficácia desse antimicrobiano a longo prazo devem ser implantadas, entre elas o uso ponderado desse antimicrobiano para descolonização, em situações especiais, visto que a utilização rotineira não é recomendada. Entretanto, há de se considerar que em circunstâncias específicas, ele pode ser recomendado (CDC,2007). Também novas pesquisas devem ser realizadas para identificar e testar outros medicamentos e/ou medidas eficazes de controle da disseminação de MRSA, associado a medidas já existentes e comprovadas.

Esta orientação também se faz necessária para proteção ocupacional do trabalhador e para evitar sua disseminação no ambiente hospitalar e conseqüentemente para prevenir um problema mundial de saúde pública.

Constatamos que a medida de controle de MRSA, de descolonização com mupirocina, está se tornando uma medida ineficaz onde ocorre resistência a esse antimicrobiano. 


\section{CONCLUSÕES}

Entre as 1053 culturas da saliva dos trabalhadores de um hospital público estadual, 186(17,7\%) mostraram-se positivas. Encontramos uma prevalência de $58,9 \%$ de sujeitos não colonizados e $41 \%$ de carreadores de Staphylococcus aureus, sendo $81,2 \%$ carreadores transitórios e 18,8\% carreadores persistentes. Entre esses $29,6 \%$ colonizados por MSSA, 7,1\% por MRSA e 4,3\% não identificados. Constatamos, portanto, na cavidade bucal, um potencial reservatório e uma fonte de disseminação de Staphylococcus aureus nos serviços de saúde, bem como um fator de risco de infecção para o trabalhador.

Constatou-se também uma resistência de $73,1 \%$ à mupirocina dentre os portadores de MRSA e de 9,3\% nos MSSA, configurando relevante resultado por interferir nas medidas de prevenção atualmente recomendadas.

Traçou-se o perfil de colonização desses profissionais, comparando a prevalência com os locais lotados nas diferentes unidades investigadas, levando em consideração o tempo de atuação profissional, jornada no hospital e de contato com os pacientes desses hospitais bem como caracterizar os trabalhadores colonizados por Staphylococcus aureus, segundo seu perfil demográfico e profissional. Também objetivou-se conhecer o perfil fenotípico dos Staphylococcus aureus isolados.

Os resultados evidenciaram que são os enfermeiros e os técnicos de enfermagem a categoria profissional mais suscetível ao MRSA. O tempo na instituição não teve uma forte correlação com a colonização do profissional, pois trabalhadores com menor tempo na instituição também tiveram alta incidência de colonização.

Uma situação de risco identificada foi a presença de portadores de MRSA em setores de maior suscetibilidade da sua clientela e conseqüentemente configuração de uma situação de maior gravidade. Os setores citados são a unidade metabólica, UTI, unidade de transplante de fígado, hematologia e clinica ginecológica e obstétrica. Faz-se premente a continuidade da investigação dos trabalhadores dessas unidades, bem como sua subsequente descolonização por configurar fator de risco. Em revisão de literatura, constatamos que a presença de um ou mais 
portadores colonizados com MRSA na unidade foram suficientes para desencadear um surto local.

Configurou-se uma situação de risco para o paciente e para o trabalhador que requer estudos específicos e intervenções de prevenção e controle de MRSA, principalmente considerando a condição de setores especiais. 
CONSIDERAÇÕES FINAIS 


\section{CONSIDERAÇÕES FINAIS}

Ao avaliarmos todo o panorama encontrado vem à mente a seguinte pergunta: Podemos fazer alguma coisa para reverter tal situação? Este não é o reflexo do que ocorre na maioria dos hospitais brasileiros? Mas... então, o que fazer? Se ao menos nós atendêssemos às recomendações existentes, já estaríamos melhorando e muito nossa condição atual. A realização do screening do paciente recém-admitido no hospital, com seu isolamento até a liberação do resultado, seria outra medida satisfatória, contudo poucos hospitais praticam essa ação. O número limitado de leitos em nossos hospitais colaboram grandemente para 0 descumprimento da atividade, somado a isto a incredulidade e/ou falta de conhecimento de nossos profissionais sobre essa medida de segurança. O resultado não poderia ser menos desastroso, a disseminação incontrolada do MRSA em nossos pacientes e trabalhadores de saúde. Porém, uma situação não pode ser julgada, avaliada, se ela não existe; é o que acontece conosco, trabalhadores da área da saúde, não conhecemos nossa condição de portadores de Staphylococcus aureus e seguimos colocando em risco nossa saúde e dos pacientes que se encontram sob nossos cuidados. Compartilho com Cruz (2008) a necessidade do trabalhador conhecer sua situação de portador, como um direito do trabalhador, para que reflita e reveja suas práticas frente ao risco ocupacional, bem como tenha a possibilidade de realizar sua descolonização.

Contudo, Albrich e Harbarth (2008) nos fazem refletir sobre esta questão: São os trabalhadores de saúde fonte, vetores ou vítimas do MRSA? A revisão de literatura mostrou diferentes papéis dos trabalhadores de saúde em relação ao MRSA. Aproximadamente $5 \%$ de trabalhadores de saúde que são colonizadas com MRSA contraem a doença clínica. Baseado nas evidências publicadas, eles têm importante papel na transmissão de MRSA, a maioria age como vetores e não como a fonte principal de transmissão de MRSA. Assim, a prática de higiene das mãos permanece essencial para controlar a expansão de MRSA. Trabalhadores da área da saúde são como reservatórios persistentes de MRSA nas instituições e os cuidados com a saúde são raros, todavia importantes. Finalmente, os trabalhadores podem ser inocentes espectadores sem qualquer papel na transmissão de 
pacientes. Esses papéis não são exclusivos, portanto difíceis de diferenciar. Entretanto, políticas de investigação parecem justificadas em situações de surto.

Seria uma ingenuidade muito grande acreditar que somente as medidas citadas seriam suficientes para mudar esta situação, seria fundamental políticas públicas com programas específicos, campanhas nacionais? que contemplem esta problemática e associado a isto o investimento em novas pesquisas para elucidar melhor os mecanismos de disseminação destes agentes, como também o desenvolvimento de novas drogas para os casos de falência dos antimicrobianos atuais. Somado a isto, devemos ainda nos preocupar com os uniformes contaminados de trabalhadores, como exposto na pesquisa com os jalecos dos trabalhadores e lembrar também que a correta desinfecção do ambiente hospitalar tem papel importante nesta cadeia de transmissão do agente. Portanto, somente ações sistematizadas e controladas poderão suportar o desafio da disseminação das bactérias multidrogas resistentes.

Atualmente o trabalho em equipe é considerado essencial para a
assistência em saúde; sendo a comunicação entre a equipe, um indicativo
da cultura organizacional. Todos os membros da equipe devem ser
considerados igualmente importantes, independente de sua função, sendo
não apenas encorajados a falar, mas solicitados a participarem. (FIVE
MILLION LIVES CAMPAIGN, 2008. p.37).

Constatando a necessidade de nos unirmos na busca de solução para a problemática apresentada. 
REFERÊNCIAS 


\section{REFERÊNCIAS ${ }^{1}$}

ABRAMSON, M. A.; SEXTON, D. J. Nosocomial methicillin-resistant and methicillinsusceptible Staphylococcus aureus primary bacteremia: at what costs? Infect Control Hosp Epidemiol, Chicago, v. 20, p. 408-411, 1999.

ALBRICH, W. C.; HARBARTH, S. Health-care worker: source, vector, or victim of MRSA? Lancet Infectious Diseases, New York, v.8, n. 5, p. 289-301, may 2008.

ALGHAITHY, A. A.; BILAL, N. E.; GEDEBOU, M.; WEILY, A. H. Nasal carriage and antibiotic resistance of Staphylococcus aureus isolates from hospital and nonhospital personnel in Abha, Saudi Arabia. Trans R Soc Trop Med Hyg, v. 94, p. 504-507, 2000.

ALLIGNET, J.; SOLH, N. E. Characterization of a new staphylococcal gene, vgaB, encoding a putative $A B C$ transporter conferring resistance to streptogramin $A$ and related compounds. Gene, Netherlands, v. 202, p. 133-138, 1997.

ALLIGNET, J.; LIASSINE, N.; SOLH, N. E. Characterization of a staphylococcal plasmid related to pUB110 and carrying two novel genes, vatC and vgbB, encoding resistance to streptogramin $A$ and $B$ and similar antibiotics. Antim Ag Chem, v. 42, n.7, p. 1794-1798, 1998.

ASKARIAN, M.; ZEINALZADEH, A.; JAPONI, A.; ALBORZI, A.; MEMISH, Z.A. Prevalence of nasal carriage of methicillin-resistant Staphylococcus aureus and its antibiotic susceptibility pattern in healthcare workers at Namazi Hospital, Shiraz, Iran. Int J Infect Dis, Canadá, v.13, n.5, p.241-47.Mar, 2009.

ASSOCIAÇÃO PAULISTA DE ESTUDOS E CONTROLE DE INFECÇÃO HOSPITALAR (APECIH). Manual de microbiologia clínica aplicada ao controle de infecção hospitalar. 2. ed. São Paulo: APECIH, 2004.

ASSOCIAÇÃO PAULISTA DE ESTUDOS E CONTROLE DE INFECÇÃO HOSPITALAR (APECIH). Precauções e isolamento. 2. ed. São Paulo: APECIH, 1999.

BADDOUR, M. M.; ABUELKHEIR, M. M.; FATANI, A. J. Trends in antibiotic susceptibility patterns and epidemiology of MRSA isolates from several hospitals in Riyadh, Saudi Arabia. Ann Clin Microbiol Antimicrob. v. 5, n. 5, p. 30, Dec. 2006. 
BELISSIMO-RODRIGUES, F. Antimicrobial drug use and antibiotic-resistant bacteria. Emerg Infect Dis. v. 14, n. 1, p. 187-188, Jan. 2008.

BEN-DAVID D, MERMEL LA, PARENTAL S. Methicillin-resistant $S$. aureus transmission: the possible importance of unrecognized health care worker carriage. Am J Infect Control. v. 36, n.2, p. 93 - 97. 2008.

BERNARD, L. et al. Comparative analysis and validation of different assays for glycopeptide susceptibility among methicillin-resistant $S$. aureus strains. J Microbiol Meth. v. 57, n. 2, p. 231-239, 2004.

BHALLA, A. et al. Acquisition of nosocomial pathogens on hands after contact with environmental surfaces near hospitalized patients. Infect Control Hosp Epidemiol. v. 25, n. 2 , p. 164-167, 2004.

BISAGA, A; PAQUETTE, K; SABATINI, L; LOVELL, E.O. A prevalence study of methicillin-resistant Staphylococcus aureus colonization in emergency department health care workers. Ann Emerg Med. v. 52, n.5, p. 525 - 528, Nov. 2008.

BISCHOFF, W. E.; REYNOLDS, T. M.; SESSLER, C. N.; EDMOND, M. B.; WENZEL, R. P. Handwashing compliance by health care workers. The impact of introducing an accessible, alcohol-based hand antiseptic. Arch Intern Med. v. 160, n.7, p. 1017-1021, 2000.

BOOTSMA, M. C.; DIEKMANN, O.; BONTEN, M. J. Controlling methicillin-resistant Staphylococcus aureus: quantifying the effects of interventions and rapid diagnostic testing. Proc Natl Acad Sci. v. 103, n. 14, p. 5620-5625, 2006.

BOYCE, J. M. Methicillin-resistant Staphylococcus aureus in hospitals and long-term care facilities: microbiology, epidemiology and preventive measures. Infect Control Hosp Epidemiol. v. 13, n.12, p. 725-737, 1992.

BOYCE, J. M. MRSA patients: proven methods to treat colonization and infection. J Hosp Infect. England, v. 48, p. S9 -S14, Aug. 2001. Supplement A.

BOYCE, J. M.; POTTER-BYNOE, G.; CHENEVERT, C.; KING, T. Environmental contamination due to methicillin-resistant Staphylococcus aureus: possible infection control implications. Infect Control Hosp Epidemiol. v. 18, n. 9, p. 622-627, 1997.

BRADY, R. R.; MCDERMOTT, C.; GRAHAM, C.; HARRISON, E.M; EUNSON, G.; FRAISE, A.P; DUNLOP, M.G.; GIBB, A.P. A prevalence screen of MRSA nasal colonization amongst UK doctors in a non-clinical environment. Eur $\mathbf{J}$ Clin Microbiol Infect Dis, Germany, v.28, n.8, p.991- 995. Feb, 2009. 
BRASIL. Ministério da Saúde. Portaria n 2.616 de 26 de maio de 1998.

BRUMFITT, W.; HAMILTON-MILLER, Methicillin-resistant Staphylococcus aureus. N. Engl. J. Med. v. 320, n.18, p. 1188 - 1196, 1989.

CALFEE, D. P.; DURBIN, L. J.; GERMANSON, T. P.; TONEY, D. M.; SMITH, E. B.; FARR, B. M. Spread of methicillin-resistant Staphylococcus aureus (MRSA) among household contacts of individuals with nosocomially acquired MRSA. Infect Control Hosp Epidemiol. v. 24, n.6, p. 422-426, 2003.

CARDOSO, J. L. Prevalência e tipagem molecular de Staphylococcus aureus isolados da nasofaringe de crianças no município de Goiânia - GO, 2005. Dissertação (Mestrado) - Instituto de Patologia Tropical e Saúde Pública, Universidade Federal do Goiás, Goiânia, 2005.

CARVALHO, M. J. et al. Prevalence of methicillin-resistant and methicillinsusceptible s. aureus in the saliva of health professionals. Clinics, São Paulo, v. 64, n. 4, p. 295-302. Apr. 2009.

CARLING, P. C.; PARRY, M. F.; VON BEHEREN, S. M. Healthcare environmental hygiene study group. Identifying opportunities to enhance environmental cleaning in 23 acute care hospitals. Infect Control Hosp Epidemiol. v. 29, n. 1, p. 1-7, Jan. 2008.

CASSETTARI, V. C.; STRABELLI, T.; MEDEIROS, E. A. S. Staphylococcus aureus bacteremia: what is the impact of oxacillin resistance on mortality ? Braz $\mathbf{J}$ Infect Dis, Brazil, v. 9, n. 1, p. 70-6, 2005.

CENTERS FOR DISEASE CONTROL AND PREVENCTION (CDC). Four pediatric deaths from community-acquired methicillin-resistant Staphylococcus aureus Minesota and North Dakota, 1997-1999. JAMA. v. 282, n.12, p. 1123-1125, 1999.

CENTERS FOR DISEASE CONTROL AND PREVENCTION (CDC). Guideline for isolation precautions: preventing transmission of infectious agents in healthcare settings. 2007.

CENTERS FOR DISEASE CONTROL AND PREVENCTION (CDC). SIEGEL, J.D; RHINEHART, E; JACKSON, M; CHIARELLO, L. HEALTHCARE INFECTION CONTROL PRACTICES ADVISORY COMMITTEE (HICPAC). Management of Multidrug-Resistant Organisms in Healthcare Settings. Atlanta (GA). 74p. 2006. 
CESPEDES, C.; MILLER, M.; QUAGLIARELLO, B.; VAVAGIAKIS, P.; KLEIN, R. S.; LOWY, F. D. Differences between Staphylococcus aureus isolates from medical and nonmedical hospital personnel. J Clin Microbiol. v. 40, n.7 , p. 2594-2597, 2002.

CLINICAL AND LABORATORY STANDARDS INSTITUTE (CLSI). Approved Standards M2-A8. Performance Standards for Antimicrobial Disk Susceptibility Tests 8.ed. Approved Standard. NCCLS, 2005.

COIA, J.E.; DUCKWORTH, G.J.; EDWARDS, D.I.; FARRINGTON, M.; FRY, C.; HUMPHREYS, H.; MALLAGHAN, C.; TUCKER, D.R. et al. For the joint working party of the Bristish Society of Antimicrobial chemotherapy, the Hospital Infection Society, and the Infection Control Nurses Association Guidelines for the control and prevention of meticilin-resistant Staphylococcus aureus (MRSA) in healthcare facilities. Journal of Hospital Infection, v.63, p.S1-44. 2006.

COIMBRA, M. V. S; SILVA-CARVALHO, M. C.; WISPLINGHOFF, H.; HALL, G. O.; TALLENT, S., WALLACE, $S$. et al. Clonal spread of methicillin-resistant Staphylococcus aureus in a large geographic area of United States. J Hosp Infect, England, v. 53, p. 103-110, 2003.

COOKSON, B. D. Mupirocina resistance in staphylococci. J. Antim. Chemot., v. 25, p. $497-503,1990$.

COOMBS GW, VAN GESSEL H, PEARSON JC, GODSELL MR, O'BRIEN FG, CHRISTIANSEN KJ. Controlling a multicenter outbreak involving the New York/Japan methicillin-resistant S. aureus clone. Infect Control Hosp Epidemiol. v.28, n.7, p.845-52. 2007.

CRUZ, E. D. de A. Staphylococcus aureus e Staphylococcus resistente à meticilina em trabalhadores de um hospital universitário: colonização e crenças em saúde. Tese (Doutorado) - Escola de enfermagem, Universidade de São Paulo, Ribeirão Preto, 2008.

EDLUND, C.; NORD, C. E. Ecological impact of antimicrobial agents on human intestinal microflora. Alpe Adria Microbiol J., v. 3, p.137-64, 1993.

ENRIGHT, M. C.; ROBINSON, D. A.; RANDLE, G.; FEIL, E. J.; GRUNDMANN, H.; SPRATT, B. G. The evolutionary history of methicillin-resistant Staphylococcus aureus (MRSA). Proc Natl Acad Sci. v. 99, n.11, p. 7687-7692, 2002.

EVEILLARD, M. et al. Carriage of methicillin -resistant Staphylococcus aureus among hospital employees: prevalence, duration, and transmission to households. Infect Control Hosp Epidemiol. v. 25, n. 2, p. 114-120, Feb. 2004. 
FARIA, N. A.; OLIVEIRA, D. C.; WESTH, H.; MONNET, D. L.; LARSEN, A. R.; SKOV, R.; LENCASTRE, $H$. Epidemiology of emerging methicillin-resistant Staphylococcus aureus (MRSA) in Denmark: a nationwide study in a country with low prevalence of MRSA infection. J. Cli. Microbiol., v. 43, p. 1836-1842. 2005

FERNANDES, A. T. et al. Infecções Hospitalares e suas interfaces na área da saúde. São Paulo: Guanabara Koogan, 2000. v. 2, p.1402-1417.

FIVE MILLION LIVES CAMPAIGN. Getting started kit: reduce Methicillin-Resistant Staphylococcus aureus (MRSA) INfection. Cambridge, MA: Institute for Healthcare Improvement, 2008. Disponível em: <http:// www.ihi.org>. Acesso em: 14 de novembro de 2009.

FREITAS C. C.; FONSECA, A. Aspectos genéticosbioquímicos da resistência bacteriana aos antibióticos. In: ZANON, U.; NEVES, J. Infecções hospitalares: prevenção, diagnóstico e tratamento. Rio de Janeiro: MEDSI, 1987. p. 207-49.

FURUNO, J. P. et al. Identifying groups at high risk for carriage of antibiotic-resistant bacteria. Arch Intern Med. v. 166, n. 5, p. 580-585, 2006.

GOULD, I. M. The clinical significance of methicillin-resistant Staphylococcus aureus. J Hosp Infection, v. 61, n.4, p. 277-282, 2005.

GRUNDMANN, H.; AIRES-DE-SOUSA, M.; BOYCE, J.; TIEMERSMA, E. Emergence and resurgence of methicillin-resistant Staphyloccocus aureus as a public-health threat. Lancet. v. 368, n.9538, p. 874-885, 2006.

HARDY K. J. et al. Emergence and eradication of two distinct epidemic MethicillinResistant Staphylococcus aureus strains with high level mupirocin resistance. In: INTERSCIENCE CONFERENCE ON ANTIMICORBIAL AGENTS AND CHEMOTHERAPY, 47., 2007. Anais. Chicago: American Society for Microbiology, 2007.

HAYAKAWA,T; HAYASHIDERA,T; YONEDA, K.; KAGAWA, S.; KUSUNOKI, T. Preferential pharyngeal colonization of methicillin resistant stphylococcus aureus in infants. J. Pediatr. v. 134, n.2, p. 252-252, 1999.

HENDERSON, D. K. Managing methicillin-resistant staphylococci: a paradigm for preventing nosocomial transmission of resistant organisms. Am J Med. v. 119, n. 6, p.45-52, 2006. Supplement 1. 
HEROLD, B. C.; IMMERGLUCK, L. C.; MARANAN, M. C. et al. Community-acquired methicillin-resistant Staphylococcus Aureus in children with no identified predisposing risk. JAMA. v. 279, n.8, p. 593-598, 1998.

HIRAMATSU, K.; HANAKI, H.; INO, T.; YABUTA, K.; OGURI, T.; TENOVER, S. C. Methicillin-resistant Staphylococcus aureus strain with reduced vancomycin susceptibility. J. Antimicrob. Chemother, v. 40, p. 135-136, 1997.

HOSEIN, I. K.; HILL, D. W.; JENKINS, L. E.; MAGEE, J. T. Clinical significance of the emergence of bacterial resistance in the hospital environment. Symp Ser Soc Appl Microbiol .England, v. 31, p. 90S-97S, 2002.

HUANG, S. S. et al. Impact of MRSA surveillance on bacteremia. Clin Infect Dis, v. 43, n. 8, p. 971-978, 2006.

IBARRA, M.; FLATT, T.; VAN MAELE, D.; AHMED, A.; FERGIE, J.; PURCELL, K. Prevalence of methicillin-resistant Staphylococcus aureus nasal carriage in healthcare workers. Pediatr Infect Dis J. v. 27, n. 12, 1109-11, Dez. 2008.

ITO, T.; MA, X. X.; TAKEUCHI, F.; OKUMA, K.; YUZAWA, H.; HIRAMATSU, K. Novel type $V$ staphylococcal cassette chromosome mec driven by a novel cassette chromosome recombinase, ccrC. Antim Ag Chemot, v. 48, n.7, p. 2637-2651, 2004.

ITO, T; HIRAMATSU, K. Acquisition of methicillin resistance and progression of multiantibiotics resistance in methicillin-resistant Staphylococcus aureus. Yonsei Med J. vol.39, p. 526-533. 1998.

JERNIGAN, J. A.; TITUS, M. G.; GROSCHEL, D. H.; GETCHELL-WHITE, S.; FARR, B. M. Effectiveness of contact isolation during a hospital outbreak of methicillinresistant Staphylococcus aureus. Am J Epidemiol. v. 143, n. 5, p. 469-504, 1996.

JOHNSTON, C. P.; STOKES, A. K.; ROSS, T.; CAI, M.; CARROLL, K. C.; COSGROVE, S. E.; PERL, T. M. Staphylococcus aureus colonization among healthcare workers at a tertiary care hospital. Infect Control Hosp Epidemiol. v. 28, n. 12, p. 1404-7, Dec. 2007.

KAATZ, G. W; SEO, S. M.; DORMAN, N. J.; LERNER, S. A. Emergence of teicoplamin resistance during therapy of Staphylococcus aureus endocarditis. J. Infect. Dis. v. 161, p. 103-108, 1990.

KAMINSKI A, KAMMLER J, WICK M, MUHR G, KUTSCHA-LISSBERG F. Transmission of methicillin-resistant $S$. aureus among hospital staff in a German 
trauma centre. A problem without a current solution. J. Bone Joint Surgery $\mathbf{B r}$. England, v. 89, n.5, p.642-645, 2007.

KLEVENS, R. M. et al. Invasive methicillin-resistant Staphylococcus aureus infections in the United States. JAMA. v. 298, n.15, p. 1763-1771, 2007.

KLEVENS, R. M.; EDWARDS, J. R.; TENOVER, F. C.; MCDONALD, L. C.; HORAN, T.; GAYNES, R.; NATIONAL NOSOCOMIAL INFECTIONS SURVEILLANCE SYSTEM. Changes in the epidemiology of methicillin-resistant Staphylococcus aureus in intensive care units in US hospitals, 1992-2003. Clin Infect Dis. v. 42, n.3, p. 389-391, 2006.

KLUYTMANS, A; BELKUN, A.; VERBRUGH, H. N. Carriage of Staphylococcus aureus: epidemiology, underlying mechanisms and associated risks. Clin Microbiol Rev. v.10, n. 3, p. 505-520, 1997.

KONEMAN, E. et al. Diagnóstico microbiológico. 5. ed. Rio de Janeiro: Guanabara Koogan, 2001.

KUEHNERT, M. J.; HILL, H. A.; KUPRONIS, B. A.; TOKARS, J. I.; SOLOMON, S. L.; JERNIGAN, D. B. Methicillin-resistant Staphylococcus aureus-related hospitalizations, United States. Emerg Infect Dis. v. 11, n.6, p. 868-872, 2005.

LANKFORD, M. G.; ZEMBOWER, T. R.; TRICK, W. E.; HACEK, D. M.; NOSKIN, G. A.; PETERSON, L. R. Influence of role models and hospital design on hand hygiene of healthcare workers. Emerg Infect Dis. v. 9, n. 2, p. 217-223, 2003.

LARCOMBE, L. et al. Rapid emergence of methicillinresistant Staphylococcus aureus (MRSA) among children and adolescents in northern Manitoba, 2003- 2006.

Can Commun Dis Rep. Canada, v. 33, n. 2, p. 9-14, 2007.

LESSING, M. P.; JORDENS, J. Z.; BOWLER, I. C. When should healthcare workers be screened for methicillin-resistant Staphylococcus aureus? J Hosp Infect. England, v. 34, n. 3, p. 205-210, nov. 1996.

LEVINE, D. P.; CUSHING, R. D.; JUI, J.; BROWN, W. J. Community-Acquired Methicillin-resistant Staphylococcus aureus endocarditis in the Detroit Medical Center. Ann Intern Med. v. 97, n.3, p. 330-338,1982.

LEVY, C. E.; MONTELLI, A. C.; FURTADO, J. S. et al. Resistência a drogas em cepas bacterianas de pacientes de serviços hospitalares: laboratório de referência do sistema COBA. Rev Microbiol, v. 22, p. 21-27, 1991. 
LIMA, D. C. et al. Snake venom: any clue for antibiotics and cam? Evid Based Complement Alternat Med .England, v. 2, n. 1, p. 39-47, 2005.

LIVERMORE, D. M. Bacterial resistance: origins, epidemiology, and impact. Clin Infect Dis. v. 15, n. 36, p. 11S-23S, 2003.

LOPES, H. V. CA-MRSA: um novo problema para o infectologista. Rev Panam Infectol, v. 7, n. 3, p. 34-6, 2005.

LOWY, F. D. Staphylococcus aureus infections. N. Engl. Med. v. 339, n.8, p. 520532, 1998.

LU, P. L. et al. Risk factors and molecular analysis of community methicillin-resistant staphylococus aureus carriage. Journal of Clinical Microbiology. Taiwan, v. 43, n.1, p. 132-139, 2005.

LUCET, J. C.; CHEVRET, S.; DURAND-ZALESKI, I.; CHASTANG, C.; REGNIER, B.; MULTICENTER STUDY GROUP. Prevalence and risk factors for carriage of methicillin-resistant Staphylococcus aureus at admission to the intensive care unit: results of a multicenter study. Arch Intern Med, v. 163, n. 2, p. 181-188, 2003.

MACHADO, A. et al. Cost-effectiveness of linezolid versus vancomycin in mechanical ventilation-associated nosocomial pneumonia caused by methicillin-resistant Staphylococcus aureus. Braz J Infect Dis. Brazil, v. 9, n. 3, p. 191-200, 2005.

MAMISUKA, E. Projeto de resistência microbiana em serviços de saúde, Staphylococcus. ANVISA, 2005. Disponível em: <http//:www. anvisa. gov. br>. Acesso em: julho de 2006.

MANDELL, D. B. (Eds). Principles and practice of infectious disease. New York: Churchill Livingstone, 2009.

MAPLE, P. A. C.; HAMILTON-MILLER, J. M. T; BRUMFITT, W. World-wide antibiotic resistance in methicillin-resistant Staphylococcus aureus. Lancet. v. 1, n.8639, p. 537-540, 1989.

MATHANRAJ, S.; SUJATHA, S.; SIVASANGEETHA, K.; PARIJA, S. C. Screening for methicillin-resistant Staphylococcus aureus carriers among patients and health care workers of a tertiary care hospital in south India. Indian J Med Microbiol, England, v. 27 , n. 1, p. 62-4, Jan./Mar. 2009. 
MATTHEW, J. et al. Prevalence of Staphylococcus aureus nasal colonization in the United States, 2001-2002. J Infect Dis. v. 193, n.2, p.172-179, 2006.

MATTHEWS, P. R.; REED, K. C.; STEWART, P. R. The cloning of chromossomal DNA associated with methicillin and other resistances in Staphylococcus aureus. J Gen Microbiol. England, v. 133, p. 1919-1929,1987.

MC ELLISTREM, M.; PASS, M.; ELLIOTT, J. A.; WHITNEY, C. G.; HARRISON, L. H. Clonal group of penicillin-nonsusceptible Streptococcus pneumoniae in Baltimore, Maryland: a population-based, molecular epidemiologic study. J Clin Microbiol. v. 38, n.12, p. 4367-72, 2000.

MCMANUS, A. T.; MASON, A. D.; MCMANUS, W. F.; PRUITT, B. A. A decade of reduced gram-negative infections and mortality associated with improved isolation of burned patients. Archives of Surgery. v. 129, n. 12, p. 1306-1309, 1994.

MENEGOTTO, F. R.; PICOLI, S. U. Resistent oxacilin Staphylococcus aureus (MRSA): incidence of cepas acquired in the community (CA-MRSA) and importance of research and descolonization in hospital. RBAC, v. 39, n. 2, p. 147-150. 2007.

MOREIRA, B. M.; DAUM, R. S. Antimicrobial resistance in Staphylococci. Pediat Clins North Am. United States, v. 42, n.3, p. 619-648, 1995.

MOREIRA, E. A. S. et al. Efeito da infecção hospitalar da corrente sanguínea por Staphylococcus aureus resistente à oxacilina sobre a letalidade e o tempo de hospitalização. São Paulo: Universidade Federal de São Paulo, (Serviço de Controle e Prevenção de Infecção Hospitalar e Disciplina de Doenças Infecciosas e Parasitárias) 2007a.

MOREIRA, M. et al. Efficacy of a program of prevention and control for methicillinresistant Staphylococcus aureus infections in an intensive-care unit. Braz J Infect Dis, v. 11, n. 1, p. 57-62, Feb. 2007b.

MOURA, J. P. A adesão dos profissionais de enfermagem às precauções de isolamento na assistência aos portadores de micro-organismos multirresistentes. Ribeirão Preto, 2004. 147p. Dissertação (Mestrado) - Escola de Enfermagem de Ribeirão Preto, Universidade de São Paulo, 2004.

MUTO, C. A. et al. SHEA Guideline for Preventing Nosocomial Transmission of Multidrug-Resistant Strains of Staphylococcus aureus and Enterococcus. Infection Control and Hospital Epidemiology. v. 24, n. 5, p. 362-386, 2003. 
NAKASHIMA, A. $\mathrm{K}$ et al. Epidemic bullous impetigo in a nursery due to a nasal carrier of Staphylococcus aureus: role of epidemiology and control measures. Infect Control. v. 5, n.7, p. 326-331,1984.

NETTO DOS SANTOS, K. R.; FONSECA, L. de S.; GONTIJO FILHO, P.P. Emergence of high-level mupirocin resistance in methicillin-resistant Staphylococcus aureus isolated from Brazilian university hospitals. Infect Control Hosp Epidemiol. v. 17, n. 12, p. 813-6, Dec. 1996.

NILSSON, P.; RIPA, T. A colonização da garganta por Staphylococcus aureus é mais freqüente que a colonização na narina anterior. J. Clin Microbiol. United States, p.3334-3339, Sept. 2006.

NORAZAH A.; KOH Y.T.; GHANI KAMEL A.; ALIAS R.; LIM V.K.E. Mupirocin resistance among Malaysian isolates of methicillin-resistant Staphylococcus aureus. Int J Antimicrob Agents. Netherlands, v. 17, n. 5, p. 411-414, 2001.

NOSKIN, G. A. et al. The burden of Staphylococcus aureus infections on hospitals in the United States. Arch Intern Med. v. 165, n.15, p. 1756-1761, 2005.

OLIVEIRA, D. C.; TOMASZ, A.; LENCASTRE, H. Secrets of sucess of a human pathogen: molecular evolution of pandemic clones of methicillin-resistant Staphylococcus aureus. Lancet Infect. Dis. v. 2, n.3, p.180-189, 2002.

ONLEN, Y. et al. Antibacterial activity of propels against MRSA and synergism with topical mupirocin. J Altern Complement Med. v. 13, n. 7, p. 713-718, Sep. 2007.

ORGANIZAÇÃO MUNDIAL DE SAÚDE (OMS). World health report on infections disease 2000 - Vencendo a resistência microbiana. 2000. Disponível em: <http://www.ccih.med.br/vencendoresistencia.html>. Acesso em: 31 jan. 2003.

ORRETT, F. A. The emergence of mupirocin resistance among clinical isolates of methicillin-resistant Staphylococcus aureus in Trinidad: a first report. J Infect Dis v. 61, n. 2, p. 107-110, Mar. 2008.

PALOS, M. A. P. Staphylococcus aureus e Staphylococcus resistente (MRSA) em profissionais de saúde e as interfaces com as infecções nosocomiais. Ribeirão Preto, 2006. Tese (Doutorado) - Escola de Enfermagem, Universidade de São Paulo, 2006.

PANG, K. MRSA: a growing global problem. Lancet. v.374, july 3, 2009. 
PATEL, M.; WEINHEIMER, J.D., WAITES, K.B.; BADDLEY, J.W. Active surveillance to determine the impact of methicillin-resistant Staphylococcus aureus colonization on patients in intensive care units of a Veterans Affairs Medical Center. Infect Control Hosp Epidemiol. v.29, n.6, p. 503-9. 2008.

PITTET, D. et al. Effectiveness of a hospital-wide programme to improve compliance with hand hygiene. Lancet. v. 356, n. 9238, p. 1307-1312, 2000.

PITTET, D.; MOUROUGA, P.; PERNEGER, T. V. Compliance with handwashing in a teaching hospital. Infection Control Program. Ann Intern Med. v. 130, n. 2, p. 126130, 1999.

POOLE, T.L; GENOVESE, K.J; CALLAWAY, T.R; BISCHOFF, K.M; DONSKEY, C.J; NISBET, D.J. Competitive exclusion of a glycopeptide-resistant Enterococcus faecium in the presence of vancomycin but not equivalent concentrations of tylosin or gentamicin. Poult Sci. v. 83, n. 7, p. 1099-1105, Jul. 2004

RAMMELKAMP, C. H.O.; MAXON, T. Resistance of Staphylococcus aureus to the action of penicillin. Proc Royal Soc Exper Biol Med, v. 51, p. 386-389, 1942.

RIBEIRO, J. et al. Prevalence of methicillin-resistant Staphylococcus aureus (MRSA) among patients visiting the emergency room at a tertiary hospital in Brazil. Braz $\mathbf{J}$ Infect Dis. Brazil, v. 9, n. 1, p. 52-5, 2005.

ROBERTS, M. C.; SUTCLIFFE, J.; COURVALIN, P.; JENSEN, L. B.; ROOD, J.; SEPPALA, H. Nomenclature for macrolide and macrolide-lincosamide-streptogramin B resistance determinants. Antin Ag Chem, v. 43, p. 2823-2830, 1999.

ROBICSEK, A.; BEAUMONT, J. L.; PAULE, S. M.; HACEK, D. M.; THOMSON JR, R. B.; KAUL, K. L.; KING, P.; PETERSON, L. R. Universal surveillance for methicillinresistant Staphylococcus aureus in 3 affiliated hospitals. Ann Intern Med. v. 148, n. 6, p. 409-418, 2008.

RODRIGUES, C. A.; VESGA, O. Staphylococcus aureus resistente à vancomicina. Biomédica. Brasil, v. 25, p. 575-587, 2005.

RODRIGUES, E. A. C. et al. Infecções hospitalares: prevenção e controle. São Paulo: Sarvier, 1997. p. 573-591.

RODRIGUES, J. L. N. Surto de bacteremia nosocomial por Staphylococcus aureus resistente à oxacilina em uma unidade de terapia intensiva: aspectos epidemiológicos em microbiológicos. Tese (Doutorado) - Escola Paulista de Medicina, Universidade de São Paulo, São Paulo, 1991. 
SALGADO, M. M.; PIGNATARI, A. C. C.; BELLINATI-PIRES, R. Phagocytosis and killing of epidemic methicillin-resistant Staphylococcus aureus by human neutrophils and monocytes. Braz J Infec Dis. Brazil, v. 8, n.1, p. 80-89, 2004.

SANTOS, A. I. et al. Staphylococcus aureus: visitando uma cepa de importância hospitalar. J Bras Patol Med Lab. Brazil, v. 43, n. 6, p. 413-423, dez. 2007.

SANTOS, B. M. de O. Prevalência de portadores säos de Staphylococus aureus em pessoal de diferentes categorias de enfermagem de um hospital geral escola. Dissertação (Mestrado) - Escola de Enfermagem de Ribeirão Preto, Universidade de Säo Paulo, Ribeirão Preto, 1987.

SARAVOLATZ, L. D.; MARKOWITZ, N.; ARKING, L.; POHLOD, D.; FISHER, E. Methicillin-resistant Staphylococcus aureus: epidemiologic observations during a community-acquired outbreak. Ann Intern Med. v. 96, n.1, p. 11-6, 1982.

SCHMITZ, F. J. The prevalence of low- and high-level mupirocin resistance in staphylococci from 19 European hospitals. J Antimicrob Chemother. England, v. 42, n. 4, p. 489-95, Oct. 1998.

SCHULMAN, G., DASSEY, D., MASCOLA, L. Community-acquired methicillinresistant Staphylococcus aureus. JAMA., v.280 p. 421-422. 2004.

SEFTON, A. M. Mechanisms of antimicrobial resistance: their clinical relevance in the new millenium. Drugs New Zealand, v. 62, n.4, p. 557-566, 2002.

SESSO, R.; BARBOSA, D.; LEME, I.; SADER, H.; CANZIANI, M. E.; MANFREDI, S. et al. Staphylococcus aureus prophylaxis in hemodialysis patients using central venous catheter: effect of mupirocin ointment. J Am Soc Nephrol. v. 9, p. 10851092, jun 1998.

SHEAGREN, J. N. Staphylococcus aureus: The persistent pathogen (second of two parts). N. Engl.J. Med. v. 310, n.22, p.1437-1442,1984.

SHERETZ, R. J; REAGAN, D. R; HAMPTON, K. D. A cloud adult: the Staphylococcus aureus - virus interaction revisited. Ann Intern Med. v. 124, p. 539547, 1996.

SIERADZKI, K.; ROBERTS, R.B.; HABER, S.W.; TOMASZ, A. The development of vancomycin resistance in a patient with methicillin-resistant Staphylococcus aureus infection. N. Engl. J. Med. v. 340, n.7, p. 517-23, 1999. 
SIMOR, A. E. et al. Canadian Nosocomial Infection Surveillance Program. Mupirocinresistant, methicillin-resistant Staphylococcus aureus strains in Canadian hospitals.

Antimicrob Agents Chemother, v. 51, n. 11, p. 3880-6, Nov. 2007.

SMITH, T. L. et al. For the glycopeptide-intermediate Staphylococcus aureus Working Group: emergence of vancomycin resistance in Staphylococcus aureus. N Engl J Med. v. 340, n.7, p. 493-501, 1999.

SMITH, A.J. et al. Staphylococcus aureus in the patients in a regional burns unit. $\mathbf{J}$ Hosp Infect, London, v.55, n.3, p.184-189, nov. 2003.

SOUSA, M. A.; MIRAGAIA, M.; SANCHES, I. S.; ÁVILA, S.; ADAMSON, I.; ASAGRANDE, $S$. $T$. et al. Three-year assessment of methicillin-resistant Staphylococcus aureus clones in Latin America from 1996 to 1998. J Clin Microbiol. v. 39, n.6, p. 2197-205, 2001.

SOUZA, L. B. G.; FIGUEIREDO, B. B. Prevalência de infecções nosocomiais provocadas por Staphylococcus aureus resistente à meticilina (M. R. S. A) no Hospital Universitário Regional de Maringá. Rev. bras. Anal.clin, Brasil, v.40, n.1, p. 31-34, 2008.

SRINIVASAN, A.; DICK, J. D.; PERL, T. M. Vancomycine resistence in staphylococci. Clin Microbiol Rev. v. 15, n. 3, p. 430-8, 2002.

STARLING, C. E. F.; SILVA, E. U. (Coords.). Controle de Infecções Hospitalares: isolamento, precauções e controle de bactérias multirresistentes. Belo Horizonte: IEA, 1998.

SUFFOLETTO, B.P; CANNON, E.H; ILKHANIPOUR, K; YEALY, D.M. Prevalence of S. aureus nasal colonization in Emergence Department Personnel. Ann Emerg Med. 2008; v. 52, n.5, p. 529-33, Apr. 2008.

SULLIVAN, A.; EDLUND, C.; NORD, C. E. Effect of antimicrobial agents on the ecological balance of human microflora. Lancet Infect Dis, v. 1, n.2, p. 101-114, 2001.

TAVARES, W. Bactérias gram-positivas problemas: resistência do estafilococo, do enterococo e do pneumococo aos antimicrobianos. Rev Soc Bras Med Trop, Brasil, v. 33, n.3, p. $281-301,2000$.

TAVARES, W. Manual de antibióticos e quimioterápicos antiinfecciosos. Rio de Janeiro: Atheneu, 1999. 
TAVARES, W. Manual de antibióticos e quimioterápicos antiinfecciosos. Rio de Janeiro: Atheneu, 2002.

TEIXEIRA, L. A.; RESENDE, C. A.; ORMONDE, L. R.; ROSENBAUM, R.; FIGUEIREDO, A. M. S. et al. Geographic spread of epidemic multiresistant Staphylococcus aureus clone in Brazil. J Clin Microbiol. v. 33, n.9, p. 2400-2404. 1995.

TENOVER, F. C.; MCDONALD, L. C. Vancomycin-resistent staphylococci and enterococci: epidemiology and control. Curr Opin Infect Dis. n. 18, p. 300-305, 2005.

TIWARI, H. K.; SEN, M. R. Emergence of vancomycin resistant Staphylococcus aureus (VRSA) from a tertiary care hospital from northern part of India. BMC Infect Dis. England, v. 6, n. 156, 2006.

TRABULSI, L. R.; ALTHERTHUM, F. Microbiologia: Staphylococcus aureus. São Paulo: Atheneu, 2005.

TRAUTMANN, M.; STECHER, J.; HEMMER, W.; LUZ, K.; PANKNIN, H. T. Intranasal mupirocin prophylaxis in elective surgery: a review of published studies. Chemotherapy. Switzerland, v. 54, n. 1, p. 9-16, 2008.

TREAKLE, A. M.; THOM, K. A.; FURUNO, J. P.; STRAUSS, S. M.; HARRIS, A. D.; PERENCEVICH, E. N. Bacterial contamination of health care workers' white coats. Am J Infect Control. v. 37, n. 2, p.101-105, Mar. 2009.

UDO, E. E.; JACOB, L. E.; MATHEW, B. The spread of a mupirocinresistant/methicillin-resistant Staphylococcus aureus clone in Kuwait hospitals. Acta Trop. Netherlands, v. 80, n. 2, p. 155-61, Oct. 2001a

UDO, E. E.; JACOB, L. E.; MATHEW, B. Genetic analysis of methicillin-resistant Staphylococcus aureus expressing high- and low-level mupirocin resistance. J Med Microbiol. England, v. 50, n. 10, p. 909-15, Oct. 2001b.

UNEMURA, Y.; ISHIDA, Y.; SUZUKI, Y.; YANAGA, K. Impact of prophylactic mupirocin for radical esophagectomy. J Infect Chemother. Japan, v. 12, n. 5, p. 257-263, Oct. 2006.

VAN RIJEN, M.; BONTEN, M.; WENZEL, R.; KLUYTMANS, J. Mupirocin ointment for preventing Staphylococcus aureus infections in nasal carriers. Cochrane Database of Systematic Reviews. In: The Cochrane Library, n. 3, Art. No. CD006216. DOI: 10.1002/14651858.CD006216.pub4. 2009. 
VELÁQUEZ, J. et al. Vigilancia de la resistencia de Staphylococcus aureus a la oxacilina-vancomicina y patrones de corresistencia. Rev Per Soc Med Intern, v. 15, n. 4, p.184-189, 2002.

VELÁZQUEZ-MEZA, M. E. Staphylococcus aureus methicillin-resistant: emergence and dissemination. Salud Pública de México. México, v. 47, p. 381-7, 2005.

VOSS, A. Preventing the spread of MRSA. Common sense and observational studies are of benefit. BMJ. England, v. 329, 2004.

WANG, J. T. et al. A hospital-acquired outbreak of methicillin-resistant Staphylococcus aureus infection initiated by a surgeon carrier. J Hosp Infect. England, v. 47, p. 104-109, 2001.

WATANABE, H.; MASAKI, H.; ASOH, N.; WATANABE, K.; OISHI, K.; KOBAYASHI, $S$. et al. Low concentrations of mupirocin in the pharynx following intranasal application may contribute to mupirocin resistance in methicillin-resistant Staphylococcus aureus. J Clin Microbiol. v. 39, n. 10, p. 375-377, Oct. 2001.

WEISS, R. D. N.; FAGUNDES, C. B.; MEZZOMO, N. Prevalência e suscetibilidade de "Staphylococcus aureus" colonizadores de fossas nasais da equipe de enfermagem do Hospital Universitário de Santa Maria, RS. In: CONGRESSO BRASILEIRO DE CONTROLE DE INFECÇÃO E EPIDEMIOLOGIA HOSPITALAR, 8., 2002, Curitiba. Anais. Curitiba: ABIH, 2002. p. 246.

WERTHEIM, H.F.L.; MELLES, D.C.; VOS, M.C.; LEEUWEN, W.V. BELKUM, A.V.; VERBRUGH, H.A.; NOUWEN, J. The role of nasal carriage in Staphylococcus aureus infections. Lancet Infectious Diseases. v.5, n.12, p.751 - 762, December 2005a doi:10.1016/S1473-3099(05)70295-4

WERTHEIM, H. F; VOS, M. C. Can mupirocin prevent methicillin-resistant Staphylococcus aureus infections? Crit Care. England, v.9, n.3, p.257-8, May 2005b.

WESTERGREN, G.; KRASSE, B. Evaluation of a micromethod for determination Streptococcus mutans and Lactobacillus infection. J Clin Microbiol. v. 7, n.1, p. 82-83, 1978.

WESTPHAL, $K$. et al. Incidence and risk factors of methicillin-resistant Staphylococcus aureus colonization in an intensive care unit. Infection. Germany, v. 25, n. 5, p. 323, 1997.

WISE, R. I.; OSSMAN, E. A.; LITTLEFIELD, D. R. Personal reflections on nosocomial staphylococcal infections and the development of hospital surveillance. Rev. Infec. Dis. v. 11, n.6, p. 1005-1019, 1989. 


\section{APÊNDICES}

\section{APÊNDICE A - TERMO DE CONSENTIMENTO LIVRE E ESCLARECIDO}

Eu, Josely Pinto de Moura, enfermeira, aluna da Escola de Enfermagem de Ribeirão Preto da Universidade de São Paulo, estou realizando uma pesquisa sobre Staphylococcus aureus meticilina resistentes em profissionais de saúde e as interfaces com as infecções nosocomiais deste hospital, para elaboração da minha tese de doutorado.

Esta pesquisa se propõe a verificar a colonização da orofaringe da equipe de enfermagem deste hospital por Staphylococcus aureus meticilina resistentes, para estabelecer critérios que possam minimizar o risco dessa colonização e evitar a propagação dessa bactéria no hospital.

Para tanto preciso que você responda um questionário e forneça cerca de $3 \mathrm{ml}$ de saliva em um tubo, a qual será analisada em laboratório credenciado. A coleta se repetirá 03 vezes, sendo a primeira no mês de fevereiro, a segunda em abril e a terceira em junho.

Coloco-me à disposição para esclarecer qualquer dúvida sobre o assunto e asseguro que terá acesso aos resultados da pesquisa, assim que for concluída.

Sua participação será espontânea. As informações obtidas serão tratadas de forma anônima e sigilosa. Você poderá cancelar a sua participação no estudo em qualquer momento e não sofrerá nenhum tipo de sanção ou prejuízo.

Os resultados desta pesquisa serão informados à $\mathrm{CClH}$ do hospital em estudo para que sejam tomadas as medidas, caso se faça necessárias, após avaliação da mesma.

De acordo com a resolução do CONEP n.196/96, que dispõe sobre pesquisa com seres humanos, minha assinatura revela que concordo em participar da pesquisa citada acima.

Assinatura do sujeito da pesquisa

RG:

Ribeirão Preto, de de 2007.

\footnotetext{
Assinatura da pesquisadora Josely Pinto de Moura Telefone: 602.4408
} 
Perfil de sensibilidade aos antimicrobianos de isolados das três amostras da saliva de trabalhadores da saúde em hospital público estadual, 2008

\begin{tabular}{|c|c|c|c|c|c|c|c|c|c|c|c|c|c|}
\hline nosuj & Oxa & Peni & Cefo & Erit & Clin & Tetra & Rifa & Cipr & Gent & Sulf & Vanc & Line & Mup \\
\hline $4 a$ & $S$ & $\mathrm{R}$ & $S$ & 1 & $S$ & $S$ & $\mathrm{~s}$ & $S$ & $S$ & $S$ & $S$ & $S$ & $\mathrm{~s}$ \\
\hline $6 a$ & $S$ & $\mathrm{R}$ & $S$ & $S$ & $S$ & $S$ & $S$ & $S$ & $S$ & $S$ & $S$ & $S$ & $\mathrm{~s}$ \\
\hline $8 a$ & $S$ & $\mathrm{R}$ & $S$ & $\mathrm{R}$ & $S$ & $S$ & $S$ & $S$ & $S$ & $S$ & $S$ & $S$ & $S$ \\
\hline $10 a$ & $S$ & $\mathrm{R}$ & $\mathrm{R}$ & $S$ & $\mathrm{R}$ & $S$ & $\mathrm{R}$ & $S$ & $R$ & S & $S$ & $R$ & $\mathrm{R}$ \\
\hline $12 a$ & $S$ & $R$ & $S$ & $S$ & $S$ & $S$ & $S$ & $S$ & $S$ & S & $S$ & $S$ & s \\
\hline $13 a$ & $S$ & $S$ & S & S & $S$ & $S$ & $S$ & $S$ & $S$ & S & $S$ & $S$ & S \\
\hline $14 a$ & $\mathrm{R}$ & $\mathrm{R}$ & $\mathrm{R}$ & $S$ & $\mathrm{R}$ & $\mathrm{R}$ & 1 & $S$ & $R$ & S & $S$ & $S$ & $\mathrm{R}$ \\
\hline $15 a$ & $\mathrm{R}$ & $\mathrm{R}$ & $\mathrm{R}$ & $S$ & $\mathrm{R}$ & $S$ & $\mathrm{R}$ & $S$ & 1 & $S$ & $S$ & $S$ & $\mathrm{R}$ \\
\hline $25 a$ & $\mathrm{R}$ & $R$ & $R$ & S & $\mathrm{R}$ & $\mathrm{R}$ & 1 & $\mathrm{~S}$ & $\mathrm{R}$ & S & $S$ & $S$ & $\mathrm{R}$ \\
\hline $26 a$ & $S$ & $R$ & S & $\mathrm{R}$ & $S$ & $\mathrm{R}$ & $R$ & $S$ & $S$ & $\mathrm{~s}$ & $S$ & $S$ & $S$ \\
\hline $34 a$ & $\mathrm{R}$ & $\mathrm{R}$ & $\mathrm{s}$ & S & $S$ & $S$ & $\mathrm{~S}$ & $\mathrm{~S}$ & $S$ & $\mathrm{~s}$ & $\mathrm{~S}$ & $\mathrm{~s}$ & $\mathrm{~s}$ \\
\hline $35 a$ & $S$ & $R$ & $S$ & 1 & $S$ & $S$ & $S$ & $S$ & $S$ & $\mathrm{~s}$ & $S$ & $S$ & $S$ \\
\hline $36 a$ & NR & NR & NR & NR & NR & NR & $\mathrm{NR}$ & NR & NR & NR & NR & NR & NR \\
\hline $38 a$ & $S$ & $R$ & S & $\mathrm{R}$ & $R$ & $S$ & $S$ & $S$ & $R$ & 1 & $S$ & $S$ & $\mathrm{~s}$ \\
\hline $39 a$ & $\mathrm{R}$ & $R$ & $\mathrm{R}$ & $\mathrm{R}$ & $\mathrm{R}$ & $S$ & $S$ & $S$ & $R$ & S & $S$ & S & $\mathrm{R}$ \\
\hline $44 a$ & $S$ & $R$ & $\mathrm{R}$ & $\mathrm{R}$ & $S$ & $S$ & $S$ & $S$ & $\mathrm{~S}$ & $S$ & $S$ & $S$ & $\mathrm{~s}$ \\
\hline $49 a$ & $S$ & $\mathrm{R}$ & $\mathrm{s}$ & 1 & $S$ & $S$ & $S$ & $S$ & $S$ & $S$ & $S$ & $S$ & $S$ \\
\hline $51 a$ & $S$ & $R$ & $S$ & $S$ & $S$ & $S$ & $S$ & $S$ & $S$ & $S$ & $S$ & $S$ & $S$ \\
\hline $55 a$ & $S$ & $\mathrm{R}$ & $S$ & $S$ & $S$ & $S$ & $S$ & $S$ & $S$ & $\mathrm{~s}$ & $S$ & $S$ & $\mathrm{~S}$ \\
\hline $56 a$ & $S$ & $\mathrm{R}$ & $S$ & $\mathrm{R}$ & $S$ & $S$ & $S$ & $S$ & $S$ & $S$ & $S$ & $S$ & $S$ \\
\hline 61a & $S$ & $\mathrm{R}$ & $S$ & $S$ & $S$ & $S$ & $S$ & $S$ & $S$ & $S$ & $S$ & $S$ & $S$ \\
\hline $62 a$ & $\mathrm{R}$ & $\mathrm{R}$ & $S$ & $\mathrm{R}$ & $\mathrm{R}$ & $S$ & $S$ & $S$ & $\mathrm{R}$ & $S$ & $S$ & $S$ & $S$ \\
\hline $68 a$ & $S$ & $\mathrm{R}$ & $S$ & 1 & $S$ & $S$ & $S$ & $S$ & $S$ & $S$ & $S$ & $S$ & $S$ \\
\hline $74 a$ & $S$ & $\mathrm{R}$ & $S$ & $\mathrm{R}$ & $S$ & $S$ & $S$ & $S$ & $S$ & $S$ & $S$ & $S$ & $S$ \\
\hline $78 a$ & $S$ & $\mathrm{R}$ & $S$ & $\mathrm{R}$ & S & $S$ & $S$ & $S$ & $S$ & $S$ & S & $S$ & S \\
\hline $79 a$ & $\mathrm{R}$ & $\mathrm{R}$ & $\mathrm{s}$ & $\mathrm{R}$ & $\mathrm{R}$ & $R$ & 1 & $\mathrm{R}$ & $R$ & $\mathrm{R}$ & $S$ & $S$ & $\mathrm{R}$ \\
\hline $85 a$ & $\mathrm{~S}$ & $R$ & $S$ & $R$ & $\mathrm{~S}$ & $S$ & $S$ & $S$ & $S$ & $S$ & $\mathrm{~S}$ & $S$ & $\mathrm{~S}$ \\
\hline $90 a$ & $S$ & $\mathrm{R}$ & $\mathrm{S}$ & $S$ & $S$ & $\mathrm{~S}$ & $S$ & $S$ & $S$ & $S$ & $S$ & $\mathrm{~S}$ & $\mathrm{~s}$ \\
\hline $91 a$ & $S$ & $R$ & $S$ & $S$ & $S$ & $S$ & $S$ & $S$ & $S$ & $S$ & $S$ & $S$ & $S$ \\
\hline $94 a$ & $S$ & $R$ & $\mathrm{R}$ & $S$ & $S$ & 1 & $S$ & $R$ & $S$ & $S$ & $S$ & 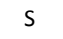 & $S$ \\
\hline $97 a$ & $S$ & $S$ & $S$ & $S$ & $S$ & $S$ & $S$ & $S$ & $S$ & $S$ & $S$ & $S$ & $\mathrm{~s}$ \\
\hline $100 a$ & $S$ & $R$ & $\mathrm{~s}$ & $\mathrm{~s}$ & $S$ & $\mathrm{~s}$ & $S$ & $S$ & $S$ & $\mathrm{~s}$ & $S$ & $\mathrm{~s}$ & $\mathrm{~s}$ \\
\hline 101a & $\mathrm{R}$ & $\mathrm{R}$ & $\mathrm{R}$ & $S$ & $\mathrm{R}$ & 1 & $\mathrm{R}$ & $S$ & $\mathrm{R}$ & $\mathrm{s}$ & $\mathrm{s}$ & $S$ & $\mathrm{R}$ \\
\hline $104 a$ & $S$ & $R$ & $\mathrm{~s}$ & 1 & $\mathrm{~S}$ & $\mathrm{~S}$ & $S$ & $\mathrm{~S}$ & $\mathrm{~S}$ & $\mathrm{~S}$ & $\mathrm{~S}$ & $\mathrm{~S}$ & $\mathrm{~s}$ \\
\hline $106 a$ & $S$ & $S$ & $\mathrm{~s}$ & 1 & $S$ & $\mathrm{~s}$ & $S$ & $S$ & $\mathrm{R}$ & $S$ & $\mathrm{~s}$ & $\mathrm{~s}$ & $\mathrm{~s}$ \\
\hline 120a & $R$ & $R$ & $\mathrm{R}$ & $\mathrm{s}$ & $S$ & $\mathrm{~s}$ & $\mathrm{R}$ & $S$ & $\mathrm{~s}$ & $\mathrm{R}$ & $S$ & $\mathrm{~s}$ & $\mathrm{~s}$ \\
\hline $122 a$ & $S$ & $S$ & $S$ & $S$ & $S$ & $S$ & $S$ & $S$ & $S$ & $\mathrm{~s}$ & $S$ & $S$ & $\mathrm{~s}$ \\
\hline $128 a$ & $S$ & $S$ & $S$ & 1 & $\mathrm{~S}$ & $\mathrm{~S}$ & $S$ & $S$ & $S$ & $\mathrm{~s}$ & $\mathrm{~S}$ & $S$ & $\mathrm{~s}$ \\
\hline $135 a$ & $S$ & $\mathrm{R}$ & $\mathrm{S}$ & $\mathrm{S}$ & $S$ & $\mathrm{~S}$ & $S$ & $S$ & $S$ & $\mathrm{~S}$ & $S$ & $\mathrm{~S}$ & $\mathrm{R}$ \\
\hline $136 a$ & NR & NR & NR & $\mathrm{NR}$ & $\mathrm{NR}$ & NR & $\mathrm{NR}$ & $\mathrm{NR}$ & $N R$ & NR & NR & $\mathrm{NR}$ & NR \\
\hline 140a & $R$ & $R$ & $\mathrm{R}$ & $\mathrm{s}$ & $\mathrm{S}$ & $\mathrm{S}$ & $S$ & $\mathrm{~S}$ & $S$ & $\mathrm{~s}$ & $\mathrm{~S}$ & $S$ & $\mathrm{~s}$ \\
\hline $141 a$ & $S$ & $\mathrm{R}$ & $S$ & $S$ & S & $S$ & $S$ & $S$ & $S$ & S & S & $S$ & $S$ \\
\hline $143 a$ & $S$ & $R$ & $S$ & $R$ & $R$ & $S$ & $R$ & $S$ & $\mathrm{R}$ & $S$ & $S$ & $S$ & $S$ \\
\hline
\end{tabular}




\begin{tabular}{|c|c|c|c|c|c|c|c|c|c|c|c|c|c|}
\hline $144 a$ & $\mathrm{~S}$ & $\mathrm{R}$ & $S$ & $\mathrm{~s}$ & $S$ & $\mathrm{~S}$ & $\mathrm{~s}$ & $\mathrm{~s}$ & $\mathrm{~S}$ & $\mathrm{~s}$ & $S$ & $S$ & $\mathrm{~s}$ \\
\hline $148 \mathrm{a}$ & $S$ & $\mathrm{R}$ & $S$ & s & $S$ & $S$ & $S$ & $S$ & S & $S$ & $S$ & S & s \\
\hline $154 a$ & $S$ & $\mathrm{R}$ & $S$ & $\mathrm{~s}$ & $S$ & $\mathrm{~S}$ & $\mathrm{~s}$ & $\mathrm{~s}$ & $\mathrm{~S}$ & $\mathrm{~s}$ & $S$ & $S$ & $\mathrm{~s}$ \\
\hline $168 \mathrm{a}$ & $S$ & $\mathrm{~s}$ & $S$ & $\mathrm{R}$ & $\mathrm{R}$ & S & $S$ & $S$ & $S$ & $S$ & $S$ & $\mathrm{~S}$ & $\mathrm{R}$ \\
\hline 170a & $S$ & $R$ & $S$ & 1 & $S$ & 1 & $S$ & $S$ & $\mathrm{R}$ & $S$ & $S$ & $\mathrm{~S}$ & $S$ \\
\hline $173 a$ & $\mathrm{~S}$ & $\mathrm{R}$ & $S$ & $s$ & $S$ & $\mathrm{~S}$ & $\mathrm{~s}$ & $\mathrm{~s}$ & $\mathrm{R}$ & $\mathrm{s}$ & $\mathrm{s}$ & $\mathrm{s}$ & $S$ \\
\hline $176 a$ & NR & NR & $\mathrm{NR}$ & NR & NR & NR & NR & NR & NR & NR & NR & NR & NR \\
\hline $177 a$ & NR & NR & NR & NR & NR & NR & NR & NR & NR & NR & NR & NR & NR \\
\hline 179a & S & $\mathrm{R}$ & S & s & $S$ & S & S & $S$ & $S$ & s & $\mathrm{s}$ & $S$ & s \\
\hline 180a & $\mathrm{S}$ & $\mathrm{R}$ & $S$ & $\mathrm{~s}$ & $\mathrm{~S}$ & $S$ & $S$ & $S$ & $S$ & $S$ & $S$ & $S$ & $\mathrm{~s}$ \\
\hline $185 a$ & $\mathrm{R}$ & $\mathrm{R}$ & $\mathrm{R}$ & $\mathrm{R}$ & $\mathrm{R}$ & $R$ & $S$ & $S$ & $R$ & $S$ & $S$ & $S$ & $\mathrm{R}$ \\
\hline $192 a$ & $\mathrm{R}$ & $\mathrm{R}$ & $\mathrm{R}$ & $\mathrm{R}$ & $\mathrm{R}$ & $\mathrm{R}$ & 1 & $\mathrm{~s}$ & $\mathrm{R}$ & $\mathrm{S}$ & $\mathrm{s}$ & $S$ & $\mathrm{R}$ \\
\hline $195 a$ & $\mathrm{R}$ & $\mathrm{R}$ & $\mathrm{R}$ & 1 & $\mathrm{R}$ & $\mathrm{S}$ & $\mathrm{R}$ & $S$ & $\mathrm{R}$ & $S$ & $\mathrm{~s}$ & $S$ & $\mathrm{R}$ \\
\hline $196 a$ & S & $\mathrm{R}$ & S & S & $S$ & S & $S$ & S & S & S & S & S & s \\
\hline $198 \mathrm{a}$ & $\mathrm{R}$ & $\mathrm{R}$ & $\mathrm{R}$ & 1 & $\mathrm{R}$ & $\mathrm{S}$ & $\mathrm{R}$ & $S$ & $\mathrm{R}$ & $S$ & $\mathrm{~s}$ & $S$ & $\mathrm{R}$ \\
\hline 199a & $S$ & $R$ & $S$ & $\mathrm{~s}$ & $S$ & $S$ & $S$ & $S$ & $S$ & $S$ & $S$ & $S$ & $\mathrm{R}$ \\
\hline $200 a$ & $S$ & $\mathrm{R}$ & $\mathrm{R}$ & s & $S$ & $S$ & $S$ & $\mathrm{~S}$ & $S$ & $S$ & $S$ & $S$ & $\mathrm{R}$ \\
\hline $203 a$ & $S$ & $\mathrm{R}$ & $S$ & s & $S$ & $\mathrm{~S}$ & 1 & $S$ & $\mathrm{~S}$ & $S$ & $\mathrm{~s}$ & $S$ & $\mathrm{~s}$ \\
\hline $205 a$ & $S$ & $\mathrm{R}$ & S & s & $S$ & S & $S$ & S & S & $S$ & $S$ & S & s \\
\hline 209a & $S$ & $\mathrm{R}$ & S & S & $S$ & S & $S$ & S & S & S & S & S & S \\
\hline $212 a$ & $S$ & $S$ & S & 1 & S & S & $S$ & S & S & $\mathrm{S}$ & $\mathrm{S}$ & S & $\mathrm{s}$ \\
\hline 221a & $S$ & $\mathrm{R}$ & $S$ & $\mathrm{~s}$ & $S$ & $S$ & $S$ & $\mathrm{~S}$ & $S$ & $S$ & $S$ & $S$ & $\mathrm{~s}$ \\
\hline $228 a$ & $S$ & $\mathrm{R}$ & $S$ & $\mathrm{R}$ & $\mathrm{S}$ & $S$ & S & S & S & $\mathrm{R}$ & $S$ & $S$ & s \\
\hline $234 a$ & S & $\mathrm{R}$ & $\mathrm{R}$ & $\mathrm{R}$ & $\mathrm{R}$ & S & $\mathrm{s}$ & S & S & S & $S$ & S & $\mathrm{R}$ \\
\hline $238 \mathrm{a}$ & $\mathrm{R}$ & $\mathrm{R}$ & $\mathrm{R}$ & 1 & $\mathrm{R}$ & S & S & S & $R$ & S & $S$ & S & $\mathrm{R}$ \\
\hline $240 a$ & $\mathrm{~s}$ & $\mathrm{R}$ & S & 1 & S & S & s & S & S & $\mathrm{s}$ & S & S & $\mathrm{R}$ \\
\hline $254 a$ & $\mathrm{R}$ & $\mathrm{R}$ & $\mathrm{R}$ & 1 & $\mathrm{R}$ & $\mathrm{R}$ & $\mathrm{R}$ & $S$ & $S$ & 1 & $S$ & $S$ & $\mathrm{R}$ \\
\hline $258 a$ & $R$ & $\mathrm{R}$ & $S$ & $R$ & $\mathrm{R}$ & $S$ & $S$ & $\mathrm{~S}$ & $R$ & $S$ & $S$ & $S$ & $\mathrm{R}$ \\
\hline $259 a$ & $S$ & $\mathrm{R}$ & $S$ & S & $S$ & $S$ & S & $S$ & $S$ & $S$ & $S$ & S & S \\
\hline $261 a$ & $S$ & $\mathrm{R}$ & $S$ & $S$ & $S$ & $\mathrm{~S}$ & $S$ & S & $\mathrm{S}$ & $S$ & $S$ & $S$ & $\mathrm{~s}$ \\
\hline $263 a$ & S & S & S & S & $S$ & S & S & S & S & $\mathrm{S}$ & $S$ & S & S \\
\hline $265 a$ & $S$ & $\mathrm{R}$ & $S$ & $S$ & $\mathrm{~S}$ & $S$ & $S$ & $\mathrm{~s}$ & $S$ & $S$ & $S$ & $S$ & $\mathrm{~s}$ \\
\hline $268 \mathrm{a}$ & $\mathrm{R}$ & $\mathrm{R}$ & $R$ & $S$ & 1 & $R$ & $S$ & $S$ & $S$ & $S$ & $S$ & $S$ & $\mathrm{~s}$ \\
\hline 281a & S & $\mathrm{R}$ & S & 1 & $\mathrm{R}$ & 1 & S & S & S & S & $S$ & $S$ & $\mathrm{R}$ \\
\hline $287 a$ & 1 & $\mathrm{R}$ & $S$ & $S$ & $\mathrm{R}$ & $S$ & $\mathrm{R}$ & $S$ & $S$ & $S$ & $S$ & $\mathrm{R}$ & $\mathrm{R}$ \\
\hline $294 a$ & $\mathrm{~s}$ & $\mathrm{R}$ & S & 1 & $\mathrm{~S}$ & S & S & S & S & $\mathrm{R}$ & S & S & S \\
\hline $297 a$ & NR & NR & $\mathrm{NR}$ & NR & NR & NR & NR & NR & NR & NR & NR & NR & NR \\
\hline $1 b$ & $\mathrm{R}$ & S & $\mathrm{R}$ & S & $\mathrm{S}$ & S & $\mathrm{R}$ & S & S & S & $\mathrm{S}$ & S & $\mathrm{R}$ \\
\hline $2 b$ & $S$ & $\mathrm{R}$ & $R$ & 1 & $S$ & $S$ & $\mathrm{R}$ & $S$ & $S$ & $\mathrm{R}$ & $S$ & $\mathrm{R}$ & s \\
\hline $6 b$ & S & $\mathrm{R}$ & $S$ & S & $S$ & $S$ & $S$ & $S$ & S & $S$ & $S$ & $\mathrm{~S}$ & s \\
\hline $9 b$ & $\mathrm{R}$ & $\mathrm{R}$ & S & S & $\mathrm{S}$ & S & S & S & S & S & S & S & S \\
\hline $12 b$ & $\mathrm{~S}$ & $\mathrm{R}$ & S & S & $S$ & S & S & S & S & S & $S$ & S & S \\
\hline $30 \mathrm{~b}$ & NR & NR & $\mathrm{NR}$ & NR & NR & NR & NR & NR & NR & NR & NR & NR & NR \\
\hline $32 b$ & $S$ & $S$ & $S$ & $S$ & 1 & $S$ & $\mathrm{~s}$ & $S$ & S & $S$ & $S$ & $S$ & $\mathrm{~s}$ \\
\hline $33 b$ & S & S & S & S & $S$ & S & S & $S$ & S & S & $S$ & S & s \\
\hline $34 b$ & $S$ & $S$ & $S$ & $S$ & $S$ & $S$ & $S$ & $S$ & $S$ & $S$ & $S$ & $S$ & $\mathrm{~s}$ \\
\hline
\end{tabular}




\begin{tabular}{|c|c|c|c|c|c|c|c|c|c|c|c|c|c|}
\hline $42 b$ & $S$ & $\mathrm{R}$ & $S$ & 1 & $\mathrm{~s}$ & $S$ & $\mathrm{~s}$ & $S$ & $\mathrm{~s}$ & $\mathrm{~S}$ & $\mathrm{~S}$ & $S$ & $\mathrm{~s}$ \\
\hline $43 b$ & $S$ & $\mathrm{~S}$ & $S$ & $S$ & $S$ & $S$ & $\mathrm{~S}$ & $S$ & S & $S$ & $S$ & S & $S$ \\
\hline $45 b$ & $\mathrm{~S}$ & $S$ & $\mathrm{~S}$ & $\mathrm{~S}$ & $\mathrm{~S}$ & $S$ & $\mathrm{~s}$ & $S$ & $\mathrm{~s}$ & $\mathrm{~S}$ & $\mathrm{~S}$ & $S$ & $\mathrm{~s}$ \\
\hline $47 \mathrm{~b}$ & $S$ & $\mathrm{~S}$ & $R$ & S & $\mathrm{R}$ & S & $\mathrm{R}$ & $\mathrm{S}$ & $\mathrm{s}$ & $\mathrm{S}$ & S & $\mathrm{R}$ & $\mathrm{R}$ \\
\hline $48 b$ & $S$ & $\mathrm{R}$ & $S$ & $S$ & $S$ & $\mathrm{~s}$ & $\mathrm{~S}$ & $\mathrm{~S}$ & $S$ & $S$ & $S$ & $S$ & $S$ \\
\hline $51 b$ & $\mathrm{R}$ & $\mathrm{R}$ & $\mathrm{R}$ & 1 & $\mathrm{~s}$ & $S$ & $\mathrm{~s}$ & $\mathrm{~s}$ & $\mathrm{R}$ & $\mathrm{S}$ & $\mathrm{S}$ & $S$ & $\mathrm{R}$ \\
\hline $52 b$ & $S$ & $\mathrm{R}$ & $S$ & $S$ & $S$ & S & $S$ & $\mathrm{~S}$ & $S$ & $\mathrm{~s}$ & S & S & $S$ \\
\hline $65 b$ & S & $\mathrm{R}$ & S & S & $S$ & $\mathrm{~s}$ & $\mathrm{~s}$ & S & S & $\mathrm{S}$ & S & S & S \\
\hline $67 \mathrm{~b}$ & S & $\mathrm{R}$ & S & S & $S$ & S & $\mathrm{S}$ & $\mathrm{S}$ & S & $\mathrm{S}$ & $\mathrm{S}$ & S & S \\
\hline $69 \mathrm{~b}$ & $S$ & $\mathrm{R}$ & $S$ & $S$ & $\mathrm{~s}$ & $S$ & $\mathrm{~s}$ & $\mathrm{~s}$ & $\mathrm{~s}$ & $S$ & $S$ & $S$ & $\mathrm{~s}$ \\
\hline $73 b$ & $S$ & $\mathrm{~s}$ & $S$ & $S$ & $S$ & $S$ & $\mathrm{~S}$ & $S$ & $S$ & $\mathrm{~S}$ & $S$ & $S$ & $\mathrm{~s}$ \\
\hline $82 b$ & $R$ & $\mathrm{R}$ & $\mathrm{R}$ & $R$ & $\mathrm{R}$ & 1 & $S$ & $S$ & $\mathrm{R}$ & $\mathrm{s}$ & $S$ & S & $\mathrm{R}$ \\
\hline $85 b$ & $S$ & $\mathrm{R}$ & $\mathrm{R}$ & $S$ & $\mathrm{R}$ & $S$ & $\mathrm{R}$ & S & S & $\mathrm{S}$ & $S$ & $\mathrm{R}$ & $\mathrm{R}$ \\
\hline $89 b$ & S & S & S & S & $S$ & $\mathrm{~s}$ & $\mathrm{~S}$ & S & $\mathrm{S}$ & $\mathrm{S}$ & S & S & s \\
\hline $97 \mathrm{~b}$ & S & $\mathrm{R}$ & S & S & $S$ & S & $\mathrm{S}$ & $\mathrm{S}$ & $\mathrm{S}$ & $\mathrm{S}$ & $\mathrm{S}$ & S & S \\
\hline $104 \mathrm{~b}$ & $\mathrm{~s}$ & $\mathrm{R}$ & $R$ & $S$ & $R$ & $\mathrm{~s}$ & $\mathrm{R}$ & $\mathrm{S}$ & $\mathrm{R}$ & $S$ & $S$ & $R$ & $\mathrm{R}$ \\
\hline $111 b$ & NR & NR & NR & NR & NR & NR & NR & NR & NR & NR & NR & NR & NR \\
\hline $117 \mathrm{~b}$ & $S$ & $\mathrm{~S}$ & $S$ & $S$ & $S$ & S & $\mathrm{S}$ & S & S & $\mathrm{S}$ & S & S & S \\
\hline $127 \mathrm{~b}$ & S & S & S & S & $S$ & $\mathrm{R}$ & $\mathrm{S}$ & S & $\mathrm{R}$ & $\mathrm{S}$ & s & S & S \\
\hline $131 b$ & S & $\mathrm{R}$ & S & 1 & $S$ & S & $\mathrm{S}$ & S & $\mathrm{S}$ & $\mathrm{S}$ & $\mathrm{S}$ & S & S \\
\hline $132 b$ & S & $\mathrm{S}$ & S & S & S & S & $\mathrm{S}$ & $\mathrm{s}$ & $\mathrm{S}$ & $\mathrm{S}$ & S & S & S \\
\hline $134 b$ & $\mathrm{~S}$ & $\mathrm{~s}$ & $S$ & 1 & $S$ & $S$ & $\mathrm{~S}$ & 1 & $S$ & $\mathrm{~S}$ & $S$ & $S$ & $S$ \\
\hline $136 \mathrm{~b}$ & $S$ & S & $S$ & $S$ & $S$ & $S$ & $\mathrm{~S}$ & S & S & $\mathrm{S}$ & $\mathrm{s}$ & $S$ & S \\
\hline $171 b$ & S & $\mathrm{s}$ & S & $\mathrm{R}$ & S & S & $\mathrm{S}$ & $\mathrm{s}$ & S & S & $\mathrm{s}$ & S & S \\
\hline $173 b$ & S & S & S & S & $S$ & S & $\mathrm{S}$ & S & $\mathrm{S}$ & S & s & S & S \\
\hline $177 \mathrm{~b}$ & S & $\mathrm{S}$ & S & S & $S$ & S & $\mathrm{S}$ & $\mathrm{S}$ & $\mathrm{S}$ & S & S & S & S \\
\hline $182 b$ & $S$ & $\mathrm{R}$ & $S$ & $S$ & $\mathrm{~s}$ & $S$ & $\mathrm{~S}$ & $S$ & $\mathrm{~S}$ & $S$ & $S$ & $S$ & $S$ \\
\hline $185 b$ & S & $\mathrm{s}$ & $\mathrm{R}$ & S & $\mathrm{R}$ & S & $\mathrm{R}$ & S & S & S & S & $\mathrm{R}$ & S \\
\hline $191 b$ & $\mathrm{~S}$ & $\mathrm{R}$ & $S$ & $S$ & $S$ & $\mathrm{R}$ & $\mathrm{S}$ & $\mathrm{S}$ & $\mathrm{S}$ & $S$ & $\mathrm{~S}$ & $S$ & $\mathrm{~S}$ \\
\hline $200 \mathrm{~b}$ & S & $\mathrm{R}$ & S & S & S & S & $\mathrm{S}$ & S & s & S & s & S & S \\
\hline $204 \mathrm{~b}$ & S & S & S & S & $S$ & S & $\mathrm{S}$ & $\mathrm{S}$ & S & S & S & S & S \\
\hline $209 \mathrm{~b}$ & S & $\mathrm{R}$ & S & S & $\mathrm{R}$ & S & $\mathrm{R}$ & $\mathrm{s}$ & $\mathrm{S}$ & S & S & $\mathrm{R}$ & $\mathrm{R}$ \\
\hline $221 b$ & S & $\mathrm{R}$ & S & S & $\mathrm{S}$ & S & $\mathrm{S}$ & S & S & S & S & S & S \\
\hline $223 b$ & $S$ & $\mathrm{R}$ & $S$ & $S$ & $S$ & $S$ & $\mathrm{~S}$ & $\mathrm{~S}$ & $\mathrm{~S}$ & $S$ & $\mathrm{~S}$ & $S$ & $S$ \\
\hline $227 \mathrm{~b}$ & S & S & S & S & $S$ & S & $\mathrm{S}$ & S & S & S & s & S & S \\
\hline $229 b$ & S & $\mathrm{R}$ & S & S & $S$ & $\mathrm{R}$ & $\mathrm{S}$ & $\mathrm{S}$ & S & S & S & S & S \\
\hline $232 b$ & S & $\mathrm{R}$ & S & S & $S$ & S & $\mathrm{S}$ & $\mathrm{S}$ & S & S & S & S & S \\
\hline $234 \mathrm{~b}$ & S & $\mathrm{R}$ & S & S & S & S & $\mathrm{S}$ & $\mathrm{s}$ & S & S & S & S & S \\
\hline $240 \mathrm{~b}$ & $\mathrm{~S}$ & $\mathrm{R}$ & $\mathrm{R}$ & $\mathrm{S}$ & $\mathrm{R}$ & $S$ & $\mathrm{R}$ & $\mathrm{s}$ & $S$ & $S$ & $\mathrm{~s}$ & $\mathrm{R}$ & $\mathrm{R}$ \\
\hline $275 b$ & S & S & S & S & $S$ & S & $\mathrm{S}$ & S & S & $S$ & S & S & S \\
\hline $289 \mathrm{~b}$ & S & $\mathrm{R}$ & S & S & S & S & $\mathrm{S}$ & S & S & S & s & S & S \\
\hline $291 b$ & S & $\mathrm{R}$ & S & 1 & $S$ & $\mathrm{R}$ & $\mathrm{S}$ & $\mathrm{S}$ & S & S & S & S & S \\
\hline $398 \mathrm{~b}$ & NR & NR & NR & NR & NR & NR & NR & NR & NR & NR & NR & NR & NR \\
\hline $410 \mathrm{~b}$ & NR & NR & NR & NR & NR & NR & NR & NR & NR & NR & NR & NR & NR \\
\hline $1 \mathrm{c}$ & $S$ & $S$ & S & $S$ & $S$ & S & $S$ & $S$ & S & S & S & S & $S$ \\
\hline $2 c$ & S & $\mathrm{R}$ & S & 1 & S & S & $\mathrm{S}$ & S & S & S & $\mathrm{S}$ & S & S \\
\hline
\end{tabular}




\begin{tabular}{|c|c|c|c|c|c|c|c|c|c|c|c|c|c|}
\hline $6 c$ & $\mathrm{~s}$ & $\mathrm{R}$ & $\mathrm{s}$ & $\mathrm{S}$ & $\mathrm{s}$ & $\mathrm{s}$ & $\mathrm{s}$ & $\mathrm{S}$ & $\mathrm{R}$ & $\mathrm{s}$ & $\mathrm{s}$ & $\mathrm{s}$ & $\mathrm{S}$ \\
\hline $14 c$ & NR & NR & $\mathrm{NR}$ & NR & NR & NR & NR & NR & NR & NR & NR & NR & NR \\
\hline $18 c$ & $\mathrm{~s}$ & $\mathrm{R}$ & $\mathrm{s}$ & $\mathrm{s}$ & $\mathrm{s}$ & S & $\mathrm{S}$ & $S$ & $S$ & S & $S$ & $\mathrm{~S}$ & S \\
\hline $33 c$ & $\mathrm{~s}$ & $\mathrm{R}$ & $\mathrm{R}$ & $\mathrm{s}$ & $\mathrm{R}$ & $\mathrm{S}$ & $\mathrm{R}$ & $\mathrm{S}$ & $\mathrm{S}$ & $\mathrm{S}$ & $\mathrm{S}$ & $\mathrm{R}$ & $\mathrm{S}$ \\
\hline $38 c$ & $\mathrm{~s}$ & $\mathrm{R}$ & $\mathrm{s}$ & $\mathrm{s}$ & $\mathrm{S}$ & $\mathrm{S}$ & $\mathrm{s}$ & $\mathrm{S}$ & $\mathrm{S}$ & $\mathrm{s}$ & $\mathrm{S}$ & $\mathrm{S}$ & $\mathrm{s}$ \\
\hline $39 c$ & $\mathrm{~S}$ & $\mathrm{R}$ & $S$ & $\mathrm{~S}$ & $S$ & 1 & $\mathrm{~s}$ & S & S & $S$ & $S$ & $S$ & S \\
\hline $42 c$ & $\mathrm{~s}$ & $\mathrm{~S}$ & $\mathrm{~s}$ & $\mathrm{~s}$ & $\mathrm{~S}$ & $\mathrm{~S}$ & $\mathrm{~s}$ & $\mathrm{~S}$ & $\mathrm{~S}$ & $\mathrm{~s}$ & $\mathrm{~S}$ & $\mathrm{~S}$ & $\mathrm{~S}$ \\
\hline $47 c$ & $\mathrm{~s}$ & $\mathrm{R}$ & s & 1 & S & $\mathrm{S}$ & $\mathrm{s}$ & $\mathrm{S}$ & $\mathrm{S}$ & $\mathrm{s}$ & $\mathrm{S}$ & $\mathrm{S}$ & $\mathrm{S}$ \\
\hline $54 c$ & $\mathrm{~S}$ & $\mathrm{R}$ & $\mathrm{S}$ & 1 & $\mathrm{~S}$ & $\mathrm{~S}$ & $\mathrm{~s}$ & $S$ & $\mathrm{~S}$ & $S$ & $\mathrm{~S}$ & $\mathrm{~S}$ & S \\
\hline $58 c$ & $\mathrm{~s}$ & $\mathrm{R}$ & $\mathrm{s}$ & $\mathrm{S}$ & $\mathrm{S}$ & $S$ & $\mathrm{~s}$ & $\mathrm{~S}$ & $\mathrm{~S}$ & $\mathrm{~s}$ & $\mathrm{~S}$ & $\mathrm{~S}$ & $\mathrm{~S}$ \\
\hline $76 c$ & $\mathrm{R}$ & $\mathrm{R}$ & $\mathrm{R}$ & $\mathrm{S}$ & $\mathrm{R}$ & 1 & $\mathrm{~s}$ & S & $\mathrm{R}$ & $S$ & $S$ & $\mathrm{~s}$ & $\mathrm{R}$ \\
\hline $96 c$ & $\mathrm{~S}$ & $\mathrm{R}$ & S & $\mathrm{s}$ & $S$ & $S$ & $\mathrm{~s}$ & S & $S$ & S & $\mathrm{S}$ & $\mathrm{S}$ & S \\
\hline $97 \mathrm{c}$ & $\mathrm{S}$ & $\mathrm{S}$ & $S$ & $\mathrm{~s}$ & $S$ & $\mathrm{~S}$ & $S$ & $S$ & S & S & $\mathrm{S}$ & $\mathrm{S}$ & S \\
\hline $116 c$ & $\mathrm{~s}$ & $\mathrm{R}$ & $\mathrm{s}$ & $\mathrm{S}$ & $\mathrm{s}$ & $\mathrm{s}$ & $\mathrm{s}$ & $\mathrm{s}$ & $\mathrm{S}$ & $\mathrm{s}$ & $\mathrm{s}$ & $\mathrm{s}$ & $\mathrm{S}$ \\
\hline $117 c$ & $\mathrm{~S}$ & $\mathrm{~S}$ & $S$ & $\mathrm{~s}$ & $\mathrm{~S}$ & $\mathrm{~S}$ & $\mathrm{~S}$ & $\mathrm{~S}$ & $S$ & $S$ & $\mathrm{~S}$ & $\mathrm{~S}$ & $S$ \\
\hline $140 c$ & $\mathrm{R}$ & $\mathrm{R}$ & $\mathrm{R}$ & $S$ & $\mathrm{R}$ & $\mathrm{R}$ & 1 & $S$ & $\mathrm{R}$ & 1 & $S$ & $\mathrm{~S}$ & $\mathrm{R}$ \\
\hline $148 c$ & NR & NR & NR & NR & NR & NR & NR & NR & NR & NR & NR & NR & NR \\
\hline $154 c$ & $\mathrm{R}$ & $\mathrm{R}$ & $\mathrm{R}$ & $\mathrm{S}$ & $S$ & $\mathrm{~S}$ & $\mathrm{~s}$ & $S$ & S & S & $\mathrm{S}$ & $\mathrm{S}$ & S \\
\hline $163 c$ & $\mathrm{~S}$ & $\mathrm{~S}$ & $S$ & 1 & 1 & $\mathrm{~S}$ & S & $\mathrm{S}$ & $\mathrm{R}$ & S & $\mathrm{S}$ & $\mathrm{S}$ & S \\
\hline $170 c$ & $\mathrm{~s}$ & $\mathrm{R}$ & 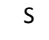 & $\mathrm{s}$ & S & $\mathrm{s}$ & $\mathrm{s}$ & $\mathrm{S}$ & S & S & $\mathrm{s}$ & $\mathrm{s}$ & S \\
\hline $177 c$ & $\mathrm{~S}$ & $\mathrm{R}$ & $S$ & $\mathrm{~S}$ & $S$ & $\mathrm{~S}$ & $\mathrm{~S}$ & $S$ & $S$ & $S$ & $\mathrm{~S}$ & $S$ & $S$ \\
\hline $181 \mathrm{c}$ & $\mathrm{S}$ & $\mathrm{R}$ & $S$ & $\mathrm{~S}$ & $\mathrm{R}$ & $\mathrm{s}$ & 1 & $S$ & $S$ & $S$ & $S$ & $\mathrm{R}$ & S \\
\hline $191 c$ & $\mathrm{~S}$ & $\mathrm{~S}$ & S & $\mathrm{s}$ & $S$ & $\mathrm{~S}$ & $\mathrm{~s}$ & $S$ & S & S & $\mathrm{S}$ & $\mathrm{S}$ & S \\
\hline $192 c$ & $\mathrm{~S}$ & $\mathrm{~S}$ & S & $\mathrm{S}$ & $S$ & 1 & $\mathrm{~S}$ & $\mathrm{R}$ & S & S & $\mathrm{S}$ & $\mathrm{S}$ & S \\
\hline $194 c$ & $\mathrm{~S}$ & $\mathrm{~S}$ & $S$ & S & $\mathrm{S}$ & $\mathrm{S}$ & $\mathrm{S}$ & $\mathrm{S}$ & $S$ & $\mathrm{~S}$ & $\mathrm{~S}$ & $\mathrm{~S}$ & S \\
\hline $195 c$ & $\mathrm{~S}$ & $\mathrm{R}$ & $S$ & $S$ & $\mathrm{~S}$ & $\mathrm{~s}$ & $S$ & $\mathrm{~S}$ & $\mathrm{~S}$ & $S$ & $\mathrm{~s}$ & $\mathrm{~s}$ & $\mathrm{~S}$ \\
\hline $199 c$ & $\mathrm{~S}$ & $\mathrm{~S}$ & $S$ & $S$ & $S$ & $\mathrm{~S}$ & $S$ & $S$ & $S$ & $S$ & $\mathrm{~S}$ & $\mathrm{~S}$ & $S$ \\
\hline $203 c$ & $\mathrm{~S}$ & $\mathrm{R}$ & $S$ & S & $S$ & $\mathrm{~S}$ & S & $S$ & S & $S$ & $S$ & $\mathrm{~S}$ & S \\
\hline $225 c$ & $\mathrm{~S}$ & $\mathrm{R}$ & $S$ & S & $S$ & $\mathrm{~s}$ & S & $S$ & $S$ & S & $\mathrm{S}$ & $\mathrm{S}$ & S \\
\hline $228 c$ & $\mathrm{~S}$ & $\mathrm{R}$ & $S$ & S & $\mathrm{S}$ & $\mathrm{S}$ & S & $\mathrm{S}$ & S & S & $\mathrm{S}$ & $\mathrm{S}$ & S \\
\hline $229 c$ & $\mathrm{~S}$ & $\mathrm{R}$ & $S$ & $S$ & $\mathrm{~S}$ & $\mathrm{~S}$ & $S$ & $\mathrm{~S}$ & $\mathrm{~S}$ & $S$ & $\mathrm{~S}$ & $\mathrm{~S}$ & $\mathrm{~S}$ \\
\hline $232 c$ & $\mathrm{~S}$ & $\mathrm{R}$ & $S$ & 1 & $S$ & $\mathrm{~S}$ & S & $S$ & $S$ & $S$ & $\mathrm{~S}$ & $\mathrm{~S}$ & $S$ \\
\hline $245 c$ & $\mathrm{~S}$ & $\mathrm{R}$ & $S$ & S & $S$ & $\mathrm{~s}$ & S & $S$ & S & $S$ & $S$ & $\mathrm{~S}$ & S \\
\hline $256 c$ & $\mathrm{~S}$ & $\mathrm{R}$ & $\mathrm{R}$ & S & $\mathrm{R}$ & $\mathrm{S}$ & $\mathrm{R}$ & $S$ & $S$ & S & $\mathrm{S}$ & $\mathrm{R}$ & $\mathrm{R}$ \\
\hline $261 c$ & $\mathrm{~S}$ & $\mathrm{R}$ & $S$ & S & $\mathrm{S}$ & S & S & $\mathrm{S}$ & S & S & $\mathrm{S}$ & $\mathrm{S}$ & S \\
\hline $267 c$ & $\mathrm{~s}$ & $\mathrm{R}$ & $\mathrm{s}$ & $\mathrm{S}$ & $\mathrm{S}$ & s & $\mathrm{S}$ & S & $\mathrm{s}$ & $\mathrm{S}$ & $\mathrm{s}$ & $\mathrm{s}$ & $\mathrm{S}$ \\
\hline $278 c$ & $\mathrm{~S}$ & $\mathrm{R}$ & S & $\mathrm{R}$ & $\mathrm{S}$ & S & S & S & $\mathrm{S}$ & S & $\mathrm{S}$ & $\mathrm{S}$ & S \\
\hline $285 c$ & NR & NR & NR & NR & NR & NR & NR & NR & NR & NR & NR & NR & NR \\
\hline $287 c$ & NR & NR & NR & NR & NR & NR & NR & NR & NR & NR & NR & NR & NR \\
\hline $298 c$ & $\mathrm{~s}$ & $\mathrm{R}$ & s & S & $\mathrm{s}$ & s & S & $\mathrm{s}$ & S & $\mathrm{s}$ & $\mathrm{S}$ & $\mathrm{s}$ & $\mathrm{S}$ \\
\hline $305 c$ & $\mathrm{~S}$ & $\mathrm{R}$ & $S$ & 1 & $\mathrm{~S}$ & S & S & $\mathrm{S}$ & S & S & $\mathrm{S}$ & $\mathrm{S}$ & $\mathrm{S}$ \\
\hline $329 c$ & NR & NR & NR & NR & NR & NR & NR & NR & NR & NR & NR & NR & NR \\
\hline $340 c$ & NR & NR & NR & NR & NR & NR & NR & NR & NR & NR & NR & NR & NR \\
\hline $352 c$ & NR & NR & NR & NR & NR & NR & NR & NR & NR & NR & NR & NR & NR \\
\hline $358 c$ & $\mathrm{~S}$ & $\mathrm{~S}$ & S & S & $S$ & s & S & $\mathrm{S}$ & $\mathrm{S}$ & $\mathrm{s}$ & $\mathrm{S}$ & $\mathrm{S}$ & $S$ \\
\hline $360 c$ & NR & NR & NR & NR & NR & NR & NR & NR & NR & NR & NR & NR & NR \\
\hline
\end{tabular}




\begin{tabular}{|c|c|c|c|c|c|c|c|c|c|c|c|c|c|}
\hline $369 c$ & S & $S$ & $\mathrm{~s}$ & $\mathrm{~s}$ & S & $S$ & $S$ & $S$ & $S$ & S & S & $S$ & s \\
\hline $388 c$ & $\mathrm{~S}$ & $R$ & $\mathrm{~S}$ & $\mathrm{~S}$ & $\mathrm{~S}$ & $S$ & $S$ & $S$ & $\mathrm{~S}$ & $\mathrm{~S}$ & $\mathrm{~S}$ & $\mathrm{~S}$ & $\mathrm{~S}$ \\
\hline $390 c$ & S & $\mathrm{R}$ & S & S & S & $S$ & $S$ & $S$ & $S$ & S & S & $S$ & $\mathrm{~S}$ \\
\hline $401 c$ & NR & NR & NR & NR & NR & NR & NR & NR & NR & NR & NR & NR & NR \\
\hline $404 c$ & NR & NR & NR & NR & NR & NR & NR & NR & NR & NR & NR & NR & NR \\
\hline $417 c$ & NR & NR & NR & NR & NR & NR & NR & $N R$ & NR & NR & $N R$ & $N R$ & NR \\
\hline $420 c$ & $\mathrm{~s}$ & $R$ & $\mathrm{~s}$ & $S$ & $\mathrm{~s}$ & $S$ & $\mathrm{~s}$ & $\mathrm{~S}$ & $S$ & $\mathrm{~s}$ & $\mathrm{~s}$ & $\mathrm{~S}$ & $\mathrm{~S}$ \\
\hline $\begin{array}{l}\text { MRSA } \\
n=26 \\
\text { MSSA }\end{array}$ & 100,0 & 96,1 & 76,9 & 46,1 & 73,1 & 42,3 & 50,0 & 3,8 & 65,4 & 15,4 & 0,0 & 3,8 & 73,1 \\
\hline$(n=142)$ & 0,0 & 72,5 & 9,1 & 26,0 & 12,0 & 7,0 & 9,8 & 2,1 & 7,0 & 2,8 & 0,0 & 7,7 & 9,8 \\
\hline
\end{tabular}




\section{ANEXO}

HOSPITAL DAS CLÍNICAS DA FACULDADE DE MEDICINA DE RIBEIRĀO PRETO DA UNIVERSIDADE DE SĀO PAULO

Oficio $\mathrm{n}^{\circ} 2437 / 2005$

$\mathrm{CEP} / \mathrm{CDGC}$

Prezada Senhora:

O trabalho intitulado "STAPHYLOCOCCUS METICILINA RESISTENTES EM PROFISSIONAIS DE SAÚDE E AS INTERFACES COM AS INFECÇÕES NOSOCOMIAIs", foi analisado pelo Comitê de Ėtica em Pesquasa, em sua $209^{2}$ Reuniāo Ordinăria realizada em 29/08/2005, e enquadrado na categoria: APROVADO, bem como o Termo de Consentimento Livre e Esclarecido, de acordo com o Processo HCRP n० 9918/2005.

Aproveito a oportunidade para apresentar a Vossa Scnhoria protestos de estima e consideraçāo.

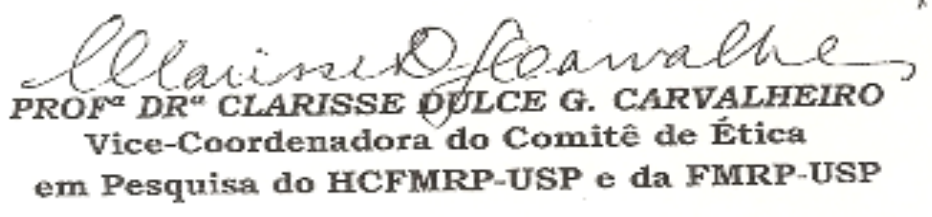

